\title{
Consumers' perspective on chicken husbandry: The case of dual-purpose chickens
}

\author{
Dissertation \\ zur Erlangung des Doktorgrades (Dr. sc. agr.) \\ der Fakultät für Agrarwissenschaften \\ der Georg-August-Universität Göttingen
}

\author{
vorgelegt von \\ Nanke Brümmer \\ geboren am 08.05.1989 in Husum
}

Göttingen, im März 2019 
1. Gutachter: PD Dr. Martin Banse, Thünen-Institut für Marktanalyse in Braunschweig

2. Gutachter: Prof. Dr. Achim Spiller, Department für Agrarökonomie und Rurale Entwicklung der Georg-August-Universität Göttingen

3. Gutachter: Jun.-Prof. Dr. Jan-Henning Feil, Department für Agrarökonomie und Rurale Entwicklung der Georg-August-Universität Göttingen

Tag der mündlichen Prüfung: 03.05.2019 


\section{Table of contents}

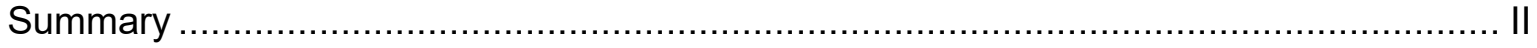

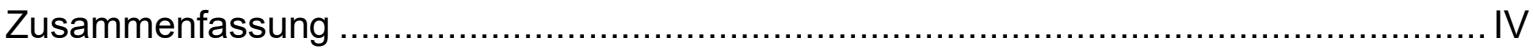

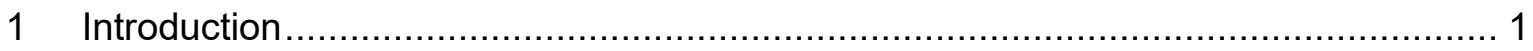

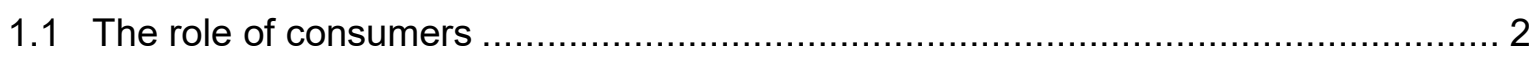

1.2 Problem of chick culling and alternatives................................................... 4

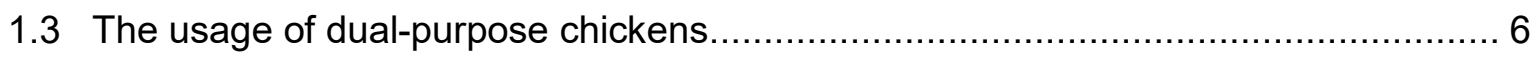

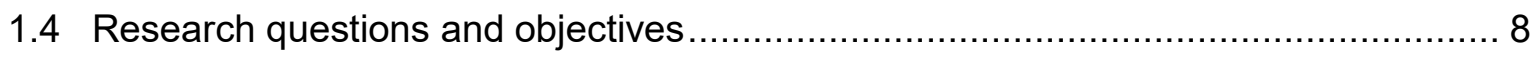

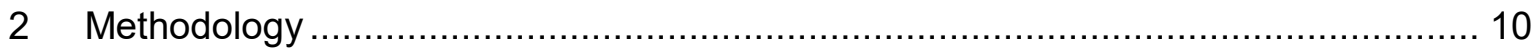

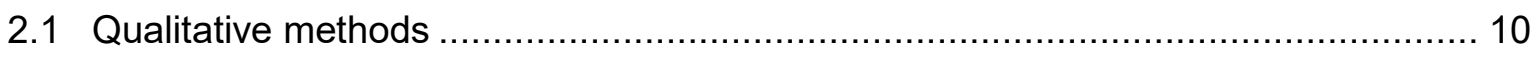

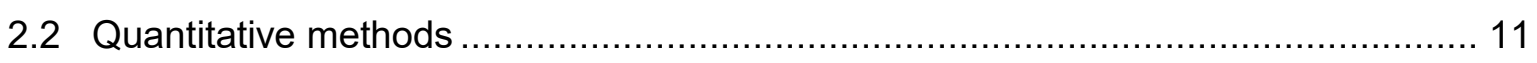

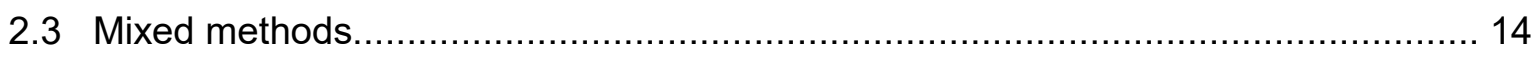

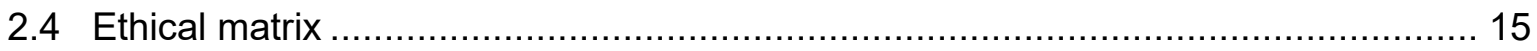

3 Structure and summary of the contributions ..................................................... 16

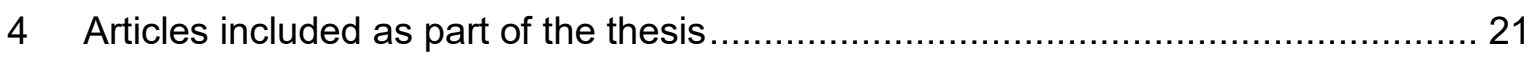

4.1 Consumers' perspective on dual-purpose chickens as alternative to

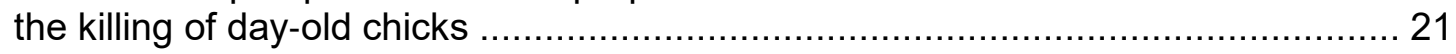

4.2 Consumer acceptance of dual-purpose chickens A mixed methods approach ........ 31

4.3 German consumers' preferences and willingness to pay for eggs and meat from dual-purpose chickens: A latent class analysis

4.4 Dual purpose chickens as alternative to the culling of day-old chicks

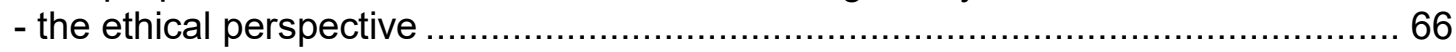

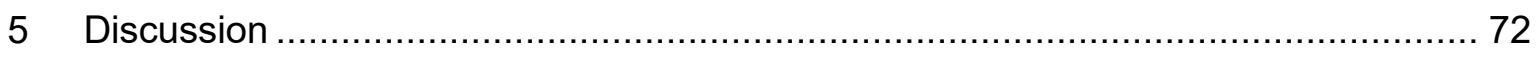

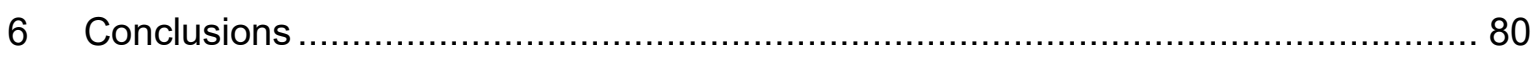

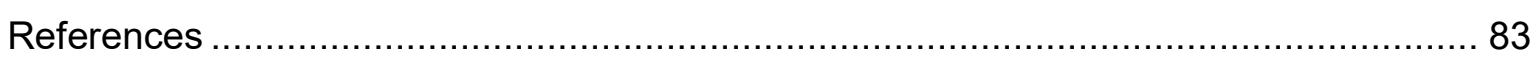

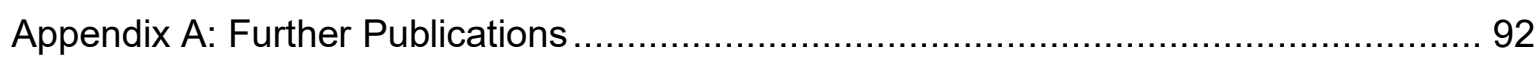

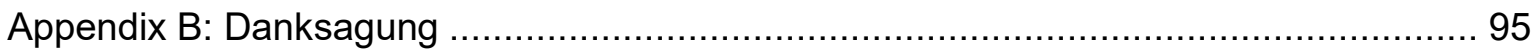




\section{Summary}

According to several studies, chicken farming is seen as the most controversial form of livestock farming among society. One element that is increasingly noticed and criticised is the culling of day-old male chicks. Annually, in Germany, 45 million male chicks of layer breeds are culled directly after hatching because the fattening of the males is unprofitable. This applies to both, conventional and organic animal husbandry. Dual-purpose chickens are one alternative to the culling of day-old chicks being discussed. They can both, produce meat and lay eggs. The hens lay fewer and smaller eggs than current specialised layers, and the cockerels put on less meat than broilers and need more time and feed to grow, which leads to a higher demand for resources. Consequently, eggs and meat from dual-purpose chickens have a different appearance and are more expensive than products from specialised chickens. Consumers, therefore, play an essential role when it comes to the acceptance and marketability of dual-purpose chickens, as they ultimately decide the success of products at the counter. Therefore, the main objective of this thesis is to analyse consumer perspectives on dual-purpose chickens in order to provide implications and recommendations for policy-makers, economy and research when discussing the use of dual-purpose chicken breeds.

In contribution 1, an explorative approach was used to gather insights into the topic. Six focus groups provided findings about consumer perspectives on dual-purpose chickens. The results show that the culling of day-old chicks was known to most of the participants and rejected for ethical reasons. They were aware of few alternatives, and information on dual-purpose chickens and the other alternatives to the culling was given to the participants. The naming was seen as inappropriate and misleading, but the participants were generally in favour of this chicken breed. Some participants raised concerns regarding economic efficiency and higher product prices. For others, ethical values predominated. Additionally, the results demonstrated that the participants had specific expectations regarding the production and labelling of dual-purpose chickens and linked better husbandry conditions to the potential purchase of products from dualpurpose chickens.

In order to analyse consumer acceptance of dual-purpose chicken breeds, a mixed methods study was applied in the second contribution. The combination of qualitative and quantitative methods is particularly suitable for this research question since little is known about this topic thus far. On the basis of the focus groups and the results from the first contribution, an online survey was conducted with 1,502 participants in Germany. The data was analysed with the help of a factor analysis in order to find independent latent variables, called factors. Seven factors were identified which explained consumer 
attitudes towards dual-purpose chickens. A cluster analysis segmented the respondents into three cluster groups based on the previously identified factors. These were opponents (37.5\%), supporters $(23.4 \%)$, and indifferents (39.1\%). A discriminant analysis was carried out for verification purposes. The indifferent segment represented the largest group of respondents and is therefore an important target group when it comes to potential marketing strategies for products from dual-purpose chickens. Within this cluster group, there is the greatest potential for reducing uncertainty by means of providing more and better information on dual-purpose chickens.

The online survey also contained a choice experiment for finding out more about consumer preferences and their willingness to pay for products from dual-purpose chickens. In contribution 3 , we applied a latent class model to account for consumer heterogeneity. Four consumer segments regarding eggs and chicken meat were identified each. For both products, the largest segments consisted of price conscious consumers. Small potential consumer groups with a willingness to pay more for dual-purpose chicken products were also identified. For eggs, $25.3 \%$ of respondents belonged to this segment, whereas a smaller segment of $16.2 \%$ showed a willingness to pay for meat from dualpurpose chickens.

Contribution 4 concerns the usage of dual-purpose chickens from an ethical standpoint and allows for a comprehensive view on dual-purpose chickens beyond consumer perspectives. Therefore, Mepham's ethical matrix was applied as a tool of applied ethics for the interpretation of stakeholder interests with regard to the ethical principles of wellbeing, autonomy and justice. The aim is to present a well-balanced consideration from different angles and thus to reduce the complexity of the topic. In this case, the rearing of dual-purpose chickens was compared to the current practice (culling of day-old chicks). We applied the matrix to five interest groups: dual-purpose chickens, consumers, egg and meat industry, farmers and the environment. The results show that dual-purpose chickens as alternative to the culling of day-old chicks is a very complex topic as, for example, the implementation of dual-purpose chicken breeds could have positive implications for the chickens itself but might affect the environment negatively.

With respect to the overarching objective of this thesis, the results illustrate the importance of analysing consumer acceptance of innovations in animal husbandry from different perspectives before new breeds are established and their products come onto the market. This thesis provides detailed insights into consumer perspectives on dualpurpose chickens and contributes to the debate surrounding alternatives to the culling of day-old chicks in Germany by showing that there is a low market potential for products from dual-purpose chickens. The potential for eggs is still significantly higher than that of 
meat. Products from dual-purpose chickens are suitable for a niche market, as small potential consumer groups with a willingness to pay for eggs and meat from dual-purpose chickens were identified. If the husbandry of dual-purpose chickens is to be promoted further, targeted consumer information could certainly attract potential consumers who still have ambivalent attitudes towards dual-purpose chickens.

\section{Zusammenfassung}

Die Hühnerhaltung gilt laut zahlreichen Studien als die gesellschaftlich umstrittenste Form der Nutztierhaltung. Ein Aspekt, der von der Gesellschaft zunehmend wahrgenommen und kritisiert wird, ist die Tötung von Eintagsküken. In Deutschland werden jährlich 45 Millionen männliche Küken von Legerassen direkt nach dem Schlupf getötet, da die Mast der männlichen Tiere unrentabel ist. Dies gilt sowohl für die konventionelle als auch für die ökologische Tierhaltung. Eine diskutierte Alternative zur Tötung von Eintagsküken ist die Haltung von Zweinutzungshühnern. Bei diesen Hühnerrassen legen die Hennen Eier und die Hähne setzen Fleisch an. Die Hennen legen jedoch weniger und kleinere Eier als die heutigen spezialisierten Rassen. Auch die Hähne setzen weniger Fleisch an als Masthühner und benötigen mehr Zeit und Futter für das Wachstum, was zu einem höheren Ressourcenbedarf führt. Folglich haben die Eier und das Fleisch von Zweinutzungshühnern ein anderes Aussehen und sind teurer als Produkte von spezialisierten Hühnerrassen. Wenn es um die Akzeptanz und Marktfähigkeit von Zweinutzungshühnern geht, spielen die Verbraucher eine wesentliche Rolle, da diese letztendlich an der Ladentheke über den Erfolg von Produkten entscheiden. Daher ist das Hauptziel dieser Dissertation die Untersuchung der Verbraucherperspektiven auf Zweinutzungshühner, um diesbezüglich Implikationen und Empfehlungen für Entscheidungsträger aus der Wirtschaft, Wissenschaft und Politik zu liefern. Die vorliegende kumulative Dissertation setzt sich aus vier Beiträgen zusammen, die sich umfassend mit Erwartungen und Einstellungen, Präferenzen und Zahlungsbereitschaften von Konsumenten gegenüber Zweinutzungshühnern und deren Produkten sowie mit der ethischen Sicht auf das Thema befassen.

Im ersten Beitrag wurde ein explorativer Ansatz verwendet, um erste Erkenntnisse über das Thema Verbrauchersicht auf Zweinutzungshühner zu gewinnen. Mit Hilfe von sechs Gruppendiskussionen wurden erste Einblicke in die Perspektive der Konsumenten gewonnen. Die Ergebnisse zeigen, dass das Thema „Töten von Eintagsküken“ den meisten Teilnehmern bekannt war und aus ethischen Gründen abgelehnt wurde. Es 
waren nur wenige Alternativen bekannt. Daraufhin wurden den Teilnehmern Informationen über Zweinutzungshühner und andere Alternativen zur Tötung von Eintagsküken gegeben. Die Bezeichnung „Zweinutzungshuhn“ wurde als unangemessen und irreführend angesehen, aber im Allgemeinen befürworteten die Teilnehmer diese Hühnerrassen. Einige Teilnehmer äußerten Bedenken hinsichtlich der Wirtschaftlichkeit und der höheren Produktpreise, für andere überwogen ethische Werte. Darüber hinaus zeigen die Ergebnisse, dass die Diskussionsteilnehmer spezifische Erwartungen an die Produkteigenschaften und die Kennzeichnung von Zweinutzungshühnern hatten und die Bedingung besserer Haltungsbedingungen mit dem möglichen Kauf von Produkten von Zweinutzungshühnern verknüpften.

Um die Wahrnehmung und Akzeptanz von Konsumenten gegenüber Zweinutzungshuhnrassen zu analysieren, wurde im Rahmen des Projektes eine MixedMethods-Studie angewandt, da die Kombination aus quantitativen und qualitativen Methoden für diese Fragestellungen besonders geeignet ist, wenn bisher wenig zu einem Thema bekannt ist. Die Ergebnisse dieser Mixed-Methods-Studie werden im zweiten Beitrag beschrieben. Auf Basis der Gruppendiskussionen und der Ergebnisse aus dem ersten Beitrag wurde eine Online-Befragung mit 1.502 Teilnehmen aus Deutschland durchgeführt. Die Daten wurden mit Hilfe einer Faktoranalyse analysiert, um auf wenige zugrundeliegende latente Variablen (Faktoren) zu schließen. Dabei wurden sieben Faktoren identifiziert, die die Einstellung der Verbraucher gegenüber Zweinutzungshühnern erklären. Eine Clusteranalyse fasste die Befragten auf Basis der zuvor identifizierten Faktoren in drei Clustergruppen zusammen: Gegner (37,5\%), Unterstützer $(23,4 \%)$ und Indifferente $(39,1 \%)$. Zur Verifizierung wurde eine Diskriminanzanalyse durchgeführt. Die Indifferenten stellen die größte Gruppe der Befragten dar und sind daher eine wichtige Zielgruppe, wenn es um mögliche Vermarktungsstrategien von Produkten von Zweinutzungshühnern geht. Innerhalb dieser Clustergruppe besteht das größte Potenzial zur Verringerung der Unsicherheit durch die Bereitstellung von mehr und detaillierten Informationen über Zweinutzungshühner.

Die Online-Befragung beinhaltete auch ein Choice-Experiment. Dieses verfolgte das Ziel, mehr über die Präferenzen der Verbraucher und die Zahlungsbereitschaft für Produkte von Zweinutzungshühnern herauszufinden. Im dritten Beitrag wurde ein LatentClass-Modell angewandt, um die Verbraucherheterogenität zu berücksichtigen. Es wurden jeweils vier Verbrauchersegmente bezüglich Eier und Hühnerfleisch identifiziert. Für beide Produkte bestehen die größten Segmente aus preisbewussten Konsumenten. Kleine potenzielle Verbrauchergruppen, die bereit sind, mehr für Zweinutzungshuhnprodukte zu zahlen, wurden ebenfalls identifiziert. Im Fall von Eiern gehören 25,3\% 
der Befragten zu diesem Segment, während ein kleinerer Teil von 16,2\% eine erhöhte Zahlungsbereitschaft für Fleisch von Zweinutzungshühnern aufweist.

Der vierte Beitrag betrachtet die Verwendung von Zweinutzungshühnern aus ethischer Sicht, um eine umfassende Sicht auf Zweinutzungshühner über die Verbraucherperspektive hinaus zu ermöglichen. Daher wurde die Ethische Matrix nach Mepham als Instrument der angewandten Ethik für die Interpretation der Interessen der Stakeholder im Hinblick auf die drei ethischen Grundsätze Wohlbefinden, Autonomie und Gerechtigkeit angewandt. Ziel ist es, eine ausgewogene Betrachtung aus verschiedenen Blickwinkeln zu präsentieren und damit die Komplexität des Themas zu reduzieren. In diesem Fall wurde die Haltung von Zweinutzungshühnern mit der aktuellen Praxis (Tötung von Eintagsküken) verglichen. Die Matrix wurde auf fünf Interessengruppen angewandt: Zweinutzungshühner, Verbraucher, Eier- und Fleischindustrie, Landwirte und Umwelt. Die Ergebnisse zeigen, dass das Thema Haltung von Zweinutzungshühnern als Alternative zur Tötung von Eintagsküken sehr komplex ist, da beispielsweise die Einführung von Zweinutzungshuhnrassen positive Auswirkungen auf das Wohlbefinden der Hühner haben könnte, aber die Umwelt negativ beeinflussen könnte.

Im Hinblick auf das übergeordnete Ziel dieser Arbeit zeigen die Ergebnisse, wie wichtig es ist, die Akzeptanz der Verbraucher im Hinblick auf Innovationen in der Nutztierhaltung aus unterschiedlichen Blickwinkeln zu untersuchen, bevor neue Rassen etabliert werden und deren Produkte auf den Markt kommen. Diese Dissertation liefert detaillierte Einblicke in die Verbraucherperspektive auf Zweinutzungshühner und trägt zur Debatte über Alternativen zur Tötung von Eintagsküken in Deutschland bei, indem sie aufzeigt, dass es ein geringes Marktpotenzial für Produkte von Zweinutzungshühnern gibt. Dabei ist das Potenzial für Eier deutlich höher als das für Fleisch. Produkte von Zweinutzungshühnern eignen sich für einen Nischenmarkt, da kleine potenzielle Verbrauchergruppen mit einer Zahlungsbereitschaft für Eier und Fleisch von diesen identifiziert wurden. Wenn das Konzept „Zweinutzungshuhn“ weiter gefördert werden soll, könnten durch gezielte Verbraucherinformation potenzielle Verbraucher gewonnen werden, die derzeit noch ambivalente Einstellungen zu Zweinutzungshühnern aufweisen. 


\section{Introduction}

Farm animal husbandry is increasingly the focus of public attention. There is a great discrepancy between industrial livestock farming and society's expectations regarding animal husbandry (e.g. Schulze et al., 2008; Weible et al., 2016; BMEL, 2015; 2017; Christoph-Schulz et al., 2018). Media coverage of farm animal husbandry and meat scandals as well as the increasing alienation of consumers from the agriculture industry has led to distrust and a growing rejection of current farming practices (Boehm et al., 2010; Spiller et al., 2012). Animal welfare is likely to become of increasing concern among the German population. In $2018,70 \%$ of the German population stated that animal welfare is important to them. Regarding meat produced under improved animal welfare conditions, $50 \%$ of the respondents stated they would be willing to pay a surcharge of up to 5 Euros, and $30 \%$ would be willing to pay more than 5 Euros extra per kilogram of meat (BMEL, 2019). In 2015, a Eurobarometer survey was conducted on attitudes of Europeans towards animal welfare. According to this survey, $94 \%$ of EU citizens consider the issue of animal welfare to be important and $82 \%$ of EU citizens believe that animal welfare should be improved. $59 \%$ of EU citizens stated that they were willing to pay a higher price for animal-friendly products and $52 \%$ of EU citizens were concerned about animal-friendly food labelling on products. $47 \%$ of respondents claimed that there were currently not enough animal-friendly food products available (EC, 2016). The Scientific Advisory Board for Agricultural Policy of the German Federal Ministry of Food and Agriculture (BMEL) published guidelines and recommendations for sustainable, socially acceptable livestock farming, and attaches great importance to the issue of animal welfare. In addition to the safety and quality of products, animal welfare aspects, consumer trust and the acceptance of animal husbandry are gaining increasing attention (BMEL, 2015). Thereby, the housing of laying hens and broiler production are evaluated more sceptical than other animal production systems (Verbeke and Viaene, 2000; Vanhonacker and Verbeke, 2009; Sossidou and Elson, 2009; Heng et al., 2013; Faucitano et al., 2017; Brümmer et al., 2018). For instance, the legal ban on conventional cages for laying hens was hardly present among the respondents (Sonntag and Spiller, 2018). High stocking densities, the use of antibiotics, large stock sizes and the culling of male layer chicks resulted in particular concerns and indignation (Bruijnis et al., 2015, Sonntag et al., 2016; 2018). 


\subsection{The role of consumers}

This thesis focuses on the role of consumers, as they have a key role to play in determining the potential of dual-purpose chicken breeds. At the end of the value chain, consumers decide whether to buy products or not (Großklaus, 2014; Meffert et al., 2019). Without consumers to purchase the goods, there would be no demand for eggs and meat from dual-purpose chicken breeds and therefore no need for further efforts of producers, breeders and food retail. Consumers' responses to food consists of several factors which include sensory and physiological characteristics but also past experiences, acquired product information, experiences, attitudes and beliefs (Costell et al., 2009; Leng et al., 2017).

Consumer attitudes towards the consumption of meat and eggs have been the subject of many studies. While for some consumers appearance, taste and price are the most important factors (McCarthy et al., 2004; Vanhonacker et al., 2007), for others health, food quality and food safety are more important. Often, compliance with high animal welfare standards is associated with healthier farm animals, better quality meat, and tastier and healthier food (Grunert et al., 2005; Mayfield et al., 2007; Evans and Miele, 2008; Vanhonacker and Verbeke, 2009; Heng et al., 2013). Several studies have revealed that consumer food choices are not only determined by the price but increasingly by credence attributes such as animal welfare, environmental aspects, health issues, and origin (Grunert, 2005; Napolitano et al., 2010; Pouta et al., 2010). Product quality can be subdivided into product and process quality. While product quality mainly refers to nutritional composition, health value, appearance and taste, which can be checked directly on the product's labelling, process quality mainly concerns the husbandry conditions of the animals, environmental protection and further production processes, all of which cannot be checked directly by the consumers (Nelson, 1970; Darby and Karni, 1973; Frank, 2006). Only with specific labelling or by providing additional information consumers can check these credence attributes, which are mainly based on consumer trust (Frank, 2006; Olynk et al., 2010). As a result of the lack of information on the consumer side, there is an information asymmetry between consumers and producers (Darby and Karni, 1973; Gräfe and Maaß, 2011). These information deficits can only be transmitted in a trustworthy manner through various certification concepts (Jahn et al., 2003; Bananno et al., 2018), while consumers differ in their labelling preferences (Bernués et al., 2003; Lagerkvist et al., 2017). Regarding these preferences, Bernués et al. (2003) segmented respondents into 'quality/safety orientated', 'traditional', 'quality unconcerned/ convenience-driven' and 'origin motivated' meat consumers. The labeling

preferences of consumers are attributed to their degree of involvement which is based on 
the importance they place on specific food attributes (Drichoutis et al., 2007). Involvement is a psychologic construct that determines attitudes and food purchasing behaviour as well as information behaviour (Laaksonen, 1994; Garcia et al., 2010). According to Michaelidou and Dibb (2008), involvement can be used to group consumers into low, moderate and high involved consumer segments which should be targeted with different marketing strategies.

Ethical values are embedded in many goods and belong to the unobservable credence attributes category. Attributes related to ethical values can cause unusual economic behavior as they are price insensitive to quantity changes as long as the ethical principles are not fulfilled, and therefore should be considered as a relevant attribute of goods (Frank, 2006). As animal husbandry is highly controversial, ethics in animal husbandry provide a condition for the acceptability of animal products and for animal husbandry as a whole (Korthals, 2006; Lassen et al., 2006; Marie, 2006; Ohl und van der Staay, 2012; Vanhonacker et al., 2012). Starr (2009) concludes that ethical consumption is positively affected by education, income, being female and socio-political participation. Additionally, social norms play a significant role when it comes to ethical consumption, as people tend to make ethical purchasing decisions when their social environment makes them too.

In Germany, the consumption of chicken meat and eggs has increased in recent years, while overall meat consumption is declining. With $11.7 \mathrm{~kg}$ per capita and year, chicken meat is the preferred poultry meat in Germany (BLE, 2018). German egg consumption in 2016 averaged 235 eggs per person (BLE, 2017a, 2017b). In 2017, approximately 48.5 million laying hens were kept in Germany. $10 \%$ of these laying hens were kept in small group housing, $65 \%$ in barn husbandry, $15 \%$ in free-range husbandry and $10 \%$ in organic husbandry systems. According to an analysis of the GfK consumer panel, German households bought $1 \%$ eggs from small group housings, $58 \%$ barn-laid eggs, $23 \%$ freerange eggs, $13 \%$ organic eggs and $6 \%$ eggs with an undefined origin (BMEL, 2018a).

Based on a qualitative study, Kennedy et al. (2004) analysed consumer perceptions of poultry meat and identified appearance (e.g. meat colour and form) as an indicator of quality. Other important factors when buying chicken meat were value (e.g. healthiness and taste) and convenience (described as preference for chicken fillet breast, whereas the cooking of a whole chicken was perceived as traditional). According to Stein (2015), a very abstract image of chicken as a "whole entity" exists, because whole chickens are rarely prepared anymore. Consumers increasingly buy convenience products and perceive the raw meatiness and reference to the animal as disgusting and repulsive. The more the chicken meat is processed, the more abstract chicken appears as an ingredient. This may also be related to the fact that the act of slaughtering, which precedes the 
consumption of meat, is distanced as far as possible and an abstract visualisation distracts the consumer from the fact that animals have to be slaughtered for meat.

Pouta et al. (2010) have shown preference heterogeneity among consumers for broiler meat and revealed very strong positive preferences for domestically produced broiler meat. Preference heterogeneity regarding chicken breast meat was also investigated by Van Loo et al. (2011). The findings show that consumers were willing to pay a premium for organic chicken breast, especially the segment including habitual organic buyers. In a study by Napolitano et al. (2012), the authors revealed that information on organic production might have a bigger impact on consumer preferences than sensory properties of the product.

For eggs, Guyonnet (2012) looked at several studies dealing with consumers' attitudes towards eggs and egg products. According to the author, prevailing eggs buying decisions depended on the price, freshness, remaining shelf-life and quality of the eggs. Norwood and Lusk (2008) found that respondents valued animal living conditions and were willing to pay a premium for eggs from hens raised in an aviary, pasture system when compared to a cage system. In a study by Vanhonacker and Verbeke (2009), consumer segments were identified in terms of eggs and chicken meat. Segments with a high price awareness and low ethical concerns were identified, but also segments with a high preference for animal welfare, low price sensibility and high quality-consciousness. However, across all segments, concerns were expressed about the way poultry is kept. Schjøll et al. (2013) found that animal welfare is the most important aspect for the majority of consumers when buying eggs. The results from Heng et al. (2013) show that when purchasing eggs, the respondents rate animal welfare aspects more highly than possible environmental effects which can arise, for example, from outdoor access. In a study by Lu et al. (2013), sufficient feed and water, the treatment of injuries and diseases and sufficient space were considered to be the most important husbandry parameters for laying hens. Andersen (2011), however, found that animal welfare attributes had little effect on the demand for animal products and that the estimation of the willingness to pay (WTP) for animal welfare is subject to hypothetical bias. Additionally, she found that organic and free-range eggs are considered to be very similar by the respondents.

\subsection{Problem of chick culling and alternatives}

Since the 1950s, industrialisation has been steadily progressing and society's prosperity has increased. This has led to an increasing demand for animal products, 
particularly for eggs and poultry meat. As a result, chicken husbandry was specialised into two decoupled production systems, laying and fattening lines, which were bred either for their high laying performance or high growth performance (Grashorn, 2013; Rautenschlein, 2016; Mueller et al., 2018). While with conventional broiler chickens both, the male and female animals can achieve a high growth rate, for laying hens, only the female chicks are used for egg production. The male chicks neither lay eggs nor put on enough meat, and are therefore considered uneconomical. For this reason, in Germany, more than 45 million day-old male chicks from the laying lines are culled by carbon dioxide or maceration annually (Grashorn, 2013; Beckmann, 2016; Rautenschlein, 2016; Giersberg and Kemper, 2018). This practice has been carried out in both, conventional and organic production systems for decades. A part of the day-old male chicks is then fed to zoo animals and reptiles as predator food (Leenstra et al., 2011).

In 2016, a court ruling dealing with the culling of day-old chicks attracted attention in Germany. The High Administrative Court of North Rhine-Westphalia decided that the controversial practice of killing male chicks after hatching does not violate the Animal Welfare Act because the animals die for a reasonable reason: the economic efficiency and food supply of the population. Beforehand, the former Agricultural and Environmental minister in North Rhine-Westphalia wanted to prohibit the killing of chicks with a decree from 2013. As a result, eleven hatcheries filed suit. According to the final court ruling, a ban on chick killing would not solve the problem because production would then have been relocated abroad (Beckmann, 2016). Since then, the subject of chick culling has been increasingly taken up by the media and animal welfare organisations, and is questioned ethically by consumers (Verbraucherzentrale NRW, 2017).

The German government endeavours to end the practice of chick culling as soon as possible, and is funding projects in this field (BMEL, 2018b). Currently, three approaches are being discussed with a view to solving the problem of chick culling in Germany. The breeding of dual-purpose chickens, which will be discussed in more detail in the following chapter, in-ovo sex determination and the rearing of male layer chickens. For economic and ecological reasons, in-ovo sex determination is at the forefront of policy. Using spectroscopic or endocrinological methods enables the detection of the sex in the hatching egg. The eggs with male embryos are not further incubated but sorted out and used for other industrial purposes, such as animal feed. The use of spectroscopic methods allows for sex determination on the fourth incubation day, whereas endocrinological methods can provide results after nine days of incubation (the total incubation time is 21 days). In this case, it is questionable whether or not the embryo can yet feel pain (Krautwald-Junghanns et al., 2017; Galli et al., 2018). Recently, a joint 
venture by the Rewe Group and a Dutch technology company launched a solution ready for practical use. The technology, which is based on endocrinological methods, was developed by scientists from Leipzig University and promoted using public funds. Since the end of 2018, free-range eggs with the label "Respeggt - without chick killing" have been available in selected markets of the Rewe Group (Seleggt, 2018).

However, there are also numerous initiatives that concentrate on the rearing of layer cockerels, which is mainly practiced in organic farming. The rearing of layer cockerels is associated with lower cockerel growth performance and considerably higher production costs (Rautenschlein, 2016; Krautwald-Junghanns et al., 2017). As laying lines are used in this case, the laying performance of the hens is constant. The meat from the layer cockerels differs greatly from conventional broiler meat. The share of breast meat is very small, and the statue is strung-out. Additionally, the meat is darker and has a firmer consistency and therefore requires other preparation methods. In most cases, the fattening of the layer cockerels is cross-subsidised by an additional charge of 4-5 cents on the egg price (Schütz et al., 2017). Conventional eggs from such initiatives are increasingly found in supermarkets and discounters, whereas the meat is often used in processed products and is not labelled separately (Giersberg and Kemper, 2018).

\subsection{The usage of dual-purpose chickens}

The breeding of a dual-purpose chicken, in which the laying hen provides an adequate laying performance and the cockerel a sufficient fattening performance, is currently being investigated by several breeding companies. The aim is to find a compromise between fattening and laying performance in order to produce the most economically viable chicken possible as alternative to conventional hybrid chickens (Urselmann and Damme, 2014; Damme, 2015). Traditional dual-purpose breeds such as 'Les Bleus' also find application in this sector (Giersberg and Kemper, 2018). In conventional chicken farming, the broiler chickens are fattened for about 35 days and reach a slaughter weight of $2 \mathrm{~kg}$ to $2.2 \mathrm{~kg}$ (Berk, 2014). The dual-purpose cockerels are fattened for twice as long (approx. 70 days) to reach a similar slaughter weight (Kaufmann et al., 2016). The laying lines lay an average of 310 eggs per year (Schmutz and Flock, 2014) whereas dual-purpose laying hens lay around 20\% less, with approximately 250 eggs per year (Rautenschlein, 2016; Krautwald-Junghanns et al., 2017). Furthermore, the quality of the meat differs greatly from that of conventional broiler chickens of the darker, firmer and tastier meat and the smaller share of breast meat (Grashorn, 2013; Mueller et al., 2018; Siekmann et al., 
2018). While the eggs have the same nutritional value, they are smaller, and their shell has a less typical brown colour (Bruijnis et al., 2015). According to Damme (2015), the meat of dual-purpose cockerels would be $40 \%$ more expensive than conventional broiler meat. To cover the extra costs of eggs from dual-purpose hens, a surcharge of 2.19 cents per egg is needed (Diekmann et al., 2017).

The organic association 'Demeter' recently announced that they will refuse in-ovo sex determination technologies, as they want to promote a transition to a more sustainable agriculture and are instead opting for the breeding of dual-purpose chickens (AwaterEsper, 2018; DGS, 2018). From the point of view of sustainability, the use of dual-purpose chickens is a controversial discussion, as they are currently inefficient for both, economic and ecological reasons. The longer fattening period results in higher feed costs, higher energy and production costs and rising emissions due to increased chicken manure (Murawska et al., 2005; Koenig et al., 2012; Leinonen et al., 2012; Beckmann, 2016).

Since the problem of chick culling is a relatively recently instigated discussion, there are yet not many studies on consumer attitudes and acceptance of chick culling and possible solutions. Leenstra et al. (2011) conducted a study on the acceptance of alternatives to chick culling using focus groups in the Netherlands. They concluded that $58 \%$ of the respondents were not aware of the practice of chick culling. Furthermore, they found that half of the respondents were against chick culling and another $36 \%$ were strongly against chick culling. A ranking of alternatives showed that in-ovo sex determination (with 25\%) and the breeding of dual-purpose chickens (with 24\%) showed the highest level of agreement when compared to the remaining alternatives. According to the study, two thirds of the respondents agreed positively with the concept of dualpurpose chickens. $10-15 \%$ of the respondents regarded this concept as highly critical and rejected it due to the higher price of eggs and meat, as well as the increased amount of manure. In addition, many respondents accepted the feeding of male chicks to zoo animals, as these were considered to be the source of food for zoo animals. It was questioned why new technological solutions for chick killing were being researched at all, since male chicks are not a waste product, but a by-product used for zoo animals. Leenstra et al. (2011) also stated that some of the respondents believed that laying hens do not have a good life anyway, and for this reason they did not reject chick culling.

In a study by Bruijnis et al. (2015), the socio-ethical aspects of chick culling and the alternatives, dual-purpose chickens and in-ovo sex determination, were evaluated. On the basis of a valorisation panel, expert interviews were conducted with four stakeholder groups or representatives for society, the egg sector, day-old chicks and the environment. They discussed the fact that chick culling is considered ethically unacceptable and that 
day-old chicks were considered an important source of food for predators in zoos. They also discussed the need to substitute day-old chicks with alternatives such as mice and rats. The authors emphasised the fact that dual-purpose chickens are a solution because the life of day-old chicks is saved, and it respects important aspects of integrity, naturalness and intrinsic values. The experts assessed dual-purpose chickens as being a niche product and argued that a ban on chick culling would result in the industry no longer being competitive, and that the production would have relocated abroad. However, the study did not reach a consensus on environmental and animal rights aspects. According to Damme and Ristic (2003), the rearing of day-old chicks is classified as a waste of resources and not accepted by consumers, as they would not be willing to pay a higher price for products from dual-purpose chickens. They discussed the fact that the feeding of male chicks to zoo animals and reptiles should be accepted by society until an efficient solution to the ethical concern of chick culling has been found.

Gagnat et al. (2018) investigated willingness to pay and attitudes towards dual-purpose poultry among Swiss consumers. The findings showed that knowledge about agriculture, familiarity with dual-purpose chickens and the type of products usually purchased (organic or conventional) influenced willingness to pay for eggs and meat from dual-purpose poultry, and that the willingness to pay was generally declared to be higher for eggs than for meat from dual-purpose poultry. The Verbraucherzentrale NRW commissioned a Forsa survey with 1,000 respondents which addressed this subject in Germany. The results show that nine out of ten respondents would be willing to accept a price premium on eggs to avoid the killing of male chicks. $35 \%$ of respondents stated that they would be willing to pay an extra 4 to 6 cents per egg and $52 \%$ even stated they would be willing to pay 6 cents or more for an egg from a farm where male chicks are also raised (Verbraucherzentrale NRW, 2017).

\section{$1.4 \quad$ Research questions and objectives}

Society's concerns about modern production methods in animal husbandry, including the practice of chick culling, are increasingly the focus of public attention. Therefore, policymakers are under increasing pressure to generate solutions to the problem of chick culling as well as to enhance acceptance of animal husbandry in general. There is growing interest in the potential of dual-purpose chickens as being one alternative to the culling practice that is rejected by a large part of the population. For this, consumer acceptance plays a major role as consumers must be willing to bear the higher costs and 
accept the difference in appearance for products from dual-purpose chickens. Therefore, three research questions $(R Q)$ arise in order to depict consumers' perspectives on dualpurpose chickens in a differentiated way.

1. Are consumers aware of the culling of day-old male layer chicks and do they have moral concerns? What are consumers' ethical evaluations of dualpurpose chickens as an alternative to the culling of day-old male layer chicks?

2. What are consumers' reactions to the concept of dual-purpose chicken breeds and under which conditions would consumers buy products from dual-purpose chickens?

3. Are there consumer segments with preferences and a willingness to pay (WTP) for eggs and meat from dual-purpose chickens? If so, is their WTP sufficient? 


\section{Methodology}

To answer the research questions, different methods were used to shed light on the topic from a variety of perspectives. The methodologies used in this thesis cover qualitative as well as quantitative research approaches and an Ethical Matrix which belongs to the discipline of applied ethics. In the following, a short overview of the methodologies is given, including potentials, limitations and the applied analysis techniques.

\subsection{Qualitative methods}

Qualitative research practices are becoming increasingly important in a rapidly changing environment in which new social contexts and perspectives evolve quickly. Deductive methods which first derive hypotheses from theoretical models and then test these hypotheses empirically reach their limits. Therefore, inductive methods can better respond to changes in social contexts. Qualitative methods are characterised by a naturalistic and interpretative approach which explores phenomena from "the inside" (Flick, 2009; Ritchie et al., 2014). Qualitative research is not so much a matter of quantifying information as of gaining the most varied and in-depth insights into a subject matter possible (Kuß, 2007). Particularly for research fields not yet investigated, the open and interpretative approach of qualitative methods is useful for the detection of new issues (Buber and Klein, 2009). Additionally, qualitative methods allow for deep insights into underlying values that are important to understand, such as consumer behaviour (Arnould and Thompson, 2005). The main limitations of qualitative methods are the limited generalisability of the findings and potential researcher bias (Creswell and Clark, 2011). The results have to be interpreted against the background of their context, and cannot be generalised for the whole population, both because of the limited number of study participants and the fact that they can be transferable to other settings (Flick, 2009; Anderson, 2010). There are different types of qualitative methods, including in-depth interviews, focus groups and observational methods (Buber and Klein, 2009). In this thesis, focus groups were applied because this method is especially useful when testing new concepts or products (Kuß, 2007). 


\section{Focus groups}

Focus groups are an empirical research method with an emphasis on group dynamics and interactions between participants (Finch and Lewis, 2003). According to Morgan (1997: 6), "focus groups are a research technique that collects data on group interactions on a topic determined by the researcher". The aim of focus groups is to create an atmosphere that fosters an almost natural conversational setting with diverse opinions and statements (Lamnek, 2005). Furthermore, by responding to other participants, the conversational setting leads to deeper insights into motivations and justifications, stimulating new thoughts (Finch and Lewis, 2003). This method is therefore particularly suitable for the detection of perceptions and needs of consumers and the identification of aspects that need to be considered in a standardised survey, and does not replace surveys as the findings are not representative due to small sample sizes (Kuß, 2007). Focus group discussions are normally conducted with a small group of six to ten people who discuss a given subject for 60-120 minutes. The discussion is guided by a moderator. The interactive group setting is structured by a questioning route and the role of the moderator is to encourage the participants to express their opinions and keep the discussion on track and ensure that all participants contribute (Kühn and Koschel, 2011). Limitations of this method are that comparability across different focus groups is hardly given because of the different group dynamics, and potential researcher bias when analysing the outcomes of the focus groups. This can be mitigated by joint discussions between several researchers (Flick, 2009). Additionally, the presence of other people in the setting of focus groups can lead to socially desirable behaviour among the participants, and social conventions can result in conformism (Smithson, 2007; Acocella, 2012). On the other hand, Kitzinger and Farquhar (1999) argue that focus groups are particularly suitable for sensitive topics, as focus groups enable discussions and reflections and can therefore be used to discover the social construction of sensitive issues.

\subsection{Quantitative methods}

While qualitative methods are firstly concerned with the "why", quantitative methods are appropriate for deductive approaches and focus on the "who" and "what". The main purpose of quantitative studies is to generalise findings for a larger population by using an objective process with closed ended questions (Bryman, 2014). Numerical data is often collected through surveys, observations or secondary data. Statistical analyses contribute 
to the testing of hypotheses (Borrego et al., 2009; Creswell, 2013). Quantitative methods include a wide range of data collection methods, for example questionnaires (e.g. mail, online or web surveys), interviews and observation, and data analysis techniques such as descriptive, explorative and experimental approaches (Jacob et al., 2013; Cleff et al., 2015). In the following, online surveys will be discussed in more detail, as this approach was chosen for collecting the numerical data for this thesis, because a large number of participants can be questioned cost-effectively in a short time (Evans and Marthur, 2005). The data was analysed by using a factor and cluster analysis and a discriminant analysis in order to structure and reduce the data and to segment the respondents into homogenous groups. A choice experiment was applied to identify the potential of specific products not yet on the market by estimating preferences and willingness to pay for product attributes.

\section{Online survey}

Survey research is characterised by written questionnaires or formal interviews used to gather information on behaviours, beliefs and attitudes. Generally, the survey participants are sampled by a random technique which allows for generalisation (Neuman, 2014). Due to the sharp rise in the use of the internet, online surveys are often used for the collection of quantitative data. Advantages of online surveys are that a large number of people can be questioned cost-effectively in a short time frame (Evans and Marthur, 2005). Online surveys offer many possibilities that have a positive effect on the data quality, such as using pictures, videos, filters or logic checks (Kuß, 2007). Additionally, socially desirable behaviour occurs less often than in surveys in which an interviewer is involved, and the interviewer bias is also eliminated in this format (Brace, 2013). Some disadvantages associated with online surveys are the inability to draw truly random samples due to selfselection bias, as only those who signed up have the chance to participate in the survey (Wright, 2005), and the uncertainty whether the respondent is the person who conducts the survey and not another person (Schmidt, 1997). Furthermore, the whole target group might not be covered, because elder people especially do not use the internet, or some who do not have access to it (Kuß, 2007). Another drawback of online surveys is that, in case of comprehension problems, there is no interviewer available to clarify questions (Evans and Marthur, 2005; Brace, 2013). In order to minimise this disadvantage, cognitive pretesting should be a prerequisite in the design of a questionnaire (Porst, 2000; Lenzner et al., 2016). 


\section{Factor, cluster and discriminant analysis}

Since consumer attitudes is a latent construct that is composed not of a single item but of many overlapping items, multivariate analysis is an advantage in this study (Cleff, 2015; Hair et al., 2010). In multivariate methods, more than two variables are considered and related simultaneously in the analysis. Factor analysis is one of these methods. This method allows for the analysis of a large number of variables and complex data structures analysis and is often used for data structuring and data reduction (Kuß, 2007). There are various methods of factor analysis. In the present thesis, an explorative factor analysis is carried out because the number of factors to be extracted was not known previously (Schendera, 2010). The groups of highly correlated variables are combined into an independent latent factor (Backhaus et al., 2011). In order to examine the measurability and suitability of the variable correlations for a factor analysis, several criteria must be used before the latent factors can be formed (Backhaus et al., 2011).

In this thesis, the factor analysis is followed by a cluster analysis. A cluster is a group of objects or people with similar characteristics, whose properties have been defined beforehand (Cleff, 2015). The difference between a factor analysis and a cluster analysis is that factor analysis refers to groups of variables and cluster analysis to groups of individuals (Hair et al., 2010). The aim of a cluster analysis is to combine similar individuals into homogeneous groups, which in turn stand out clearly from each other (Kuß, 2007). By using a cluster analysis, complex data sets can be used to segment different groups (Cleff, 2015).

In order to verify the quality and validity of the results, a final discriminant analysis can be carried out to explain the relationship between the dependent variables (cluster groups) and the independent variables (factors) (Brosius, 2011). Discriminant analysis therefore assesses the adequacy of the classifications. The analysis consists of two steps: the estimation of the discriminant function and the classification of the cases (persons) into different groups (Janssen and Laatz, 2009).

\section{Choice experiment}

With the help of discrete choice procedures, the choice behaviour between alternatives is analysed. Preferences and willingness to pay for individual product attributes can then be obtained. Procedures are characterised by the fact that respondents make repeated choices between several alternatives with varying attributes instead of placing the products in a ranking or order (Adamowicz et al., 1998). In survey-based choice experiments, respondents select the one they prefer most from various alternatives. By 
specifically varying the characteristics of these alternatives, their influence on the selection decisions can be determined and a far more direct examination of causal relationships can be achieved than with "conventional" survey data (Auspurg and Liebe, 2011). Choice experiments are based on Lancastrian consumer theory (Lancaster, 1966) which states that consumers do not derive the utility from the good itself but from the product attributes and attribute levels and the random utility theory (McFadden, 1974). This assumes that individuals are rational and try to maximise their utility within their budget constraints. Discrete choice experiments are often conducted as part of online surveys. Another important advantage for choice experiments over other methods is that there is no need to investigate existing alternatives, as alternatives as well as their attributes can be freely chosen. This enables the identification and quantification of attributes that increase and reduce utility and the investigation of willingness to pay for products that are not yet on the market (Auspurg and Liebe, 2011). Breyer et al. (2005) give an advantage of choice experiments as holding less risk of manipulating the selection behaviour of the respondents through strategic behaviour. This is due to the fact that it is less clear what should be evaluated in the setting of choice experiments. Hanley et al. (1998) argue that choice experiments are especially suitable for the assessment of particular attributes. A disadvantage of this method is the complexity of the task of judgment. Cognitive overload might result in lower consistencies in response behaviour, the use of decision heuristics or complete refusal (Swait and Adamowicz, 2001; Hensher et al., 2005; Christoph, 2007; Carlsson, 2011). Additionally, the estimated willingness to pay should not be interpreted as being accurate, as it is often overstated by the respondents, especially when it concerns products with a normative character (List and Gallet, 2001; Gerini et al. 2016). Nevertheless, in the category of stated preference methods, choice experiments are the method which yields the most realistic willingness to pay estimates (Louviere et al., 2000; Hensher et al., 2015).

\subsection{Mixed methods}

According to Creswell and Clark (2011), mixed methods combine both, qualitative and quantitative methods with the objective of obtaining a deeper understanding of the research topic than one method alone could provide. The sequential or simultaneous use of quantitative and qualitative research approaches can contribute to the evaluation of a topic from different perspectives, and they can each compensate for the weaknesses of the other method (Denscombe, 2008; Flick, 2009). Two goals can be pursued with the 
mixed methods approach. Firstly, obtaining a broader knowledge by not using just one approach and secondly, validating the findings (Kelle, 2004; Flick, 2009). Particularly when the subject matter is new, sequencing qualitative and quantitative methods can help to understand and to identify the research topic from the outset, and quantify the results in a subsequent step (Burke Johnson and Onwuegbuzie, 2004; Kuckartz, 2014; Ritchie et al., 2014). By using an exploratory sequential mixed methods approach, the research process starts with qualitative research. The second phase builds up on this qualitative data. This way, appropriate instruments and specific variables can be identified, and the findings can be incorporated into the quantitative phase (Creswell, 2013). Ritchie et al. (2014) argue that the use of mixed methods contributes to a fuller picture of complex social phenomena, but not self-evidently to a more reliable picture.

\subsection{Ethical matrix}

The Ethical Matrix according to Mepham (2000), is a tool in applied ethics for explaining the interests of affected groups in relation to ethical principles. The aim is to present a well-founded consideration from different perspectives and thus reduce complexity, and to provide guidance in the ethical evaluation of a topic (Zichy et al., 2014). The objective of an ethical matrix is not to provide decisions but to facilitate ethical assessment. Participatory methods can encourage this evaluation in terms of fact finding (Kaiser and Forsberg, 2010; Schroeder and Palmer, 2003). The ethical principles of wellbeing, autonomy and justice were identified by Beauchamp and Childress (1994) and are guided by the three main theories of ethics, which are utilitarianism (well-being), Kantianism (autonomy) and the Rawls' theory (justice). These ethical principles are applied to a number of interest groups which might be also groups that are not able to express their concerns, but which nonetheless have an ethical status, such as animals or wildlife (Klint Jensen et al., 2011). Forsberg (2007) suggests that a wide range of stakeholders should participate in ethical evaluation but argues at the same time that this process is very time consuming and costly, and therefore not always feasible. 


\section{Structure and summary of the contributions}

The cumulative thesis consists of four contributions (see Table 1) using the previously presented theories and research approaches. The first three articles deal explicitly with consumers' views on dual-purpose chickens and build on each other. The fourth article deals with a more holistic view on the topic from an ethical perspective.

Table 1: Overview of the articles

\begin{tabular}{|c|c|c|c|}
\hline Article & Authors & Title & Published in \\
\hline (1) & $\begin{array}{l}\text { N. Brümmer } \\
\text { I. Christoph-Schulz } \\
\text { A. Rovers }\end{array}$ & $\begin{array}{l}\text { Consumers' perspectives on dual- } \\
\text { purpose chickens as } \\
\text { alternatives to the killing of day- } \\
\text { old chicks }\end{array}$ & $\begin{array}{l}\text { International Journal on } \\
\text { Food System Dynamics } \\
\text { (2018). 9(5), 390-398. }\end{array}$ \\
\hline (2) & $\begin{array}{l}\text { N. Brümmer } \\
\text { W. Petersen } \\
\text { I. Christoph-Schulz }\end{array}$ & $\begin{array}{l}\text { Consumer acceptance of dual- } \\
\text { purpose chickens. } \\
\text { A mixed methods approach }\end{array}$ & $\begin{array}{l}\text { German Journal of Agricultural } \\
\text { Economics (2018). Special } \\
\text { Issue Future Options for } \\
\text { Animal Husbandry in Europe, } \\
67(4), 234-245 .\end{array}$ \\
\hline (3) & $\begin{array}{l}\text { N. Brümmer } \\
\text { I. Christoph-Schulz }\end{array}$ & $\begin{array}{l}\text { German consumers' preferences } \\
\text { and willingness to pay for eggs } \\
\text { and meat from dual-purpose } \\
\text { chickens: } \\
\text { A latent class analysis }\end{array}$ & Not published yet \\
\hline (4) & $\begin{array}{l}\text { N. Brümmer } \\
\text { I. Christoph-Schulz A. } \\
\text { Rovers }\end{array}$ & $\begin{array}{l}\text { Dual purpose chickens as } \\
\text { alternative to the culling of day-old } \\
\text { chicks - the ethical perspective }\end{array}$ & $\begin{array}{l}\text { Eursafe Conference } \\
\text { Proceedings (2018). } \\
\text { S. Springer, \& H. Grimm (Eds.), } \\
\text { Professionals in food chains } \\
\text { (pp. 141-145). }\end{array}$ \\
\hline
\end{tabular}

These four contributions were realised within the framework of the project "SocialLab Nutztierhaltung im Spiegel der Gesellschaft". SocialLab is a joint project of various German research institutions pursuing the aim to conduct evidence-based research for a socially accepted and consensual animal husbandry. In this process, the perspectives of consumers and citizens as well as those of farmers and food retailers were considered in order to develop concrete policy recommendations. The project was supported by funds of the Federal Ministry of Food and Agriculture (BMEL) based on a decision of the Parliament of the Federal Republic of Germany via the Federal Office for Agriculture and Food (BLE) under the innovation support programme. Within the SocialLab project, the 
studies regarding consumer perspectives on dual-purpose chickens were situated within a work package dealing with the assessment of innovative concepts as service for other research fields. In this context, a cooperation with the project "IntegHof" has been initiated. IntegHof has the aim to test the feasibility of dual-purpose chickens from different perspectives such as animal welfare and health, consumer acceptance and economic viability. Within this framework, SocialLab studied the consumer perspective.

In article (1), an explorative and qualitative approach was used to gather insights into the topic. For research fields not yet investigated, the open and interpretative approach of qualitative methods is especially useful for the detection of new issues. With the help of six focus groups in three German locations, with 47 participants in total (all consumers of chicken meat and eggs), insights into consumers' chicken meat and egg preferences, their perception of chicken farming in general and their attitudes towards dual-purpose chickens were gained. The focus groups were scheduled for 90 minutes, guided by a moderator, documented by audio and video and transcribed verbatim. The transcripts were evaluated content-analytically, according to Mayring (2015). The findings from the focus groups show that participants prefer to buy chicken cuts and hardly ever cook a whole chicken. Regarding chicken meat, husbandry conditions were noted as being difficult to understand on the basis of the packaging, in contrast to eggs, where the husbandry system was indicated as an important purchase criterion. With regard to eggs, some participants stated a preference for large eggs, while the egg shell colour did not seem to be relevant. The topic culling of day-old chicks was something that was known to most participants and rejected for ethical reasons. However, few alternatives were known. Therefore, information on dual-purpose chickens and other alternatives were given to the participants. The naming of 'dual-purpose chickens' was seen as inappropriate and misleading, but participants were generally in favour of this chicken breed. Some participants raised concerns regarding the economic efficiency and higher product prices. For others, ethical values predominated. Additionally, the results demonstrated that the discussants had specific expectations regarding the product characteristics and the labelling of dual-purpose chickens, and attached better husbandry conditions to the potential purchase of products from dual-purpose chickens.

In article (2), a mixed methods approach was applied, using qualitative and quantitative methods sequently. Article (2) builds on the findings from the focus groups in article (1). The statements made in the discussions are particularly well represented in this article. An online survey with 1,502 chicken and egg consumers was conducted in Germany. The sample was widely representative for the German population with regards to gender, region and age, except for education, employment rate and income. Respondents 
answered questions concerning inter alia their dietary habits, knowledge of chicken husbandry and socio-demographics. Additionally, respondents assessed 40 items on a seven-point Likert scale. Seven factors were identified by conducting an explanatory factor analysis. These accounted for $55 \%$ of the overall error variance. Five factors demonstrated critical and opposing consumer attitudes towards modern chicken husbandry and, accordingly, a favourable attitude towards dual-purpose chickens. In contrast, there were two factors related to the endorsement of modern chicken husbandry and the high priority of low prices for chicken meat and eggs. These factors contained opposing opinions towards dual-purpose chickens. Based on the factors extracted, a cluster analysis segmented respondents into three cluster groups: opponents (37.5\%), supporters (23.4\%), and indifferents (39.1\%). A discriminant analysis confirmed the validity of the clusters found. Bivariate analyses were used to detect further details of the segments found. These cluster groups differed significantly regarding their level of knowledge and their experience with agriculture, as well as in purchase behaviour and sociodemographic characteristics. The results show that there are significantly more males among opponents and that they have less knowledge of chicken husbandry and less experience with agriculture than supporters, who are more likely to be female and more often have pets. The indifferent group makes up the largest cluster, at $39.1 \%$. Therefore, it is the most important consumer group with regard to the marketing of dualpurpose chicken products. The indifferents have an above-average preference for dualpurpose chickens compared to the total sample on the one hand, while maintaining an above-average supportive attitude for conventional farming practices and affordable chicken meat and eggs on the other. Indifferents are likely to be female and have lower incomes than supporters. Additionally, they have a moderate knowledge of chicken husbandry and a moderate level of education. It can be concluded that there is the greatest potential for reducing uncertainty by means of providing more and better information on dual-purpose chickens within this cluster group, which may increase consumer acceptance.

The online survey also contained a choice experiment in order to find out more about consumer preferences and their willingness to pay for products from dual-purpose chickens. In article (3), a discrete choice experiment was conducted with a mixed methods approach, involving an online survey based on the focus groups. A discrete choice experiment was chosen because no purchase data was available yet for products from dual-purpose chickens, as they are rarely present on the market. Consequently, choice experiments are a suitable method for estimating the effects of different egg and meat characteristics on consumers' utility and to determine their willingness to pay. Respondents made repeated choices between several alternatives. Eight choice sets 
were presented to each respondent, including four choice situations with eggs and four choice situations with chicken breast meat. Each choice set consisted of four alternatives with varying attributes, including husbandry system, price, size (only in the case of eggs), dual-purpose chicken label and origin. To account for preference heterogeneity, we applied a latent class model. Consumer heterogeneity is explained by the results of the factor analysis on consumer attitudes towards dual-purpose chickens and chicken husbandry in general, as well as variables such as pet ownership and organic purchasing behaviour. Four consumer segments regarding eggs and chicken meat were identified, each including 'price-conscious consumers', 'environmentalists', 'opponents of dualpurpose chickens' and 'supporters of dual-purpose chickens'. For both products, the largest segments consisted of 'price conscious consumers'. Small potential consumer groups with a willingness to pay more for dual-purpose chicken products were also identified. In the case of eggs, $25.3 \%$ of respondents belong to this segment whereas a smaller segment of $16.2 \%$ had a willingness to pay more for chicken meat from dualpurpose chickens. All in all, the results in article (3) show that the segment which supports dual-purpose chicken meat is considerably smaller than the segment which supports eggs from dual-purpose chickens. It was also noted that localness was strongly preferred for both products.

In article (4), the usage of dual-purpose chickens was regarded from an ethical standpoint and allowed for a comprehensive view on dual-purpose chickens, beyond consumer perspectives. The Ethical Matrix, according to Mepham, was applied. It is a tool of applied ethics for the interpretation of the interests of stakeholders with regard to ethical principles. The aim was to present a well-balanced consideration from different angles, and, thus, reduce the complexity of the topic. In this case, the keeping of dual-purpose chickens was compared to the current practice (culling of day-old chicks). We applied the matrix to five interest groups: dual-purpose chickens, consumers, the egg and meat industry, farmers and the environment. The results show that dual-purpose chickens as an alternative to the culling of day-old chicks is a very complex topic. For the chickens themselves, this could imply wellbeing if the husbandry is adapted to the needs of the animals. Consumers could be affected by affordability if chicken meat and eggs became more expensive. The transition to eggs and meat from dual-purpose chickens could have far-reaching implications for both, the egg and meat industry as well as farmers, because the whole supply chain has to be adapted to the differing properties. Additionally, profitability plays a big role. The environment could also be affected by the usage of dualpurpose chickens, as the longer fattening period of the cockerels results in higher usage of resources and more manure is produced. The findings from this article illustrate the complexity of the topic, with many ethical facets which do not only affect consumers. 
The cumulative dissertation consists of the above mentioned four articles. Further publications are listed in Annex A. One additional publication deals with the results of a canteen survey in Hanover in which the taste, quantity and appearance of meat from dualpurpose cockerels were compared with the meat of male layer-type chickens. Two other publications address the image of poultry farming in the German print media, and further publications involve citizens' perceptions of recent livestock production systems in Germany, also with regard to pig and cattle husbandry. 


\section{$4 \quad$ Articles included as part of the thesis}

\subsection{Consumers' perspective on dual-purpose chickens as alternative to the killing of day-old chicks}

Nanke Brümmer, Inken Christoph-Schulz and Anja-Karolina Rovers

International Journal on Food System Dynamics (2018). 9(5), 390-398.

(With kind permission of Int. Journal on Food System Dynamics, University of Bonn)

Declaration of originality: The research design and procedure of this study were jointly developed by Dr. Inken Christoph-Schulz and the author. For the formulation of the questioning route, experts in the field of chicken husbandry were consulted. The focus groups were conducted by all three authors. The evaluation of the transcripts was done by the author, who also wrote the raw manuscript. The results were discussed by the authors and Dr. Inken Christoph-Schulz revised the manuscript. The recruitment of the focus group participants was done by an external market research agency. 


\title{
Consumers' Perspective on Dual-purpose Chickens as Alternative to the Killing of Day-old Chicks
}

\author{
Nanke Brümmer, Inken Christoph-Schulz, and Anja-Karolina Rovers
}

Thünen Institute of Market Analysis, Braunschweig, Germany

nanke.bruemmer@thuenen.de; inken.christoph@thuenen.de; anja-karolina.rovers@thuenen.de

Received November 2017, accepted September 2018, available online October 2018

\begin{abstract}
The usage of dual-purpose chicken breeds - a chicken breed which provides meat and eggs at the same time is one of the discussed alternatives to prevent cockerel chicks of laying hens from being killed for economic reasons. Therefore, the aim of this study is to analyse consumers' perspective on dual-purpose chickens. To get an insight into consumers' perspective, we initially conducted six focus groups with German consumers focussing on their chicken meat and egg preferences, perception of chicken farming and attitudes towards dual-purpose chicken breeds. The results show that most of the participants were aware of the killing of day-old chicks. However, alternatives were scarcely known. After giving the participants information about dual-purpose chickens, they were generally in favour of this chicken breed. Some participants raised concerns regarding the economic efficiency and the higher product prices. For others, ethical values predominated. All in all, the results demonstrate that the discussants have specific expectations regarding the husbandry conditions but also regarding the product characteristics and the labelling of dual-purpose chickens.
\end{abstract}

Keywords: consumers; dual-purpose chickens; perception; focus groups; day-old chicks 
In Germany, annually more than 40 million male chicks are killed after hatching. The killing of day-old chicks is common practice in the commercial production of laying hens because the fattening of cockerels from laying breeds is unprofitable. The sex determination in the egg ${ }^{1}$, the fattening of layer-type males ${ }^{2}$ or dual-purpose breeds are alternatives to the killing. Breeders of dual-purpose chickens are facing the problem that meat growth and the number of eggs are negatively correlated. Therefore, the hens lay fewer and smaller eggs and the cockerels put on less meat and need more time and feed to grow. Consequently, eggs and meat from dual-purpose chickens have a foreign appearance to consumers and are more expensive than products from chicken breeds which are either specialized for meat or egg production.

Farmers and breeders potentially need to adopt marketing strategies to increase consumer acceptance of dual-purpose chickens because this is essential for market success. Aim of this study is to gain first insights into consumers' perspective on dual-purpose chickens as there is a great need for research regarding the emerging debate on killing day-old chicks and possible alternatives (Leenstra et al., 2011; Bruijnis et al., 2015). Thus, several research questions arise. First, are consumers aware of the killing of day-old chicks and do they have morals concerns? Second, what is the reaction to the concept of dualpurpose chicken breeds? Third, whether and under which conditions would consumers buy products from dual-purpose chickens and would they be willing to pay a surcharge? In section two of this paper the background of the topic and relevant literature on consumers and dual-purpose chickens are presented. Then, the method is described and followed by the results of the focus groups. The paper concludes with the discussion of the results.

\section{Background}

Since the 1950s the industrialization and prosperity of society led to a growing demand for animal products. The increasing demand for chicken meat and eggs and new opportunities in sexing at hatch resulted in a specialization in chicken breeding. Nowadays, there are genotypes specialized in meat growth and genotypes that are specialized in egg production (Leenstra et al., 2010; Grashorn, 2013). As a result, in the breeding of laying hens there is only use for the female animals as the fattening of layer-type males is unprofitable due to the negative correlation between meat growth and laying performance and therefore the males do not put on sufficient weight. For this reason, it is common practice that male layer-types are killed as day-old chicks, in conventional as well as organic farming (Rautenschlein, 2016).

In Germany, the consumption of chicken meat and eggs is still slightly increasing. In 2016 the per capita consumption was $20.9 \mathrm{~kg}$, in 2006 the average consumption was $16.7 \mathrm{~kg}$ (BMEL, 2008, 2017a). Additionally, the Germans consumed on average 234 eggs in 2016 (BLE, 2017), and therefore 25 more eggs than in 2006 (BMEL, 2008). At the same time, animal husbandry is in the focus of public criticism. Especially the keeping of laying hens and the broiler production are seen more sceptical than other animal husbandries (Verbeke and Viaene, 2000; Vanhonacker and Verbeke, 2009; Sossidou and Elson, 2009; Heng et al., 2013; Faucitano et al., 2017). Besides critical aspects like stocking density, antibiotics and farm size, the society is becoming increasingly aware of the killing of day-old chicks (Bruijnis et al., 2015). The debate in Germany intensified in May 2016 when a court in North Rhine-Westphalia decided that the killing of male chicks is in line with the animal welfare legislation. The reason given for this is the fact that the fattening of layer-type males is economically inefficient and technical solutions are not yet practicable (Beckmann, 2016). The practice raises moral concerns not only among consumers (Aerts et al., 2009) but is also an issue on the political agenda. That is why the German Ministry of Food and Agriculture is funding research in the field of sex determination in the egg as well as in the field of dual-purpose chickens with the aim to stop the killing of chicks (BMEL, 2017b).

Dual-purpose chickens are one alternative to the killing of day-old chicks. They can do both: produce meat and lay eggs. The hens lay fewer eggs and the cockerels put on less meat and need more time and feed to gain weight and therefore more resources (e.g. land, water) (Koenig et al., 2012; Damme, 2015). Consequently, eggs and meat from dual-purpose chickens have a foreign appearance to consumers and are more expensive than products from hybrid chickens. To a great extent the eggs are smaller (mainly

\footnotetext{
${ }^{1}$ Sex determination in the egg implies that the sex of the embryo can already be detected in the hatching egg and the eggs with male embryos are not further incubated (Bruijnis et al., 2015).

${ }^{2}$ Fattening of layer-type males means that male layer-type chicks are not culled but fattened despite their poor meat growing performance (Damme and Ristic, 2003).
} 
small and medium sized) and colored light beige. The meat of the cockerels has a firmer consistency and a darker color (Grashorn, 2013; Rautenschlein, 2016). Additionally, the share of breast meat, which enjoys great popularity in Germany, is much smaller compared to conventional broilers. Therefore, dual-purpose chickens are less suitable for the marketing of cuts like chicken breasts (Kaufmann et al., 2016).

With the help of a qualitative study Kennedy et al. (2004) investigated consumer perceptions of poultry meat and identified appearance (e.g. meat color and form) as indicator for quality. Other important factors when buying chicken meat were value (e.g. healthiness and taste) and convenience (described as preference for chicken breast fillet, whereas the cooking of a whole chicken was perceived as traditional). In the case of eggs, Guyonnet (2012) looked at several studies dealing with consumers' attitudes towards eggs and egg products. According to the author, the prevailing eggs buying decisions depend on the price, the freshness, the remaining shelf-life and the quality of the eggs.

The role of consumers is essential for the success of products from dual-purpose chickens. At the same time consumer behavior is the most unpredictable part of the supply chain (Terlau and Hirsch, 2015). Ethical issues including animal welfare, environmental issues and human rights are gaining in importance within society (Schröder and McEachern, 2004; De Backer and Hudders, 2015). The Eurobarometer report (European Commission, 2016) has shown that the protection of farm animals is very important to $61 \%$ of the German respondents and $42 \%$ of the surveyed Germans stated that they would be willing to pay a surcharge of more than $5 \%$ for products from animal-friendly production systems. However, what people say is often not reflected in their real purchase behavior and attitudes are not always followed by the intentions. This phenomenon is called attitude-behavior-gap (Homer and Kahle, 1998; Vermeier and Verbeke, 2006). According to Auger and Devinney (2007) the problem of this inconsistency often lies in the survey methods (e.g. rating scales) as they have a big effect on the results. Especially, sensitive ethical issues could encourage consumers to respond in a socially acceptable way. Consequently, a combination of methods is recommended to achieve more reliable results.

Leenstra et al. (2011) conducted a study focussing on the public opinion on alternatives to the killing of day-old chicks in the Netherlands. With the help of focus groups and an online survey they found out that $58 \%$ of the respondents were not aware of the killing of day-old chicks. The participants were informed about the alternatives by a documentary film and were then asked about their perceptions. Regarding the concept of dual-purpose chickens, the results show that it was seen positive but also as unrealistic on grounds of the two-fold increase in prices for eggs and chicken meat. In a ranking with other alternatives, the dual-purpose chicken was ranked second from five potential alternatives directly after the sex determination in the egg. The study also revealed the complexity that consumers as well as experts are facing when evaluating different alternatives to the killing of day-old chicks with limited information. In a study of Bruijnis et al. (2015) the killing of day-old chicks and the alternatives sex determination in the egg as well dual-purpose chickens were ethically evaluated. Therefore, they identified four stakeholder groups with the assistance of experts: society, egg-sector, day-old chicks and the environment. They used an ethical matrix in order to evaluate the perspectives with regards to the ethical principles wellbeing, autonomy and justice. The findings show that the killing of day-old chicks is problematic from the ethical point of view. But also the two alternatives raise new ethical dilemmas like e.g. between animal-friendly and environmentally-friendly production and therefore, there is no morally sound solution to the problem. According to Bruijns et al. (2015) better innovations that are free from dilemmas are needed in this field.

Gremmen and Blok (2016) also dealt with the ethical evaluation of the topic and applied the ethical matrix to compare the use of dual-purpose chickens and in-ovo sex determination to the current situation of killing day-old chicks. Building on this, the authors conducted an online survey with 1,022 respondents in the Netherlands. The results show that $55 \%$ were aware of the killing of day old chicks and $30 \%$ of the respondents agreed with this practice. The most preferred alternative $(20.7 \%)$ was the use of GM techniques which prevents from the killing of chicks and embryos followed by the fattening of layer-type males (18.2\%) and the use of dual-purpose chickens (15.9\%). The findings also show that there is no clear preference for dealing with the killing of day-old chicks.

A swiss study conducted by Gagnat et al. (2018) focusses on the willingness to pay for meat and eggs from dual-purpose poultry. The authors used questionnaires in eight grocery stores with 402 respondents in total. The questionnaires included questions regarding consumption frequency, purchase habits, knowledge about chicken husbandry and statements questions in order to capture attitudes. Additionally, dual-purpose poultry was introduced as alternative to the killing of chicks and the respondents were asked about their willingness to pay (WTP) for dual-purpose poultry products. According to the authors, respondents' WTP for dual-purpose poultry meat and eggs lies between the prices for conventional and organic products and was comparatively higher for eggs. 
Additionally, the WTP mainly depends on the degree of knowledge about agriculture, the types of products that are usually bought by the respondents and the familiarity with dual-purpose poultry.

\section{$3 \quad$ Method}

In Germany, no studies have been conducted on consumers' perception of dual-purpose chickens yet. For this reason, an inductive qualitative method approved as appropriate way to analyze this complex and still unexplored topic. As a consequence of a rapidly changing world and emerging challenges inductive methods gain in importance because they can respond better to changes in the social context than deductive approaches (Flick, 2009). To generate qualitative data, we conducted focus groups. Focus groups are an empirical research method with focus on group dynamics and interactions between participants (Finch and Lewis, 2003). According to Morgan (1997:6), "focus groups are a research technique that collects data on group interactions on a topic determined by the researcher". The aim of focus groups is to create an atmosphere that fosters an almost natural conversation setting with diverse opinions and statements (Lamnek, 2005). Furthermore, by responding to other participants, the conversation setting leads to deeper insights in motivations and justifications and stimulates new thoughts (Finch and Lewis, 2003). Therefore, this method is particularly suitable for the detection of perceptions and needs of consumers and the identification of aspects that need to be considered in a standardized survey. Focus groups do not replace representative surveys (Kuß, 2007).

Focus groups are normally conducted with a small group of six to ten people (in our case strangers) who discuss about a given subject for 60-120 minutes. The discussion is guided by a moderator. The interactive group setting is structured by a questioning route and the role of the moderator is to encourage the participants to express their opinions, but also to keep the discussion on track and ensure that all discussants contribute (Kühn and Koschel, 2011). We created a questioning route with the help of experts in the field of chicken farming. The questioning route was semi-structured in order to get comparable results, but also with the aim to stay flexible and to keep the explorative character (Lamnek, 2005). Discussion topics were preferences for chicken meat and eggs, the perception of chicken farming, known alternatives to the killing of day-old chicks and the concept of the dual-purpose chickens including advantages and disadvantages as well as purchase criteria.

In June 2016, we conducted six focus groups with each seven to nine participants (total number of 47 participants) in Berlin, Munich and Cloppenburg (town within intensive poultry region in Lower Saxony). People with a professional background in agriculture, food industry or market research were not recruited. In addition, quotas concerning age (between 20 and 70 years old), gender (share of males and females between $33.3 \%$ and 66.6\%) and employment (rate around 67\%) were fulfilled in order to ensure heterogeneous groups. The discussions were scheduled for 90 minutes and the participants received incentives. The participants were identified by a market research company and all of them were consumers of poultry meat and eggs. The discussions were documented by audio and video and after that verbatim transcribed. The transcripts of the focus groups were evaluated content-analytically according to Mayring (2015). The discussion topic was not announced in advance in order to avoid that the participants familiarize with the topic and are biased. Questions that were raised directly to the moderator in the course of the discussion were not answered and despite a standardized information text about dualpurpose chickens no additional information was given.

\section{$4 \quad$ Results}

\subsection{Purchase criteria for chicken meat and eggs and consumption habits}

At the beginning of the discussions the participants were asked for their consumption habits and purchase criteria regarding chicken meat and eggs. According to the discussants, chicken meat was purchased mainly in supermarkets and discount stores or sometimes in organic food stores. Some stated that they would buy the meat directly on the farm or on the local market. The most named purchase criteria were the meat color, the best-before date and a regional origin. Organic production was an aspect which was also named frequently. Some participants stated that they would not be able to afford organic chicken meat and would therefore buy conventionally produced chicken meat. On this aspect, it was also mentioned that husbandry conditions would be difficult to understand based on the packaging because besides the organic label there is usually no declaration of the husbandry system on chicken meat. With respect to consumption habits, it became clear that the discussants prefer cuts like chicken breast or 
wings to a whole chicken. Reasons that were mentioned were "it is too much meat for me alone" ${ }^{3}$ or "I do not like bones". Few discussants said that they would sometimes buy a whole chicken primarily to cook chicken soup.

Eggs were also purchased by all discussants. According to the participants, eggs were bought in supermarkets and discount markets, on the local market, in organic food stores or if possible directly on the farm. Regarding the husbandry system only some discussants said that they would not pay attention to it. To other discussants this aspect was very important and they looked especially for free-range or organic eggs. An interesting point was that some participants differentiated between eggs for cooking and baking and boiled eggs for breakfast and, therefore preferred organic or free-range eggs as breakfast eggs, whereby the origin of eggs for processed food was indicated as less relevant. The egg color was not mentioned as a relevant purchase criterion. Few discussants stated that they would buy explicitly white or brown eggs because of their association with the husbandry conditions. Only at Easter white eggs seemed to be more preferred as they can be colored. Regarding the egg size, the opinions were more diverse. Some discussants stated that they would not pay attention to the egg size whereas others said they would look for preferably big eggs. One discussant was unaware that different egg sizes exist. All in all, the husbandry system, a regional origin, the best-before date and the intactness of the eggs were named as purchase criteria for eggs.

\subsection{Perceptions of chicken farming in general}

The perception of chicken farming was dominated by terms like "factory farming", "lack of transparency" and "greed for profit". Regarding the husbandry of laying hens the discussants were mainly concerned about the feed. It was presumed that the hens would be fed with "rubbish" and this is reflected in the egg quality. The topic beak trimming was also mentioned in this context. The picture of hens in battery cages, where the hens are packed together and have no space to move was still present although these battery cages are forbidden in Germany since 2010. The fattening of broilers was associated with broilers that have to eat all day to gain weight. The discussants assumed also that there would be no human-animal interaction and that the stable workers would not handle the animals appropriate. The prophylactic use of antibiotics was also often mentioned by the discussants and harshly criticised when they were asked for their perception of chicken farming in general. According to some participants, free-range husbandry best meets their expectations.

\subsection{Moral concerns and reactions to the concept of dual-purpose chickens}

The topic killing of day-old male chicks was addressed in every focus group without being mentioned by the moderator. Most of the participants stated to know about this practice. This could be attributed to the fact that the topic was present in the media at that time because of the court ruling dealing with the killing of male chicks. Regardless, many discussants expressed their disgust at the killing of day-old chicks. Statements such as "imagine, they were humans. Shredding the boys and feeding them to animals. That's terrifying" or "they kill all the men" underline that humanization of farm animals also plays a role when it comes to this topic. Most of the discussants agreed that the killing of chicks is clearly unacceptable from the moral point of view and they demanded to stop the practice. Others claimed that the chickens would be killed anyway and that it does not matter if sooner or later. Discussing the reasons, it was assumed that "it's for profit reasons" and "they don't have enough meat growth". Additionally, it was mentioned that consumers could not change the situation because they would be powerless compared to the industry.

Asked for alternatives few were known by the participants. Sex determination in the egg was one alternative that was named several times. Some participants also mentioned the fattening of layer-type males as a potential alternative to the killing of day-old chicks, whereas the use of dual-purpose chicken breeds was not mentioned once. When the participants were asked if they have an idea what is meant by the "dual-purpose chicken" few could think of anything. The participants responded for example: "I have no idea what could be meant. Do they have two heads?" or "it sounds like they were produced in a factory". The discussants agreed that the naming is inappropriate and causes misleading associations.

Since the focus of this study is on consumers' perspective on dual-purpose chickens, at this stage of discussion the concept of this chicken breed was explained to the participants. Therefore, following text was presented to the discussants: Dual-purpose chickens are a breeding line where both, the male and the female animals can be used. The males are kept for meat production and the females still lay enough eggs to be kept as laying hens. The eggs of the hens are slightly smaller than "typical" eggs and fewer eggs are

\footnotetext{
${ }^{3}$ Citations were translated from German into English.
} 
laid per year. This is reflected in a higher price. The male chickens have a longer fattening period than "typical" broilers. For this reason, much more feed is needed and the meat is correspondingly more expensive.

After the concept was presented, the reactions were mostly positive but concerns were also raised. The positive aspects that were named were primarily ethical and moral aspects, that include that the life of the males is saved. Others presumed that the meat quality could be better due to a longer fattening period and slower meat growth. The most frequently named negative aspect was the higher price for meat and eggs from dual-purpose chickens. Some participants described a dilemma between saving the life of male chicks and having to pay more for chicken meat and eggs as they saw a conflict between moral aspects and a limited budget for food. Other aspects that were named in this context were the presumption that the fattening of the cockerels would be economic inefficient. Only one discussant remarked that too many resources would be used to produce meat. Another important point that was stressed by some discussant was the fear that genetic engineering would be used to breed dual-purpose chickens.

\subsection{Purchase criteria for products from dual-purpose chickens}

In the end, the participants were asked to name potential purchase criteria for the case that they would buy meat and eggs from dual-purpose chickens. The criteria that were explicitly named were collected and written down on a flipchart. After that, the discussants were given six stickers each and they had to assign three stickers to the most important aspects for chicken meat and three stickers to the most important aspects for eggs. Discussants could see each others' rankings of purchase criteria and, therefore the answers could be biased by other participants' rankings. The following table shows the number of stickers that the respondents assigned to the before named potential purchase criteria (not all participants used all their stickers).

Table 1.

Discussants rating of potential purchase criteria regarding dual-purpose chickens

\begin{tabular}{lcc}
\hline & & eggs \\
potential purchase criteria & chicken meat & 31 \\
\hline better husbandry conditions & 25 & 17 \\
taste & 21 & 20 \\
declaration of origin & 18 & 12 \\
price & 14 & 10 \\
no GM techniques & 10 & 7 \\
better controls & 9 & 4 \\
product freshness & 9 & 7 \\
good quality & 6 & 2 \\
no killing of male chicks & 6 & 2 \\
regional origin & 3 & 4 \\
less antibiotics & 3 & 4 \\
healthy and robust breed & 3 & 1 \\
good feed & 2 & 7 \\
declaration as dual-purpose chicken & 2 & 1 \\
small farm size & 2 & 2 \\
big egg size & - & 6 \\
other aspects & 8 & $n=137$ \\
\hline number of assignments & $n$ & \\
\hline
\end{tabular}

During the discussions it became clear that for many participants the prevention from killing day-old chicks is not enough and they would only buy products from dual-purpose chickens if the husbandry conditions would be improved as well. As examples for better husbandry conditions "good feed", "no antibiotics", "much more space" and "litter" were named. Another important point that was often named, was a good taste with emphasis on the meat. As shown in Table 1, the declaration of origin was also a notable criterion for the discussants. In this context, some discussants suggested e.g. "the address of the 
chicken farm on the package" as indication of origin. As expected, the price also plays a role as a purchase criterion when it comes to dual-purpose chickens. GM techniques were another important subject of discussion. Some participants presumed that dual-purpose chickens could be genetically modified and they strongly opposed GM techniques. Further listed criteria were often connected to quality aspects like product freshness.

When the discussants talked about the prices of dual-purpose chicken meat and eggs, the majority of the discussants stated that they would pay a surcharge for meat and eggs on the grounds of "sympathy with the chicks" or "to eat meat with a good conscience". "It depends on how much more I have to pay" was also often mentioned by the discussants. In the case of eggs, some discussants indicated to be willing to pay a surcharge of 50 percent. For meat, the willingness to pay a surcharge seemed not that high. "I would pay a surcharge of 20 percent if the meat tastes better" and "I would not pay additional 10 Euro". Paying more money for the meat and therefore reduce the consumption of meat was seen as the solution by several discussants. Few participants said that they would not be able or willing to pay a surcharge.

\section{Discussion}

The focus group discussions have shown that the participants prefer to buy chicken cuts and hardly ever cook a whole chicken. This is also reflected in the study of Kennedy et al. (2005). Regarding chicken meat it was remarked that husbandry conditions are difficult to understand on the basis of the packaging in contrast to eggs where the husbandry system was indicated as an important purchase criterion. Some discussants stated to prefer large eggs, whereas the egg color did not seem to be relevant. These results could have implications on the potential marketing of eggs and meat from dual-purpose chickens and should be considered in further process.

Although all participants of the focus groups were consumers of chicken meat and eggs, the perception of chicken farming was mainly negative and associated with words like "factory farming" and "antibiotics". This results accord with previous studies (Verbeke and Viaene, 2000; Vanhonacker and Verbeke, 2009; Heng et al., 2013) that dealt with consumer attitudes on laying hens and broilers. Compared to the study of Leenstra et al. (2011) where only $42 \%$ of the respondents knew about the killing of male chicks, our discussants stated to be mostly aware of the killing of day-old chicks. One reason could be that the topic was very present in the media at that time and the issue is increasingly addressed by politicians and NGOs. Most of the discussants refused to accept the practice on the grounds of moral concerns and got indignant about it. However, alternatives to the killing were scarcely known. According to Gremmen and Blok (2016) there is no clear preference for one alternative and Leenstra et al. (2011) found out that the topic is very complex and respondents experience difficulties when they have to rank the alternatives with limited information. These results were also reflected in the conducted focus groups where the concept of dual-purpose chickens was not known. After presenting the concept of dual-purpose chickens, the participants had difficulties to imagine what is meant by the name dual-purpose chicken (Zweinutzungshuhn). In general, the participants were in favor of the dual-purpose chicken breed but they also raised concerns and revealed dilemmas. For example, they presumed that genetic engineering is used or that the fattening of the cockerels is economic inefficient. Identified purchase criteria were a clear labelling of meat and eggs from dual-purpose chickens and improved husbandry conditions for the chickens. Regarding the willingness to pay a surcharge, the opinions were diverse. Most of the participants said that they would be willing to pay an additional charge with the aim of eating meat and eggs with a good conscience. Some stated not to be willing or able to pay more for products from dualpurpose chickens. However, it should be noted that this statements have to be interpreted with caution as it can be often observed that there are inconsistencies between attitudes and actual purchasing behavior (attitude-behavior-gap).

In conclusion, the findings show that the participants were interested in the topic and that they have specific expectations (e.g. labelling or husbandry conditions) regarding products from dual-purpose chickens. Therefore, it is important to take consumers' perspective into account when discussing alternatives to the killing of day-old chicks. This study provides a first glance at consumers' perspectives and gives valuable information on a topic that has not been studied adequately in Germany yet. Especially for producers, breeders and other actors in this field, it is essential to learn more about consumers' view on dual-purpose chickens as they are the ones responsible for the market success in the end. The results of the focus groups are not representative. Therefore, the findings were used to develop a questionnaire. In February/March 2017 a representative online survey $(n=1,502)$ was conducted in order to quantify the results and to carry out a choice-experiment with the aim to find out more about preferences and willingness to pay for meat and eggs from dual-purpose chickens. 


\section{Acknowledgements}

This study is part of the joint research project "SocialLab - Nutztierhaltung im Spiegel der Gesellschaft". The project is funded by the Federal Ministry of Food and Agriculture (BMEL) by decision of the German Bundestag. Within the innovation funding the project is managed by the Federal Office for Food and Agriculture (BLE). Special thanks goes to the colleagues in the "Integhof-project" who provided us with valuable information regarding dual-purpose chickens.

\section{Literature}

Aerts, S., Bruggeman, V., De Tavernier, J., Decuypere, E., and Boonen, R. (2009). Culling of Day-Old Chickens: Opening the debates of Moria? In: Ethical Futures: Bioscience and Food Horizons, Wageningen Academic Publishers: $117-122$.

Auger, P., Devinney, T.M. (2007). Do What Consumers Say Matter? The Misalignment of Preferences with Unconstrained Ethical Intentions. Journal of Business Ethics, 76(4): 361-383.

Beckmann, M. (2016). Über den vernünftigen Grund im Sinne des §1 S. 2 TierSchG bei der Tötung von männlichen Eintagsküken. Natur und Recht, 38 (6): 384-390.

BLE (Bundesanstalt für Landwirtschaft und Ernährung) (2017b). Jeder Deutsche isst 235 Eier pro Jahr. Retrieved 10.04.2017, from http://www.ble.de/SharedDocs/Pressemitteilungen/DE/2017/170317_Eier.html.

BMEL (Bundesministerium für Ernährung und Landwirtschaft) (2008). Statistisches Jahrbuch über Ernährung, Landwirtschaft und Forsten. Retrieved 24.05.2018, from http://www.bmelstatistik.de/footernavigation/archiv/statistisches-jahrbuch/.

BMEL (Bundesministerium für Ernährung und Landwirtschaft) (2017a). Statistisches Jahrbuch über Ernährung, Landwirtschaft und Forsten. Retrieved 24.05.2018, from http://www.bmelstatistik.de/footernavigation/archiv/statistisches-jahrbuch/.

BMEL (Bundesministerium für Ernährung und Landwirtschaft) (2017b). Eine Alternative zum Töten männlicher Küken. Retrieved 18.01.2017, from http://www.bmel.de/DE/Tier/Tierwohl/_texte/Tierwohl-Forschung-InOvo.html.

Bruijnis, M.R.N., Blok, V., Stassen, E.N., and Gremmen, H.G.J. (2015). Moral “Lock-In" in Responsible Innovation: The Ethical and Social Aspects of Killing Day-Old Chicks and Its Alternatives. Journal of Agricultural and Environmental Ethics, 28(5): 939-960.

Damme, K., Ristic, M. (2003). Fattening performance, meat yield and economic aspects of meat and layer type hybrids. World's Poultry Science Journal, 59(1): 50-53.

Damme, K. (2015). Economics of Dual-Purpose Breeds - a comparison of meat and egg production using dual purpose breeds versus conventional broiler and layer strains. LOHMANN Information, 50(2): 4-9.

De Backer, J.S., Hudders, L. (2015). Meat morals: relationship between meat consumption consumer attitudes towards human and animal welfare and moral behavior. Meat Science, 99: 68-74.

European Commission (2016). Special Eurobarometer 422. Attitudes of Europeans towards Animal Welfare. Retrieved 12.04.2017, from http://ec.europa.eu/COMMFrontOffice/publicopinion/index.cfm/ResultDoc/download/DocumentKy/71348.

Faucitano, L., Martelli, G., Nannoni, E., and Widowski, T. (2017). Fundamentals of Animal Welfare in Meat Animals and Consumer Attitudes to Animal Welfare. In: Purslow, P. P. (Ed.), New Aspects of Meat Quality: From Genes to Ethics: 537-568.

Finch, H., Lewis, J. (2003). Focus Groups. In: Ritchie, J. and Lewis, J. (2003): Qualitative Research Practice, Sage Publications Ltd., London: 170-197.

Flick, U. (2009). An Introduction to Qualitative Research. London: Sage Publications.

Guyonnet, V. (2012). Eggs and egg products: Consumers' attitudes, perceptions and behaviours. XXIV World's Poultry Congress, Salvador, Brazil. 
Grashorn, M. (2013). Verwendung der männlichen Küken der Legeherkünfte. Retrieved 15.05.2013, from http://www.wing vechta.de/themen/verwendung_der_maennlichen_legeherkuenfte/verwendung_der_m_nnlichen_k_ken_der_legeherk_nfte.html.

Gremmen, B., Blok, V. (2016). The lesser of two evils? The killing of day-old male chicks in the Dutch egg sector. In: Food futures: ethics, science and culture, Wageningen Academic Publishers: 165-176.

Heng, Y., Peterson, H., and Li, X. (2013). Consumer Attitudes towards Farm-Animal Welfare: The Case of Laying Hens. Journal of Agricultural and Resource Economics, 38(3): 418-434.

Homer, P., Kahle, L. (1998). A Structural Equation Test of the Value-Attitude-Behavior Hierarchy. Journal of Personality and Social Psychology, 54(4): 638-646.

Kaufmann, F., Nehrenhaus, U., and Andersson, R. (2016). Das Duale Huhn. Der Verbraucher müsste umdenken. DGS, 35: 22-25.

Kennedy, O.B., Stewart-Knox, B.J., Mitchell, P.C., and Thurnham, D.I. (2004). Consumer perceptions of poultry meat: a qualitative analysis. Nutrition \& Food Science, 34 (3): 122-129.

Koenig, M., Hahn, G., Damme, K., and Schmutz, M. (2012). Utilization of laying-type cockerels as "coquelets“: Influence of genotype and diet characteristics on growth performance and carcass composition. Archiv für Geflügelkunde, 76(3): 197- 202.

Kühn, T., Koschel, K. (2011). Gruppendiskussionen. Ein Praxis-Handbuch. Wiesbaden: VS Verlag für Sozialwissenschaften.

Kuß, A. (2007). Marktforschung: Grundlagen der Datenerhebung und Datenanalyse. Wiesbaden: Gabler-Verlag.

Lamnek, S. (2005). Gruppendiskussion. Theorie und Praxis. Weinheim: UTB.

Leenstra, F., Horne, P. van, and Krimpen, M. van (2010). Dual purpose chickens, exploration of technical, environmental and economic feasibility. Proceedings XIIIth European Poultry Conference, Tours, France.

Leenstra, F.R., Munnichs, G., Beekman, V., Heuvel-Vromans, E. van den, Aramyan, L.H., and Woelders, H. (2011). Killing day old chicks? Public opinion regarding potential alternatives. Animal Welfare, 20: 37-45.

Mayring, P. (2015). Qualitative Inhaltsanalyse. Grundlagen und Techniken. Weinheim: Beltz Verlag.

Morgan, D.L. (1997). Focus Groups as Qualitative Research. California: Sage Publications.

Rautenschlein, S. (2016). Einsatz des Zweinutzungshuhns in Mast und Eierproduktion: Ansätze für ein integriertes Haltungskonzept. Rundschau für Fleischhygiene und Lebensmittelüberwachung (RFL), 68(8): 276-278.

Schröder, M.J.A., McEachern, M.G. (2004). Consumer value conflicts surrounding ethical food purchase decisions: a focus on animal welfare. International Journal of Consumer Studies, 28: 168-177.

Sossidou, E., Elson, H. (2009). Hens' welfare to egg quality: A European perspective. World's Poultry Science Journal, 65(4): 709-718.

Terlau, W., Hirsch, D. (2015). Sustainable Consumption and the Attitude-Behaviour-Gap Phenomenon - Causes and Measurements towards a Sustainable Development. International Journal on Food System Dynamics, 6(3): 159-174.

Vanhonacker, F., Verbeke, W.A.J. (2009). Buying higher welfare poultry products? Profiling Flemish consumers who do and do not. Poultry Science, 88(12): 2702-2711.

Verbeke, W., Viaene, J. (2000). Ethical challenges for livestock production: Meeting consumer concerns about meat safety and animal welfare. Journal of Agricultural \& Envrionmental Ethics, 12(2): 141-151.

Vermeier, I., Verbeke, W. (2006). Sustainable Food Consumption: Exploring the Consumer "Attitude Behavioral Intention" Gap. Journal of Agricultural and Environmental Ethics, 19(2): 169-194. 


\subsection{Consumer acceptance of dual-purpose chickens A mixed methods approach}

Nanke Brümmer, Wiebke Petersen and Inken Christoph-Schulz

German Journal of Agricultural Economics (2018). Special Issue Future Options for Animal Husbandry in Europe, 67(4), 234-245.

(With kind permission of Deutscher Fachverlag $\mathrm{GmbH}$, Frankfurt am Main)

Declaration of originality: This study is based on the findings of the focus group. The questionnaire was jointly developed by Wiebke Petersen and the author, and discussed with Dr. Inken Christoph-Schulz. A market research agency programmed the online survey and also recruited the participants. The factor and cluster analysis were primary conducted by Wiebke Petersen and supervised by Dr. Inken Christoph-Schulz. The raw manuscript was written by the author and revised by Dr. Inken Christoph-Schulz. 


\title{
Consumer Acceptance of Dual-Purpose Chickens A Mixed Methods Approach
}

\author{
Nanke Brümmer, Wiebke Petersen and Inken Christoph-Schulz \\ Thünen Institute of Market Analysis, Braunschweig
}

\begin{abstract}
The killing of day-old male chicks of laying breeds is common practice and is widely discussed within society. There are few alternatives available to replace this practice. One possibility is the use of dualpurpose chicken breeds. The use of these chicken breeds would have implications not only for the entire supply food chain but also for consumers. Their meat and eggs have a different appearance, and the resulting products would be more expensive. Furthermore, little is known about consumers' opinions of dualpurpose chickens at present. For this reason, it is essential to explore consumer acceptance of dualpurpose chickens. Mixed methods with a combination of qualitative and quantitative methods proved to be an appropriate approach to learn more about this matter. The results of six focus groups with an exploratory character served as the basis for an online survey with 1,502 respondents in Germany. The data was analysed with the aid of a factor analysis that identified seven factors explaining consumers' attitudes towards dual-purpose chickens. A cluster analysis segmented the respondents into three cluster groups: opponents (37.5\%), supporters (23.4\%), and indifferents (39.1\%). The indifferents represent the largest group of respondents and are therefore an important target group when it comes to potential marketing strategies of products from dual-purpose chickens. The results illustrate the importance of analysing consumer acceptance with regard to emerging issues and before a new product is introduced to the market.
\end{abstract}

\section{Key Words}

dual-purpose chickens; consumer acceptance; focus groups; factor analysis; cluster analysis

\section{Introduction}

In Germany more than 40 million male chicks are killed after hatching annually. The killing of day-old chicks is common practice in the commercial production of laying breeds because the fattening of layertype males is unprofitable (RAUTENSCHLEIN, 2016). It is a practice that is used in conventional as well as organic farming. Sex determination in the egg, fattening of layer-type males, and dual-purpose breeds are alternatives to this killing. Breeders of dual-purpose chickens face the problem that meat growth and the number of eggs are not comparable to that of specialized chicken breeds (KÖNIG et al., 2012). This means that the hens lay fewer and smaller eggs and the cockerels put on less meat and need more time and feed to grow. Consequently, eggs and meat from dualpurpose chickens have an unfamiliar appearance to consumers and are more expensive than products from current specialized chicken breeds.

Consumer acceptance of dual-purpose chicken breeds is fundamental for further efforts of breeders, farmers and finally also for potential marketing strategies of products from dual-purpose chickens. The purpose of this study is to gain initial insights into consumer perspectives on dual-purpose chickens because there is a great need for research regarding the emerging debate on killing day-old chicks and possible alternatives. Therefore, this study treats the extent to which the culling of day-old male chicks is perceived as a problem by consumers and how well known the concept of dual-purpose chickens is. In addition, factor and cluster analyses were performed to explore consumer attitudes toward and acceptance of dual-purpose chickens and subsequently identified segments. This study's objective is to find out whether and under which conditions consumers consider dualpurpose chickens as an acceptable alternative to the culling of day-old chicks, and which consumer groups have a supportive attitude towards dual-purpose chickens. The article is structured as follows: In Section 2 the background of the topic and relevant literature are presented. In Section 3 the methods are described. The results of the focus groups and factor and cluster analyses follow in Section 4. The paper concludes with the discussion of the results in Section 5.

\section{Background and Literature Review}

Since the 1950s the industrialisation and prosperity of society has led to a growing demand for animal 
products. The increasing demand for chicken meat and eggs as well as new options in sexing at hatch resulted in a specialization in chicken breeding. Today, there are genotypes for meat and other genotypes for egg production (LEENSTRA et al., 2010; GRASHORN, 2013). As a result, the fattening of layer-type males is unprofitable due to their less efficient meat production and their inability to lay eggs. For this reason, it is common practice that male layer-types are culled as day-old chicks in conventional and in organic farming (RAUTENSCHLEIN, 2016).

In Germany, the consumption of chicken meat and eggs is still increasing slightly. In 2016, the average consumption of poultry meat was $12.5 \mathrm{~kg}$ per person (BLE, 2017a). Additionally, Germans consumed on average 235 eggs in 2016 (BLE, 2017b). Concurrently, animal husbandry is at the focus of public criticism. Especially the housing of laying hens and the broiler production are evaluated more sceptically than other animal productions systems (VERBEKE and VIAENE, 2000; VANHONACKER and VERBEKE, 2009; SOSSIDOU and Elson, 2009; HeNG et al., 2013; FAUCITANO et al., 2017). Due to the critical aspects of modern farming practices, such as stocking density, antibiotics and farm size, society is becoming increasingly aware of the killing of day-old chicks (BRUIJNIS et al., 2015). The debate in Germany intensified in May 2016 when a court in North RhineWestphalia decided that the killing of male chicks is in line with the existing animal welfare legislation (SÜDDEUTSCHE ZEITUNG, 2016). The reason given for this is the fact that the fattening of layer-type males is economically inefficient and technical solutions for sex determination before hatch are not yet practicable (BECKMANN, 2016). The practice of killing day-old chicks raises moral concerns not only among consumers but is also an issue on the political agenda. That is why the German Ministry of Food and Agriculture is funding research in the field of sex determination in the egg as well as in the field of dualpurpose chickens with the objective of stopping the killing of male chicks (BMEL, 2017).

Dual-purpose chickens are one alternative to the killing of day-old chicks. They can both: produce meat and lay eggs. The hens lay fewer eggs than current specialized laying hens, and the cockerels put on less meat than broilers and require more time and feed to grow; this results in a higher demand for resources (e.g. land, water) (KoENIG et al., 2012; DAMME, 2015). Moreover, the eggs and meat from dualpurpose chickens look different and are more expensive than products from specialized chickens. In most cases, the eggs are smaller (mainly size $\mathrm{S}$ and $\mathrm{M}$ ) and are not only brown or white. The meat of the cockerels has a firmer consistency and a darker colour (GRASHORN, 2013; RAUTENSCHLEIN, 2016). Additionally, the proportion of breast meat, which enjoys great popularity in Germany, is much smaller than in broilers. Therefore, dual-purpose chickens are less suitable for the marketing of cuts such as chicken breasts (KAUFMANN et al., 2016).

LEENSTRA et al. (2011) conducted a study focussing on the public opinion on alternatives to the killing of day-old chicks in the Netherlands. With the aid of focus groups and an online survey, they found out that $58 \%$ of the respondents were not aware of the killing of day-old chicks. By means of a documentary film, the participants were informed about the alternatives and were then asked for their opinions. With regard to the utilization of dual-purpose chickens, the results show that the use of dual-purpose chickens was seen positively, but also unrealistic on grounds of the two-fold increase in prices for eggs and chicken meat. A ranking consisting of five potential alternatives showed that the dual-purpose chicken was ranked second directly after the sex determination in the egg. The study has also revealed the complexity of the situation that consumers as well as experts face when evaluating different alternatives to the killing of dayold chicks with only limited information.

In a study of BRUIJNIS et al. (2015), the killing of day-old chicks and both the alternatives sex determination in the egg and dual-purpose chickens were ethically evaluated. To facilitate this, they identified four stakeholder groups with the assistance of experts: society, egg-sector, day-old chicks and the environment. They used an ethical matrix in order to evaluate the perspectives with reference to the ethical principles well-being, autonomy and justice. The findings show that the killing of day-old chicks is problematic from an ethical point of view. Furthermore, the two alternatives raise new ethical dilemmas, such as conflicts between animal-friendly and environmentallyfriendly production systems. Therefore, there is currently no morally sound solution to the problem. According to BRUIJNIs et al. (2015), novel innovations that are free from dilemmas are required in this field.

\section{Methodological Approach and Data}

According to CRESWELl and ClaRK (2011), mixed methods combine both qualitative and quantitative 
methods with the objective of obtaining a deeper understanding of the research topic than only one method alone could provide. The combination of two methods can contribute to the evaluation of a topic from different perspectives, and they can each compensate for the weaknesses of the other method (DENSCOMBE, 2008). Especially when the subject matter is new, sequencing qualitative and quantitative methods can help to understand and identify the research topic from the outset and quantify the results in a subsequent step (RITCHIE et al., 2014).

In our case, qualitative data was obtained via focus groups in a first step in order to explore the new topic of dual-purpose chickens. Focus groups are an empirical research method which focus on group dynamics and interactions between participants (KÜHN and KosCHEL, 2011). According to MORGAN (1997: 6) "focus groups are a research technique that collects data on group interactions on a topic determined by the researcher". The objective of focus groups is to create an atmosphere that fosters an almost natural conversational setting with diverse opinions and statements (LAMNEK, 2005). Furthermore, as a result of the responses to other participants the conversational setting leads to deeper insights into motivations and justifications, and stimulates new thoughts (FINCH and LEWIS, 2003). In June 2016, six focus groups, each with six to eight participants, were conducted in Berlin, Munich and Cloppenburg (town located in an intensive poultry-farming region in Lower Saxony). The respondents were recruited by a private market research company. Respondents with a professional background in agriculture, the food industry, or market research were excluded from the study. In addition, quotas for age (between 20 and 70 years old), gender (proportion of males and females between $33.3 \%$ and $66.6 \%$ ) and employment (rate: approximately $67 \%$ ) were implemented to ensure heterogeneous groups. Each discussion lasted for 90 minutes. All participants were consumers of poultry meat and eggs. Discussion topics were preferences for chicken meat and eggs, the perception of chicken farming, known alternatives to the killing of day-old chicks, and the concept dual-purpose chicken including advantages and disadvantages as well as purchase criteria. The discussions were documented by audio and video and after that transcribed verbatim. The transcripts of the focus groups were evaluated content-analytically in accordance with MAYRING (2015). The discussion topic was not announced in advance to avoid participants becoming familiar with the topic and preventing biases. Questions that were directed at the moderator in the course of the discussion were not answered. At the end of discussion, respondents had the opportunity to ask questions. The topic was introduced by presenting a short information text to the participants.

Based on the outcomes of the focus groups, an online survey among chicken and egg consumers was conducted in February 2017. The survey was administered by a private market research company. Requirements were 1,500 respondents meeting specified sociodemographic quotas. In total, 1,502 respondents completed the questionnaire. The sample was widely representative for the German population with regards to gender, region and age except for education, employment status and income. People having a professional background in agriculture or market research and people having participated in a survey on agriculture or nutrition in the last six months were excluded (see Table 1 for more information). Respondents answered questions concerning inter alia their dietary habits, knowledge of chicken husbandry as well as socio-demographics. Additionally, respondents assessed 40 items on a seven-point Likert scale which ranged from 1 "I do not agree at all" to 7 "I totally agree". These items are based on statements made by the participants in the focus groups. The statements focused on general chicken husbandry, purchasing behaviour, trust and in particular dual-purpose chickens and are listed in Table 2 and 3. A choice-experiment was also included in the questionnaire but will not be presented in this paper.

An exploratory factor analysis was performed on the data from the online survey using IBM SPSS Statistics 24 to define the underlying structure in the data matrix (HAIR et al., 2009). In the factor analysis, factors were generated from many single items which were answered similarly (HÜTTNER and SCHWARTING, 2002). The statements were pretested on a sample of 150 respondents in February 2017 to ensure the suitability of the questions used. To assess the adequacy of the final sample for factor analysis, a sampling adequacy test (results: ranging from 0.787 to 0.969), Kaiser-Meyer-Olkin test (result: 0.934) and the Bartlett test of sphericity (result: 0.000) were performed. Subsequently, a principal component analysis was performed using a promax four rotation (HAIR et al., 2009).

Based on the extracted factors, a cluster analysis was performed to assign respondents to different clusters. Clusters are defined as a group of objects or persons with similar characteristics (CLEFF, 2015; KUß, 2007). With regard to our analysis, these characteristics were the standardised factor levels for each 
Table 1. Sample characteristics

\begin{tabular}{|c|c|c|c|}
\hline & absolute & $\begin{array}{l}\text { relative } \\
(\%)\end{array}$ & $\begin{array}{c}\text { Germany } \\
(\%)\end{array}$ \\
\hline Sample size & 1,502 & 100 & - \\
\hline \multicolumn{4}{|l|}{ Sex } \\
\hline Male & 760 & 50.6 & 49.0 \\
\hline Female & 742 & 49.4 & 51.0 \\
\hline Median of age group & $45-54$ & 21.6 & 44.3 \\
\hline \multicolumn{4}{|l|}{ Income } \\
\hline $\begin{array}{l}\text { Median of households' net monthly income } \\
\text { (in Euro) }\end{array}$ & $1,700-1,999$ & 10.3 & - \\
\hline \multicolumn{4}{|l|}{ Place of residence } \\
\hline North Germany & 281 & 18.7 & 16.1 \\
\hline West Germany & 470 & 31.3 & 35.3 \\
\hline East Germany & 318 & 21.2 & 19.8 \\
\hline South Germany & 433 & 28.8 & 28.8 \\
\hline \multicolumn{4}{|l|}{ School education level } \\
\hline Currently attending an education institution & 15 & 1.0 & 3.6 \\
\hline Without a school-leaving qualification & 5 & 0.3 & 3.7 \\
\hline German Hauptschule (9 school years) & 369 & 24.6 & 32.9 \\
\hline Polytechnic secondary school (10 school years) & 136 & 9.1 & 6.7 \\
\hline German Realschule (10 school years) & 433 & 28.8 & 22.7 \\
\hline Qualification to study at college or university & 544 & 36.2 & 29.5 \\
\hline \multicolumn{4}{|l|}{ Employment } \\
\hline Employed & 799 & 53.2 & 61.9 \\
\hline Unemployed & 703 & 46.8 & 38.1 \\
\hline Median size of place of residence & $20,000-100,000$ & 23.8 & - \\
\hline \multicolumn{4}{|l|}{ Number of persons in the household } \\
\hline Mean & 2.18 & - & - \\
\hline Persons having a child or children & 244 & 16.4 & 19.7 \\
\hline $\begin{array}{l}\text { Experience with agriculture } \\
\text { (e.g. farm holidays or farm visits) }\end{array}$ & 687 & 45.7 & - \\
\hline Ownership of pets & 716 & 47.7 & - \\
\hline
\end{tabular}

Source: own calculation; STATISTISCHES BundeSAMT (2015, 2016, 2017a, b) firmed the validity of the clusters found (BACKHAUS et al., 2011). To increase the understanding of the thusformed clusters, the mean values of the clusters were statistically analysed using cross-tabulation and the chisquare test for socio-demographic variables and knowledge of chicken husbandry.

\section{Results}

\subsection{Focus Groups}

The main results of the focus groups relate to the topics purchase criteria for chicken meat and eggs as well as consumption habits, general perceptions of chicken farming practices, and more importantly, the concept of dual-purpose chickens. The topic killing of day-old male chicks was addressed in every focus group without being mentioned by the moderator. Most of the participants stated that they had previous knowledge of this practice. This could be

respondent (resulting from the factor analysis). Initially, a hierarchical cluster analysis was conducted with a random subset of 99 respondents of the total sample of 1,502 respondents. In a first step, a single linkage analysis was performed to identify and eliminate outliers. As a consequence of our analysis, two respondents were identified as outliers and eliminated from our sample. Then, Ward's method was applied to identify the potential number of clusters. By analysing the dendrogram and the elbow graph, three clusters that define respondents' structure were identified. Then, all respondents were clustered using a K-means cluster analysis taking the cluster centres from the hierarchical analysis as the initial seed points. In this manner, respondents with homogenous attitudes with regard to dual-purpose chickens were grouped in one cluster, whereas respondents with significantly different attitudes were interpreted as other cluster groups. Bivariate analyses were used to detect further details of the found segments. A discriminant analysis con- attributed to the fact that the topic was present in the media at that time because of the court ruling dealing with the killing of male chicks. Regardless, many discussants expressed their disgust towards the killing of day-old chicks. Statements such as 'imagine, they were humans. Shredding the boys and feeding them to animals. That's terrifying' or 'they kill all the men' underline that humanisation of farm animals also plays a role when it comes to this topic. Most of the discussants agreed that the killing of chicks is clearly unacceptable from a moral point of view and they demanded that the practice be discontinued. Others claimed that the chickens would be killed anyway and that it does not matter if sooner or later. Discussing the reasons for killing day-old chicks, it was assumed that 'it's for profit reasons' and 'they don't have enough meat growth'. Additionally, it was mentioned that consumers could not change the situation because they would be powerless compared to the industry. When asked for alternatives, few were known to the 
participants. Sex determination in the egg was one alternative that was referred to several times. Some participants also mentioned the fattening of layer-type males as a potential alternative to the killing of day-old chicks, whereas the use of dual-chicken breeds was not mentioned at all. When the participants were asked if they have any idea of what is meant by the term 'dualpurpose chicken', very few could think of anything. The participants responded for example: 'I have no idea what could be meant. Do they have two heads?' or 'It sounds like they were produced in a factory'. The discussants agreed that the naming is inappropriate and causes misleading associations. Since the focus of this study is on consumers' acceptance of dual-purpose chickens, at this stage of discussion the concept of this chicken breed was explained to the participants with the following text: "Dual-purpose chickens are a breeding line in which both the male and the female animals can be used. The males are kept for meat production and the females still lay enough eggs to be kept as laying hens. The eggs of the hens are slightly smaller than "customary" eggs, and fewer eggs are laid per year. This is reflected in a higher price. The male chickens have a longer fattening period than "typical" broilers. For this reason, much more feed is needed, and the meat is correspondingly more expensive".

The reactions towards dual-purpose chickens were mostly positive, but concerns were also raised. The positive aspects that were named were primarily ethical and moral aspects, which include that the life of the males is saved. Others presumed that the meat quality could be better due to a longer fattening period and slower meat growth. The most frequently named negative aspect was the higher price for meat and eggs from the dual-purpose chickens. Some participants described a dilemma between saving the life of male chicks and having to pay more for chicken meat and eggs. Other aspects that were named in this context were the presumption that the fattening of the cockerels would be economically inefficient. Only one discussant remarked that too many resources would be used to produce meat. Another important point that was stressed by some discussants was the fear that genetic engineering would be used to breed dualpurpose chickens. The discussions clarified that for many participants the prevention of killing day-old chicks is not enough, and that they would only buy products from dual-purpose chickens if the husbandry conditions are improved as well. As examples for better husbandry conditions 'good feed', 'no antibiotics', 'much more space' and 'litter' were named. Another important point that was mentioned was a good taste with emphasis on the meat. As expected, the price also played a role when it comes to dual-purpose chickens. The majority of the discussants stated that they would pay a surcharge for meat and eggs on the grounds of 'sympathy with the chicks' or 'to eat meat with a good conscience'. Paying a higher price for meat, which could reduce the general consumption of meat, was seen as a solution by several discussants. Few participants said that they would not be able or willing to pay a surcharge for eggs and meat from dual-purpose chickens. The participants were given the information that the surcharge for eggs would per around 5 cents per egg and that the chicken meat would be $50 \%$ more expensive.

\subsection{Online Survey}

\subsubsection{Factor Analysis}

Seven factors were identified by conducting an explanatory factor analysis. These account for $55.12 \%$ of the overall error variance. Based on HAIR et al. (2009), Cronbach's alpha is consistent and reliable for each factor $(\alpha>0.6)$. The seven factors which describe consumers' attitude towards dual-purpose chickens are:

1. Quality awareness,

2. Rejection of culling day-old chicks,

3. Preference for low prices,

4. Favouring organic farming,

5. Favouring conventional farming practices,

6. Criticism of modern chicken husbandry, and

7. Support for dual-purpose chickens.

Table 2 shows each statement of the first three factors according to their factor loadings. Factor 1 is interpreted as quality awareness and describes important quality attributes of animal production such as process quality in chicken husbandry including the husbandry, feeding, transport and slaughtering of the animals, human dietary values and consumer trust. Factor 2 is the rejection of culling day-old chicks, which relates to the ethical concerns of culling and the desire of consumers to stop this practice. Factor 3 , preference for low prices, reveals financial barriers of higher prices for products from dual-purpose chickens and emphasises the importance of low prices for meat and eggs.

Table 3 illustrates each statement of factor 4 to 7 with their factor loading. Factor 4, favouring organic farming, reflects the endorsement of organic chicken farming, including the aspects trust, health and consumers' responsibility towards organic animal husbandry. Factor 5 favours conventional farming prac- 
tices, which describes the importance of the appearance of chicken meat and eggs as well as the acceptance of current farming practices. Factor 6, criticism of modern chicken husbandry, criticises farmer's profit orientation which results in the reduction of animal welfare conditions and the general distrust of conventional chicken husbandry. Factor 7 is the support for dual-purpose chickens, which indicates a favourable attitude towards dual-purpose chickens with regard to the environmental impact, the appearance and the higher price of dual-purpose chicken products.

Table 2. Factor loadings for factor 1 'Quality awareness', factor 2 'Rejection of culling day-old chicks' and factor 3 'Preference for low prices'

\begin{tabular}{|c|c|c|c|c|c|c|c|}
\hline & \multicolumn{7}{|c|}{ Factor loading } \\
\hline & $\begin{array}{l}\text { Factor } 1 \\
\alpha=0.848\end{array}$ & $\begin{array}{l}\text { Factor } 2 \\
\alpha=0.850\end{array}$ & $\begin{array}{l}\text { Factor } 3 \\
\alpha=0.843\end{array}$ & $\begin{array}{l}\text { Factor } 4 \\
\alpha=0.723\end{array}$ & $\begin{array}{l}\text { Factor } 5 \\
\alpha=0.698\end{array}$ & $\begin{array}{l}\text { Factor } 6 \\
\alpha=0.679\end{array}$ & $\begin{array}{l}\text { Factor } 7 \\
\alpha=0.625\end{array}$ \\
\hline A healthy diet is very important to me. & 0.780 & -0.063 & -0.052 & 0.136 & 0.019 & -0.041 & -0.254 \\
\hline $\begin{array}{l}\text { The quality of chicken meat is very important } \\
\text { to me. }\end{array}$ & 0.761 & -0.034 & -0.248 & -0.022 & 0.145 & 0.044 & -0.189 \\
\hline $\begin{array}{l}\text { If the chicken's life is stress free, the quality of } \\
\text { meat and eggs is better. }\end{array}$ & 0.677 & 0.088 & 0.072 & 0.030 & -0.070 & 0.109 & -0.050 \\
\hline I wish for more family farms. & 0.576 & 0.026 & 0.065 & 0.082 & -0.078 & 0.080 & 0.105 \\
\hline I don't want to feel guilty when eating meat. & 0.556 & 0.099 & -0.128 & -0.041 & 0.099 & 0.130 & -0.011 \\
\hline $\begin{array}{l}\text { Chickens are living beings and should not } \\
\text { suffer under husbandry conditions. }\end{array}$ & 0.536 & 0.271 & 0.112 & 0.016 & -0.025 & 0.186 & -0.023 \\
\hline $\begin{array}{l}\text { I think having connections to farmers can } \\
\text { improve trust in their work. }\end{array}$ & 0.525 & -0.137 & 0.027 & 0.177 & -0.060 & -0.131 & 0.221 \\
\hline $\begin{array}{l}\text { When keeping dual-purpose chickens, their hus- } \\
\text { bandry conditions must be improved as well. }\end{array}$ & 0.509 & 0.087 & 0.046 & -0.117 & -0.045 & 0.251 & 0.213 \\
\hline $\begin{array}{l}\text { The culling of day-old chicks is acceptable } \\
\text { because the chicks are used as zoo feed. }\end{array}$ & 0.040 & -0.986 & 0.020 & 0.133 & 0.029 & 0.096 & 0.130 \\
\hline $\begin{array}{l}\text { The culling of day-old chicks is acceptable be- } \\
\text { cause the life of a broiler is not pleasant anyway. }\end{array}$ & -0.063 & -0.930 & -0.027 & 0.192 & 0.084 & 0.075 & 0.069 \\
\hline $\begin{array}{l}\text { I don't care if male chicks are being killed } \\
\text { directly after hatching because they will be } \\
\text { killed sooner or later anyway. }\end{array}$ & -0.023 & -0.925 & 0.040 & 0.081 & 0.084 & 0.156 & 0.020 \\
\hline $\begin{array}{l}\text { The culling of day-old male chicks of laying } \\
\text { hens for economic reasons must stop. }\end{array}$ & 0.211 & 0.724 & 0.144 & -0.058 & 0.023 & 0.027 & 0.075 \\
\hline $\begin{array}{l}\text { The life of male chicks is more important to me } \\
\text { than the higher resource consumption of, e.g., } \\
\text { land, feed and water, caused by a longer fatten- } \\
\text { ing period of dual-purpose cockerels. }\end{array}$ & -0.188 & 0.604 & -0.033 & 0.202 & 0.263 & 0.085 & 0.240 \\
\hline $\begin{array}{l}\text { If the meat from dual-purpose chickens were } \\
\text { to be } 50 \% \text { more expensive than conventional } \\
\text { chicken meat, I could not afford it (e.g. } 7.50 \\
\text { Euro instead of } 5.00 \text { Euro for } 500 \mathrm{~g} \text { chicken } \\
\text { breast fillet). }\end{array}$ & 0.026 & 0.076 & 0.896 & 0.313 & -0.006 & 0.005 & -0.085 \\
\hline $\begin{array}{l}\text { When buying meat, a low price is important } \\
\text { to me. }\end{array}$ & -0.066 & 0.005 & 0.847 & 0.016 & 0.103 & 0.085 & 0.033 \\
\hline $\begin{array}{l}\text { When buying eggs, a low price is important } \\
\text { to me. }\end{array}$ & -0.089 & -0.008 & 0.816 & 0.033 & 0.089 & 0.057 & -0.003 \\
\hline $\begin{array}{l}\text { I am willing to pay more for meat, if the ani- } \\
\text { mals had a better life in return. }\end{array}$ & 0.161 & 0.053 & -0.498 & 0.210 & 0.112 & 0.070 & 0.174 \\
\hline $\begin{array}{l}\text { I am willing to pay } 50 \% \text { surcharge for products } \\
\text { from dual-purpose chickens, if the cockerels } \\
\text { had a longer fattening period compared to } \\
\text { conventional broilers. }\end{array}$ & -0.014 & 0.055 & -0.465 & 0.235 & 0.071 & -0.070 & 0.327 \\
\hline $\begin{array}{l}\text { When I buy meat in the supermarket, I don't } \\
\text { have the animal in mind. }\end{array}$ & -0.057 & -0.175 & 0.317 & -0.279 & 0.252 & 0.035 & 0.176 \\
\hline
\end{tabular}

$\alpha=$ Cronbach alpha; Bartlett-test $=0.000$; Kaiser-Meyer-Olkin $(\mathrm{KMO})=0.934$; MSA (measure of sampling adequacy) lowest/highest value $=0.787 / 0.969$

Source: own calculation 
Table 3. Factor loadings for factor 4 'Favouring organic farming', factor 5 'Favouring conventional farming practices', factor 6 'Criticism of modern chicken husbandry' and factor 7 'Support for dual-purpose chickens'

\begin{tabular}{|c|c|c|c|c|c|c|c|}
\hline & \multicolumn{7}{|c|}{ Factor loading } \\
\hline & $\begin{array}{l}\text { Factor } 1 \\
\alpha=0.848\end{array}$ & $\begin{array}{l}\text { Factor } 2 \\
\alpha=0.850\end{array}$ & $\begin{array}{l}\text { Factor } 3 \\
\alpha=0.843\end{array}$ & $\begin{array}{l}\text { Factor } 4 \\
\alpha=0.723\end{array}$ & $\begin{array}{l}\text { Factor } 5 \\
\alpha=0.698\end{array}$ & $\begin{array}{l}\text { Factor } 6 \\
\alpha=0.679\end{array}$ & $\begin{array}{l}\text { Factor } 7 \\
\alpha=0.625\end{array}$ \\
\hline I only trust organic chicken farming. & 0.023 & -0.082 & 0.139 & 0.940 & 0.063 & -0.147 & -0.019 \\
\hline $\begin{array}{l}\text { Organic meat and eggs are healthier than } \\
\text { conventional products. }\end{array}$ & 0.062 & -0.157 & 0.178 & 0.906 & -0.080 & -0.120 & -0.027 \\
\hline $\begin{array}{l}\text { It is important to me that the public meat } \\
\text { consumption decreases in long-term. }\end{array}$ & 0.108 & -0.093 & 0.092 & 0.638 & -0.110 & 0.198 & -0.035 \\
\hline $\begin{array}{l}\text { I consider the animal husbandry conditions } \\
\text { when buying meat in the supermarket. }\end{array}$ & 0.018 & -0.055 & -0.229 & 0.576 & -0.014 & -0.040 & -0.011 \\
\hline $\begin{array}{l}\text { The white colour of chicken meat is very im- } \\
\text { portant to me. }\end{array}$ & -0.044 & 0.083 & -0.080 & 0.202 & 0.809 & 0.133 & -0.358 \\
\hline $\begin{array}{l}\text { As a consumer, I cannot change the current } \\
\text { situation when buying meat and eggs (intensive } \\
\text { chicken farming, killing of day-old chicks). }\end{array}$ & -0.207 & -0.042 & 0.085 & -0.137 & 0.587 & 0.186 & -0.033 \\
\hline $\begin{array}{l}\text { When buying eggs, I preferably choose to buy } \\
\text { large eggs. }\end{array}$ & 0.051 & -0.068 & 0.017 & 0.046 & 0.581 & 0.159 & -0.160 \\
\hline Intensive farming is part of the modern world. & 0.164 & -0.066 & -0.072 & -0.228 & 0.569 & -0.016 & 0.015 \\
\hline $\begin{array}{l}\text { When food scandals occur, I change my pur- } \\
\text { chase behaviour, but in the long-run I fall back } \\
\text { into old consumption patterns. }\end{array}$ & -0.130 & 0.031 & 0.216 & 0.074 & 0.473 & 0.007 & 0.226 \\
\hline $\begin{array}{l}\text { I am satisfied with products (eggs and meat) } \\
\text { from the conventional chicken husbandry. }\end{array}$ & 0.089 & -0.016 & 0.223 & -0.222 & 0.430 & -0.251 & 0.069 \\
\hline $\begin{array}{l}\text { Conventional chicken farming is not about } \\
\text { animal welfare but all about profit for the } \\
\text { farmer. }\end{array}$ & 0.184 & -0.131 & -0.016 & -0.231 & 0.107 & 0.753 & 0.112 \\
\hline $\begin{array}{l}\text { In todays' chicken farming, there is no relation- } \\
\text { ship between the farmer and animal. }\end{array}$ & 0.147 & -0.155 & 0.061 & -0.120 & 0.090 & 0.722 & 0.002 \\
\hline $\begin{array}{l}\text { Chicken farmers are not being controlled suffi- } \\
\text { ciently. }\end{array}$ & 0.133 & 0.036 & 0.125 & 0.117 & 0.076 & 0.643 & -0.035 \\
\hline $\begin{array}{l}\text { I trust the declaration of the husbandry system } \\
\text { on the packaging of chicken meat and eggs } \\
\text { (e.g. organic, free-range). }\end{array}$ & 0.273 & 0.046 & 0.121 & 0.371 & 0.139 & -0.578 & 0.127 \\
\hline $\begin{array}{l}\text { Conventional chicken farming is cruel to } \\
\text { animals. }\end{array}$ & -0.047 & 0.112 & 0.059 & 0.332 & 0.038 & $\mathbf{0 . 5 3 3}$ & 0.084 \\
\hline I trust conventional chicken farming. & 0.214 & -0.018 & 0.110 & -0.072 & 0.419 & -0.460 & 0.071 \\
\hline Broilers grow too fast. & 0.237 & 0.038 & 0.088 & 0.107 & -0.034 & 0.251 & 0.217 \\
\hline $\begin{array}{l}\text { The additional environmental exposure caused } \\
\text { by the longer fattening period of dual-purpose } \\
\text { chickens is acceptable. }\end{array}$ & -0.149 & -0.080 & -0.092 & -0.008 & -0.033 & -0.016 & 0.764 \\
\hline $\begin{array}{l}\text { It is fine for me that dual-purpose chickens do } \\
\text { not put on as much meat as broilers. }\end{array}$ & 0.017 & 0.067 & 0.163 & -0.025 & -0.270 & 0.072 & 0.651 \\
\hline $\begin{array}{l}\text { If the male chicks are raised instead of being } \\
\text { culled directly after hatching, a higher price } \\
\text { for meat and eggs is justified. }\end{array}$ & -0.076 & 0.029 & -0.335 & 0.138 & 0.074 & 0.036 & 0.547 \\
\hline $\begin{array}{l}\text { If the meat of dual-purpose chickens had a } \\
\text { more intense taste than the meat of a broiler, } \\
\text { I would like that. }\end{array}$ & 0.371 & -0.141 & -0.087 & -0.196 & -0.046 & 0.042 & 0.465 \\
\hline
\end{tabular}

$\alpha=$ Cronbach alpha; Bartlett-test $=0.000$; Kaiser-Meyer-Olkin $(\mathrm{KMO})=0.934$; MSA (measure of sampling adequacy) lowest/highest value $=0.787 / 0.969$

Source: own calculation 


\subsubsection{Cluster Analysis}

Based on the factor analysis, a cluster analysis was conducted to identify different cluster groups describing respondents' attitudes towards dual-purpose chickens. Three clusters were identified:

1. Opponents,

2. Supporters and

3. Indifferents.

Figure 1 shows the standardised factor scores of each cluster with the baseline describing the total samples' mean of each factor. Each bar illustrates deviations of the factors from the total respondents' average. Bars pointing upwards or downwards express factors being either above or below the average of the total sample, respectively.

The first cluster group opponents makes up $37.5 \%$ of the total sample. Factor 3 preference for low prices, and factor 5 favouring conventional farming practices are far above the average of the total sample. The statements relating to factor 3 indicate that respondents of this cluster group prefer lower prices for chicken meat and eggs and make financial barriers responsible for not being able to buy products from dual-purpose chickens more often compared to the total respondents` average. Factor 5 illustrates the higher acceptance of modern farming practices, including the importance of the familiar appearance of chicken meat and eggs. Noticeable are the "below average" factors referring to quality awareness, rejec- tion of culling day-old chicks, favouring organic farming, criticism of modern chicken farming, and support for dual-purpose chickens. Compared to the average of the total sample, respondents of this cluster see the culling of day-old chicks necessary for economic reasons rather than a problem.

In contrast, the cluster group supporters, which is the smallest group and accounts for $23.4 \%$, describes exactly the opposite attitude towards dual-purpose chickens. Factor 1 quality awareness, factor 2 rejection of culling day-old chicks, factor 4 favouring organic farming, factor 6 criticism of modern chicken husbandry, and factor 7 support for dual-purpose chickens show factor scores that are distinctly above the average. Attitudes of respondents of this cluster relate to the importance of health, quality and animal welfare conditions. The respondents' criticisms of conventional chicken farming practices as well as the practice of culling day-old chicks are above average. Hence, the factors preference for low prices and $f a-$ vouring conventional farming are below the average of the total sample. Respondents of this cluster group are willing to pay a surcharge for products from dualpurpose chickens if the latter live in improved housing conditions.

The third cluster group indifferents represents the largest group consisting of $39.1 \%$ of the total sample. All factor scores are slightly above the average of the total sample. In particular, factor 1 quality awareness,

\section{Figure 1. Identified cluster groups and their mean factor deviation from the total sample mean}

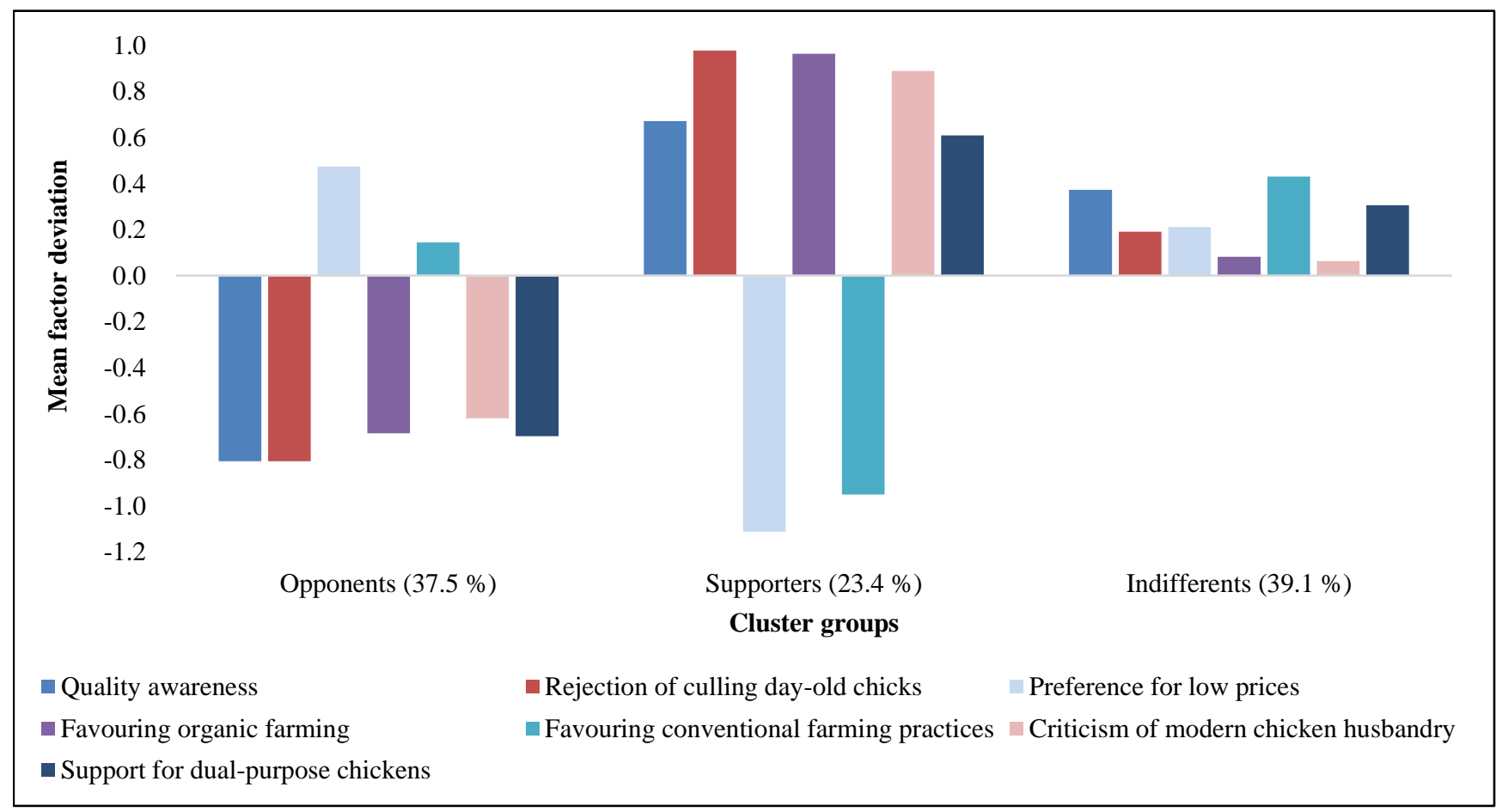

Source: own calculation 
factor 5 favouring conventional farming practices, and factor 7 support for dual-purpose chickens deviate more strongly from the mean. Compared to the average of the total sample, health and quality aspects are more important to respondents of this cluster group. Furthermore, this cluster group is characterised by a rejective attitude towards the killing of day-old chicks as well as a favourable attitude towards dualpurpose chickens compared to the average. However, this cluster group accepts current conventional farming practices and prefers a lower price for chicken meat and eggs at a level above the total sample's average. Ultimately, this cluster group shows an indifferent attitude towards dual-purpose chickens.

\subsubsection{Discriminant Analysis and Analysis of Variance}

The analysis of variance and discriminant analysis, which exhibits significant differences for all factors and cluster groups, verify the validity of the results. Table 4 shows the classification results of the discriminant analysis: $95.1 \%$ of the total sample was classified in the correct cluster groups.

A cross-tabulation was performed to identify correlations between the cluster groups and sociodemographics. Socio-demographic characteristics were categorised into groups to generate nominal scaled variables. Table 5 shows the frequency of each cluster groups' characteristics in percent as well as the correlation and its intensity between the attributes and clusters. Extremely significant, but very weak correlations were identified between the cluster groups and socio-demographics. There is a weak correlation between the cluster groups and gender as well as pet ownership. However, no correlations were found between the cluster groups and age, employment, size of residence, household and persons with children. When interpreting the results with regard to sociodemographic characteristics, it is important to emphasise that the sample is not fully representative and was

Table 4. Classification of results in absolute und relative frequency

\begin{tabular}{|c|c|c|c|c|}
\hline \multirow{2}{*}{$\begin{array}{c}\text { Cluster } \\
\text { group }\end{array}$} & \multicolumn{2}{|c|}{ Predicted group membership } & \multirow{2}{*}{ Total } \\
\cline { 2 - 4 } & $\begin{array}{c}\text { Opponents } \\
(1)\end{array}$ & $\begin{array}{c}\text { Supporters } \\
(2)\end{array}$ & $\begin{array}{c}\text { Indifferents } \\
(3)\end{array}$ & \\
\hline $\mathbf{1}$ & $\mathbf{5 4 2}$ & 1 & 21 & 564 \\
& $(\mathbf{9 6 . 1 \% )}$ & $(0.2 \%)$ & $(3.7 \%)$ & $(100 \%)$ \\
$\mathbf{2}$ & 0 & $\mathbf{3 3 4}$ & 17 & 351 \\
& $(0 \%)$ & $\mathbf{( 9 5 . 2 \% )}$ & $(4.8 \%)$ & $(100 \%)$ \\
$\mathbf{3}$ & 20 & 14 & $\mathbf{5 5 3}$ & 587 \\
& $(3.4 \%)$ & $(2.4 \%)$ & $\mathbf{( 9 4 . 2 \% )}$ & $(100 \%)$ \\
\hline
\end{tabular}

Source: own calculation biased towards a higher education, a considerably lower income and a lower employment rate than in the German population as a whole. Therefore, the following interpretations can only serve as indication for differences between the cluster groups.

Among the opponents there are significantly more males (59.6\%), and they have a medium $(29.3 \%)$ to high $(38.5 \%)$ income. In addition, they have a moderate $(35.8 \%)$ to high $(36.7 \%)$ level of education. Noticeable is the low $(44.0 \%)$ to moderate (42.9\%) level of knowledge of chicken husbandry. The opponents have significantly fewer pets $(39.2 \%)$ and less often have experience with agriculture (40.6\%) compared to the supporters. The supporters are more likely to be female $(60.7 \%)$ and have a high $(49.6 \%)$ to very high $(12.8 \%)$ income compared to the other two cluster groups. Supporters predominantly have a high level of education (43.9\%) and a moderate (56.7\%) to high $(22.5 \%)$ knowledge of chicken husbandry. In addition, they more often have pets $(62.1 \%)$ and significantly more experience with agriculture $(53.8 \%)$. The indifferents are mostly female $(51.3 \%)$ and have a high income $(40.9 \%)$, but a lower income $(27.9 \%)$ than the supporters. They have a moderate level of education (40.0\%) and knowledge of chicken husbandry (52.1\%). In addition, they have significantly fewer pets $(47.2 \%)$ and less often have experience with agriculture (45.8\%). All cluster groups predominantly live in the West and South of Germany.

\section{Discussion and Conclusions}

The objective of this study is to analyse consumer acceptance of dual-purpose chickens. The topic culling day-old chicks was very present in the media during the performance of this study and the findings revealed that the practice is rejected for ethical reasons by the majority of the respondents. The government in Germany promotes research projects that explore alternatives to the culling of day-old chicks. In this context, the focus is on sex determination in the egg and the breeding of dualpurpose chickens. Apart from aspects like animal welfare and economic efficiency, consumers' acceptance of the alternatives plays an essential role regarding the market success of the respective alternative. In order to analyse consumers' acceptance of dual-purpose chickens, a mixed methods approach was applied. In an explorative first step six focus groups were conducted with 
the objective of learning more about consumers' perception of dual-purpose chickens. The results from the focus groups show that most of the participants were aware of the culling of day-old chicks. However, alternatives were rarely ever known. After giving the participants information about the dual-purpose chicken, they were generally in favour of this chicken type. Some participants raised concerns regarding the economic efficiency and the higher product prices. For others, ethical values predominated. All in all, the results demonstrate that the discussants have specific expectations regarding the husbandry of dual-purpose chickens but also with regard to product characteristics.

Table 5. Probability of cluster membership by socio-demographics and knowledge about chicken husbandry

\begin{tabular}{|c|c|c|c|c|c|}
\hline \multirow[t]{2}{*}{ Characteristics } & \multicolumn{3}{|c|}{$\begin{array}{l}\text { Frequency in percent } \\
(\%)\end{array}$} & \multirow[t]{2}{*}{$\begin{array}{c}\text { Correlation* } \\
\text { (p-value) }\end{array}$} & \multirow{2}{*}{$\begin{array}{c}\text { Intensity by } \\
\text { Cramer** } \\
\text { (v-value) }\end{array}$} \\
\hline & Opponents & Supporters & Indifferents & & \\
\hline $\begin{array}{l}\text { Sex } \\
\text { Female } \\
\text { Male }\end{array}$ & $\begin{array}{l}40.4 \\
59.6\end{array}$ & $\begin{array}{l}60.7 \\
39.3\end{array}$ & $\begin{array}{l}51.3 \\
48.7\end{array}$ & 0.000 & 0.157 \\
\hline $\begin{array}{l}\text { Age group } \\
\text { Younger } \\
\text { Middle } \\
\text { Elder }\end{array}$ & $\begin{array}{l}21.8 \\
35.6 \\
42.6\end{array}$ & $\begin{array}{l}21.4 \\
36.5 \\
42.2\end{array}$ & $\begin{array}{l}18.9 \\
38.0 \\
43.1\end{array}$ & 0.771 & 0.025 \\
\hline $\begin{array}{l}\text { Region } \\
\text { North } \\
\text { West } \\
\text { East } \\
\text { South }\end{array}$ & $\begin{array}{l}16.5 \\
29, .3 \\
25.7 \\
28.5\end{array}$ & $\begin{array}{l}20.2 \\
32.2 \\
14.2 \\
33.3\end{array}$ & $\begin{array}{l}19.9 \\
32.7 \\
21.0 \\
26.4\end{array}$ & 0.002 & 0.083 \\
\hline Occupation & 52.0 & 56.1 & 52.6 & 0.442 & 0.033 \\
\hline $\begin{array}{l}\text { Income } \\
\text { Low } \\
\text { Medium } \\
\text { High } \\
\text { Very high }\end{array}$ & $\begin{array}{c}25.7 \\
29.3 \\
38.5 \\
6.6\end{array}$ & $\begin{array}{l}17.4 \\
20.2 \\
49.6 \\
12.8\end{array}$ & $\begin{array}{c}27.9 \\
25.0 \\
40.9 \\
6.1\end{array}$ & 0.000 & 0.113 \\
\hline $\begin{array}{l}\text { Education } \\
\text { Low } \\
\text { Moderate } \\
\text { High }\end{array}$ & $\begin{array}{l}27.5 \\
35.8 \\
36.7\end{array}$ & $\begin{array}{l}18.5 \\
37.6 \\
43.9\end{array}$ & $\begin{array}{l}28.8 \\
40.0 \\
31.2\end{array}$ & 0.000 & 0.084 \\
\hline $\begin{array}{l}\text { Knowledge } \\
\text { Low } \\
\text { Moderate } \\
\text { High }\end{array}$ & $\begin{array}{l}44.0 \\
42.9 \\
13.1\end{array}$ & $\begin{array}{l}20.8 \\
56.7 \\
22.5\end{array}$ & $\begin{array}{l}31.5 \\
52.1 \\
16.4\end{array}$ & 0.000 & 0.137 \\
\hline $\begin{array}{l}\text { Size of residence } \\
\text { Village } \\
\text { Small town } \\
\text { Medium-size city } \\
\text { Large city }\end{array}$ & $\begin{array}{l}35.1 \\
23.8 \\
19.5 \\
21.6\end{array}$ & $\begin{array}{l}35.6 \\
23.4 \\
21.4 \\
19.7\end{array}$ & $\begin{array}{l}33.2 \\
24.0 \\
23.2 \\
19.6\end{array}$ & 0.807 & 0.032 \\
\hline $\begin{array}{l}\text { Household size } \\
\text { Single } \\
\text { 2- } 4 \text { persons } \\
>4 \text { persons }\end{array}$ & $\begin{array}{c}30.5 \\
65.6 \\
3.9\end{array}$ & $\begin{array}{c}27.6 \\
69.2 \\
3.1\end{array}$ & $\begin{array}{c}28.3 \\
68.3 \\
3.4\end{array}$ & 0.794 & 0.024 \\
\hline $\begin{array}{l}\text { Persons having a } \\
\text { child or children }\end{array}$ & 17.9 & 14.8 & 15.5 & 0.385 & 0.036 \\
\hline Ownership of pets & 39.2 & 62.1 & 47.2 & 0.000 & 0.174 \\
\hline $\begin{array}{l}\text { Experience with } \\
\text { agriculture }\end{array}$ & 40.6 & 53.8 & 45.8 & 0.000 & 0.101 \\
\hline
\end{tabular}

*Chi-square by Pearson (significance level: extremely significant $\alpha \leq 0.1 \%$ ( $\mathrm{p} \leq 0.001$ ); highly significant $\alpha=0.1-1 \%$ ( $\mathrm{p}=0.001$ to $0.01)$; significant $\alpha=1-5 \%(\mathrm{p}=0.01$ to 0.05$)$; not significant $\alpha>5 \%(\mathrm{p}>0.05)$ ); **Cramer-V-Correlation: $<0.2$ extremely weak; 0.2 0.4 weak; 0.4-0.6 medium weak (BRosius, 2011)

Source: own calculation 
Based on these findings, a nearly representative online survey with 1,502 respondents was performed in Germany. A total of seven factors that explain the attitudes of consumers towards dual-purpose chickens were identified. Five factors demonstrate the critical and negative attitude of consumers towards modern chicken husbandry and, accordingly, a favourable attitude towards dual-purpose chickens. In contrast, there are two factors related to the endorsement of modern chicken husbandry and the high priority of low prices for chicken meat and eggs. These factors contain negative attitudes towards dual-purpose chickens. Subsequently, three segments were formed: opponents, supporters and indifferents with regard to dual-purpose chickens. In summary, these cluster groups represent typical consumer groups that differ significantly regarding their attitudes towards chicken husbandry, their level of knowledge and their experience with agriculture, as well as in purchase behaviour and sociodemographic characteristics. The results show that among opponents there are significantly more males and that they have less knowledge of chicken husbandry and less experience with agriculture than the supporters, who are more likely to be female and more often have pets. The group of indifferents makes up the largest fraction with $39.1 \%$. Thus, it is the most important consumer group with regard to the marketing of products of dual-purpose chickens. The indifferents have an above-average preference for dual-purpose chickens compared to the total sample, on the one hand, and, on the other hand, an above-average supportive attitude for conventional farming practices and affordable chicken meat and eggs. This ambivalent attitude is associated with a high level of uncertainty among the respondents. Indifferents are likely to be female and have lower incomes than the supporters. Additionally, they have a moderate knowledge of chicken husbandry and a moderate level of education. It can be concluded that within this cluster group there is the greatest potential for reducing uncertainty by means of providing more and better informationon dual-purpose chickens, which may increase consumer acceptance of these.

The results of this study can serve as basis for further relevant discussions regarding the usage of dual-purpose chickens in the fields of policy, economics and research. From an economic point of view, the alternative dual-purpose chicken is currently not an efficient alternative but may instead serve as a niche product, e.g., in the organic production sector. Indeed, there is still a great need for research in this area, since the conflict of objectives between animal welfare, ethics, economic and ecological efficiency has not yet been resolved. In addition, the usage of dualpurpose chicken breeds has an impact on the entire food supply chain. As a consequence, it is important to examine the differentiated perspectives of relevant actors in order to establish a comprehensive and constructive assessment of the acceptance of dual-purpose chickens. In this context, consumer willingness to pay a surcharge plays an important role as they must be willing to bear the higher costs that dual-purpose chickens entail.

\section{Literature}

Backhaus, K., B. ERichson, W. Plinke and R. Weiber (2011): Multivariate Analysemethoden. Eine anwendungsorientierte Einführung. $13^{\text {th }}$ edition. Springer Verlag, Heidelberg.

BECKMANN, M. (2016): Über den vernünftigen Grund im Sinne des $\S 1$ S. 2 TierSchG bei der Tötung von männlichen Eintagsküken. In: Natur und Recht 38 (6): 384-390.

BLE (Bundesanstalt für Landwirtschaft und Ernährung) (2017a): Deutsche essen $8 \mathrm{~kg}$ weniger Fleisch als vor 20 Jahren. In: http://www.ble.de/SharedDocs/Pressemittei lungen/DE/2017/170330_Fleisch.html, retrieved 10.04.2017.

- (2017b): Jeder Deutsche isst 235 Eier pro Jahr. In: http://www.ble.de/SharedDocs/Pressemitteilungen/DE/2 017/170317_Eier.html, retrieved 10.04.2017.

BMEL (Bundesministerium für Ernährung und Landwirtschaft) (2017): Eine Alternative zum Töten männlicher Küken. In: http://www.bmel.de/DE/Tier/Tierwohl/_texte/ Tierwohl-Forschung-In-Ovo.html, Abruf: 18.01.2017.

BRosiUS, F. (2011): SPSS 19. $1^{\text {st }}$ edition. MITP-Verlag, Heidelberg, München, Landsberg, Frechen, Hamburg.

BRUIJNIS, M.R.N., V. BLOK, E.N. STASSEN and H.G.J. GREMMEN (2015): Moral "Lock-In" in Responsible Innovation: The Ethical and Social Aspects of Killing Day-Old Chicks and Its Alternatives. In: Journal of Agricultural and Environmental Ethics 28 (5): 939-960.

ClefF, T. (2015): Deskriptive Statistik und Explorative Datenanlyse. Eine computergestützte Einführung mit Exel, SPSS und STATA. $3^{\text {rd }}$ edition. Singer Verlag, Pforzheim.

CReswell, J.W. and V.L.P. Clark (2011). Designing and conducting mixed methods research. $2^{\text {nd }}$ edition. Sage Publications, Thousand Oaks, CA.

DAMME, K. (2015): Economics of Dual-Purpose Breeds - a comparison of meat and egg production using dual purpose breeds versus conventional broiler and layer strains. In: Lohmann Information 50 (2): 4-9.

Denscombe, M. (2008): Communities of practice: a research paradigm for the mixed methods approach. In: Journal of Mixed Methods Research 2 (3): 270-283.

FAucitano, L., G. Martelli, E. NANNONI and T. WIDOWSKI (2017): Fundamentals of Animal Welfare in Meat Animals and Consumer Attitudes to Animal Wel- 
fare. In: Purslow, P.P. (ed.): New Aspects of Meat Quality: From Genes to Ethics: 537-568.

FINCH, H. and J. LEWIS (2003): Focus Groups. In: Ritchie, J. and J. Lewis (eds.): Qualitative Research Practice. Sage Publications Ltd., London: 170-197.

GRASHORN, M. (2013): Verwendung der männlichen Küken der Legeherkünfte. In: http://www.wingvechta.de/ themen/verwendung_der_maennlichen_legeherkuenfte/ verwendung_der_m_nnlichen_k_ken_der_legeherk_nft e.html, Abruf: 15.05.2016.

HAIR, J., W. Black, B. BABIN and A. ANDERSON (2010): Multivariate Data Analysis. $7^{\text {th }}$ edition. Pearson, Upper Saddle River, NJ.

Heng, Y., H. Peterson and X. Li (2013): Consumer Attitudes towards Farm-Animal Welfare: The Case of Laying Hens. In: Journal of Agricultural and Resource Economics 38 (3): 418-434.

HÜTTNER, M. and U. SCHWARTING (2002): Grundzüge der Marktforschung. $6^{\text {th }}$ edition. Oldenbourg Wissenschaftsverlag, München.

Kaufmann, F., U. Nehrenhaus and R. ANDERSSON (2016): Das Duale Huhn. Der Verbraucher müsste umdenken. In: DGS 2016 (35): 22-25.

KÖNIG, M., G. HAHN, K. DAMME and M. SchmUTZ (2012): Utilization of laying-type cockerels as „coquelets“: Influence of genotype and diet characteristics on growth performance and carcass composition. In: Archiv für Geflügelkunde 76 (3): 197-202.

KÜHN, T. and K. KosCHEL (2011): Gruppendiskussionen. Ein Praxis-Handbuch. VS Verlag für Sozialwissenschaften, Wiesbaden.

KUß, A. (2007): Marktforschung. Grundlagen der Datenerhebung und Datenanlalyse. $2^{\text {nd }}$ edition. Gabler Verlag, Wiesbaden.

LAMNEK, S. (2005): Gruppendiskussion. Theorie und Praxis. UTB, Weinheim.

LeEnstra, F., P. van Horne and M. van KrIMPEN (2010): Dual purpose chickens, exploration of technical, environmental and economic feasibility. In: Proceedings XIIIth European Poultry Conference, Tours, France.

LeEnStRA, F.R., G. MunNiCHS, V. BEEKMAN, E. can den HEUVEL-VROMANS, L.H. ARAMYAN and H. WOELDERS (2011): Killing day old chicks? Public opinion regarding potential alternatives. In: Animal Welfare 20 (1): 37-45.

MAYRING, P. (2015): Qualitative Inhaltsanalyse. Grundlagen und Techniken. Beltz Verlag, Weinheim.

Morgan, D.L. (1997): Focus Groups as Qualitative Research. Sage Publications, Thousand Oaks, CA.

RAUTENSCHLEIN, S. (2016): Einsatz des Zweinutzungshuhns in Mast und Eierproduktion: Ansätze für ein integriertes Haltungskonzept. In: Rundschau für Fleischhygiene und Lebensmittelüberwachung (RFL) 68 (8): 276 278 .
Ritchie, J., J. LeWIS, C. McNaughton Nicholls and R. ORMSTON (2014): Qualitative Research Practice. A Guide for Social Science Students and Researchers. $2^{\text {nd }}$ edition. Sage Publications, London.

Sossidou, E. and H. ELSON (2009): Hens' welfare to egg quality: A European perspective. In: World's Poultry Science Journal 65 (4): 709-718.

STATISTISCHES BUNDESAMT (2015): Ergebnisse des Mikrozensus 2011: Bildungsstand. In: https://www.destatis.de/ DE/ZahlenFakten/GesellschaftStaat/BildungForschungKu ltur/Bildungsstand/Tabellen/Bildungsabschluss.html, Abruf: 02.04.2017.

- (2016): Bevölkerung und Erwerbstätigkeit. Haushalte und Familien. Ergebnisse des Mikrozensus. Wiesbaden.

- (2017a): Bevölkerung und Erwerbstätigkeit. Bevölkerung mit Migrationshintergrund. Ergebnisse des Mikrozensus. Wiesbaden.

- (2017b): Wirtschaftsrechnungen 2015. Laufende Wirtschaftsrechnungen - Einkommen, Einnahmen und Ausgaben privater Haushalte. Wiesbaden.

SÜDDEUTSCHE ZEITUNG (20.05.2016) (2016): Darum müssen Millionen Küken sterben. In: http://www.sueddeut sche.de/wirtschaft/kueken-darum-muessen-millionen-kue ken-sterben-1.2999918, Abruf: 22.01.2018.

VANHONACKER, F. and W.A.J. VERBEKE (2009): Buying higher welfare poultry products? Profiling Flemish consumers who do and do not. In: Poultry Science 88 (12): 2702-2711.

VERBEKE, W. and J. VIAENE (2000): Ethical challenges for livestock production: Meeting consumer concerns about meat safety and animal welfare. In: Journal of Agricultural \& Envrionmental Ethics 12 (2): 141-151.

\section{Acknowledgements}

This study is part of the research project "SocialLab Nutztierhaltung im Spiegel der Gesellschaft". The project is funded by the Federal Ministry of Food and Agriculture (BMEL) by decision of the German Bundestag. Within the innovation funding the project is managed by the Federal Office for Food and Agriculture (BLE).

\section{Contact author:}

NANKE BRÜMMER

Thünen Institute of Market Analysis

Bundesallee 63, 38116 Braunschweig, Germany

e-mail: nanke.bruemmer@thuenen.de 


\title{
4.3 German consumers' preferences and willingness to pay for eggs and meat from dual-purpose chickens: A latent class analysis
}

\author{
Nanke Brümmer and Inken Christoph-Schulz \\ Not published yet
}

Declaration of originality: The research design and procedure were developed by the author with the support of co-author Dr. Inken Christoph-Schulz. The choice experiment design, calculations and analysis were performed by the author in consultation with the co-author. The raw manuscript was mostly written by the author and revised by the coauthor. The programming of the choice experiment and the online survey, as well as the recruitment of survey participants, was done by a market research agency. 


\title{
German Consumer Preferences and Willingness to Pay for Eggs and Meat from Dual-Purpose Chickens: A Latent Class Analysis
}

\begin{abstract}
The use of dual-purpose chickens is one alternative to the common practice of culling dayold male chicks. Dual-purpose chicken products, however, have a different appearance to those of specialised chicken breeds and would therefore be more expensive, and it is unclear whether consumers would be willing to pay for it. It is therefore important to investigate consumers' preferences and their willingness to pay for eggs and meat from dual-purpose chickens. In this study, a mixed methods approach involving an online survey based on focus groups with a discrete choice experiment was conducted. To account for preference heterogeneity, a latent class model was applied. Four consumer segments regarding eggs and chicken meat were identified. For both products, the largest segment consisted of price conscious consumers. Small potential consumer groups for eggs and meat from dual-purpose chickens willing to pay for dual-purpose chicken products were also identified. For eggs, this segment includes $25.3 \%$ of the respondents, whereas this segment only includes $16.2 \%$ for meat from dual-purpose chickens.
\end{abstract}

Keywords: dual-purpose chickens; consumers' acceptance; mixed methods; choice experiment; preference heterogeneity; latent class model; willingness to pay.

\section{Introduction}

In Germany, more than 45 million male chicks are culled directly after hatching each year. The culling of day-old chicks is common practice in the commercial production of laying breeds, because the fattening of layer-type males is unprofitable (Rautenschlein, 2016). This applies to conventional farming as well as organic farming. The German Federal Ministry of Food and Agriculture aims to end the routine killing day-old chicks. To this end, the ministry is promoting the development of methods for determining the sex of hatching eggs and other alternatives (BMEL, 2018). Dual-purpose chickens are one alternative to the killing of day-old chicks, as they can both produce meat and lay eggs. The hens lay fewer eggs than current specialised layers, and the cockerels put on less meat than broilers and need more time and feed to grow, leading to a higher demand for resources such as land and water (König et al., 2012; Damme, 2015). Consequently, eggs and meat from dual-purpose chickens have a different appearance and are more expensive than products from specialised chickens. To a great extent, the eggs are smaller (mainly small and medium sized) and not explicitly brown or white in colour. The meat of the cockerels has a firmer consistency and a darker colour (Grashorn, 2013; Siekmann et al., 2018). Additionally, the share of breast meat, which enjoys greater popularity in Germany, 
is much smaller when compared to broilers. Therefore, dual-purpose chickens are less suitable for the marketing of cuts such as chicken breast (Kaufmann et al., 2016; Mueller et al., 2018).

Contrary to general trends, the consumption of chicken meat and eggs is still increasing slightly in Germany. In 2016, the average consumption of poultry was $12.5 \mathrm{~kg}$ per person (BLE, 2017a). Additionally, the Germans consumed 235 eggs on average in 2016 (BLE, 2017b). At the same time, animal husbandry is a focus of public criticism. In particular, this concerns the housing of laying hens and the broiler production, which are viewed more sceptically than other animal production systems (Verbeke \& Viaene, 2000; Vanhonacker \& Verbeke, 2009; Sossidou \& Elson, 2009; Heng et al., 2013; Faucitano et al., 2017).

With regard to the marketability of eggs and meat from dual-purpose chickens in Germany, we performed a choice experiment in order to explore the relative importance of different egg and chicken meat attributes, and whether there are consumer segments with preferences and a WTP for eggs and meat from dual-purpose chickens. The paper is structured as follows: Section 2 shows the methodological approach and data used in the online survey. In Section 3, the choice experiment, experiment design and latent class model are described, and are followed by results and an estimation of the willingness to pay. Section 4 concludes with a discussion of the results and further conclusions.

\section{Background}

Several studies have revealed that consumer food choices are not only determined by the price but increasingly by credence attributes, such as animal welfare, environmental aspects, health issues, and origin (Grunert, 2005; Napolitano et al., 2010; Pouta et al. 2010). With the help of a qualitative study, Kennedy et al. (2004) investigated consumer perceptions of poultry and identified appearance (e.g. meat colour and form) as an indicator of quality. Other important factors when buying chicken meat were value (e.g. healthiness and taste) and convenience (described as a preference for chicken breast fillet, while the cooking of a whole chicken was perceived as traditional). In the case of eggs, Guyonnet (2012) looked at several studies dealing with consumer attitudes towards eggs and egg products. According to the author, prevailing egg-buying decisions depend on the price, freshness, remaining shelf-life and quality of the eggs. Pouta et al. (2010) have shown preference heterogeneity among consumers for broiler meat and revealed a strong positive preference for domestically produced broiler meat. Preference heterogeneity regarding chicken breast meat was also investigated by Van Loo et al. (2011). The findings show that consumers are willing to pay a premium for organic chicken breast, especially the segment including habitual buyers of organic products. In a study by Napolitano et al. (2010), the authors revealed that information on organic production might have a bigger effect on consumer preferences than the sensory properties of the product. Hasselbach \& Roosen (2015) have shown that German consumers rank local production highly, but even higher premiums could be achieved through a combination of local and organic claims. For eggs, the results of a study from Gracia et al. (2013) demonstrate that the largest consumer segment values a local claim more than an organic one. They also found that local and organics claim can be used together, not as substitutes for each other. Norwood \& Lusk 
(2011) found that respondents valued animal living conditions and were willing to pay a premium price for eggs from chickens raised in an aviary, pasture system, as opposed to those from a cage. In a study by Vanhonacker \& Verbeke (2009), consumer segments were identified for eggs and chicken meat. One segment was for those with a high price awareness and low ethical concerns, and another was for high preference for animal welfare, low price sensibility and high quality-consciousness. Across all segments, concerns were expressed about the husbandry of poultry. Schjøll et al. (2013) found that animal welfare is the most important aspect when buying eggs for a majority of consumers. The results obtained by Heng et al. (2013) show that when purchasing eggs, the respondents rated animal welfare more highly than environmental effects which can arise, for example, from outdoor access. In a study by Lu et al. (2013), sufficient feed and water, the treatment of injuries and diseases and sufficient space were considered to be the most important husbandry parameters for laying hens. Contrarily, Andersen (2011) found that animal welfare attributes had little effect on the demand for animal products, and that the estimation of the willingness to pay (WTP) for animal welfare is subject to hypothetical bias. Additionally, she found that organic and free-range eggs are considered to be very similar by the respondents. Gangnat et al. (2018) investigated Swiss consumers' willingness to pay and attitudes towards dual-purpose poultry. The findings show that knowledge about agriculture, familiarity with dual-purpose chickens and the type of usually purchased products (organic or conventional) influence the WTP for eggs and meat from dual-purpose poultry, and that the WTP was generally declared to be higher for eggs than for meat from dual-purpose poultry.

\section{Methodological Approach and Data}

We used a mixed methods approach, and combined qualitative and quantitative methods with the aim of gaining a deeper understanding of the research topic than one method could have delivered by itself (Creswell \& Clark, 2011). Particularly when the subject matter is new, sequencing qualitative and quantitative methods can help to understand and identify the research topic and quantify the results (Ritchie et al., 2014). In our case, qualitative data was first gathered through focus groups in order to explore the new topic of dual-purpose chickens. In June 2016, six focus groups, each with six to eight participants, were used in Berlin, Munich and Cloppenburg (a town in a region which produces much poultry in Lower Saxony). Discussion topics were the preference for eggs and chicken meat, the perception of chicken husbandry, alternatives to the killing of dayold chicks and the concept of dual-purpose chickens, including advantages, disadvantages and potential purchase criteria. The findings of this pre-study can be found in Anonymous (2018a). 


\section{Online Survey}

Based on the outcomes of the focus groups, an online survey was conducted. The data was collected through a web-based survey conducted in Germany in February and March 2017. The total sample size was 1,502 participants. These were selected by a market research company offering online research panels. All the respondents were consumers of chicken meat and eggs. Quotas concerning age, gender, school education, employment rate and household income were largely fulfilled. Nevertheless, the sample was slightly biased towards more highly-educated respondents with higher incomes. For more information on the sociodemographic characteristics, see Anonymous 2018b.

Respondents were asked questions concerning, among other things, their dietary habits, knowledge of chicken husbandry, and socio-demographics. Additionally, respondents were asked 40 items on a seven-point Likert scale, which ranged from 1 (I do not agree at all) to 7 (I totally agree). These items were based on statements made by the participants in the focus groups. The statements focused on general chicken husbandry, purchase behaviour, trust and dual-purpose chickens. The statements were pretested on a sample of 150 respondents in February 2017, to ensure the suitability of the statement questions. An exploratory factor analysis was carried out on the data from the online survey using IBM SPSS Statistics 24 to define the underlying structure in the data matrix (Hair et al., 2010). Within the factor analysis factors, many single items which were answered similarly were formed (Hüttner \& Schwarting, 2002). To measure the adequacy of the final sample for factor analysis, a sampling adequacy test (results: ranging from 0.787 to 0.969 ), KaiserMeyer-Olkin test (result: 0.934) and the Bartlett test of sphericity (result: 0.000) were performed. Next, a principal component analysis was carried out using a Promax for rotation (Hair et al., 2010). Seven factors were identified. These accounted for $55.12 \%$ of the overall error variance. Based on Hair et al. (2010), Cronbach's alpha is consistent and reliable for each factor $(\alpha>0.6)$. The seven factors which describe consumer attitudes towards dual-purpose chickens are:

- F1: Quality Awareness ( $\alpha$ : 0.848)

- F2: Rejection of Killing Day-Old Chicks ( $\alpha$ : 0.850)

- F3: Affordability ( $\alpha$ : 0.843)

- F4: Ecological Awareness ( $\alpha$ : 0.723)

- F5: Acceptance of the Current System ( $\alpha: 0.698)$

- F6: Critical Perception of Chicken Farming ( $\alpha$ : 0.679)

- F7: Support for Dual-Purpose Chickens ( $\alpha$ : 0.625)

Factor 1 is Quality Awareness, and describes important quality attributes of animal production, such as process quality in chicken husbandry (including the husbandry, feeding, transport and slaughtering of the animals), human dietary values and consumer trust. Factor 2 is the Rejection of Culling Day-Old Chicks, which relates to the ethical concerns of culling and consumer desire for stopping this practice. Factor 3, Affordability, reveals financial barriers for products from dual-purpose chickens and emphasises the importance of low prices for meat and eggs. Factor 4, Ecological Awareness, reflects the endorsement of organic chicken farming, including trust, health and consumer 
responsibility towards organic animal husbandry. Factor 5 favours conventional farming practices, which describes the importance of the appearance of chicken meat and eggs as well as the Acceptance of the Current System. Factor 6, Critical Perception of Chicken Farming, criticises farmer profit orientation to the disadvantage of animal welfare conditions and the general distrust of conventional chicken husbandry. Factor 7 is Support for Dual-Purpose Chickens, which indicates a favourable attitude to dual-purpose chickens regarding environmental impact, appearance and the higher price of dual-purpose chicken products. For more information regarding the factor analysis, please see Anonymous $2018 b$.

Questions regarding the purchase behaviour of the respondents revealed that $29 \%$ of the respondents said they primarily bought barn-laid eggs, 54\% free-rage eggs and $13 \%$ of the respondents claimed to buy organic eggs. $1 \%$ of the respondents said they bought eggs from initiatives that prevent male chick culling, and 3\% indicated "others". Regarding chicken meat, $21 \%$ of the respondents said they bought conventional chicken meat, $36 \%$ conventional and local chicken, $8 \%$ organic and $25 \%$ organic and local chicken meat. $7 \%$ bought "others" and $2 \%$ claimed to buy chicken meat from initiatives that fatten the male layer-chickens.

\section{Discrete Choice Experiment}

A discrete choice experiment was chosen because no purchase data is available yet for products from dual-purpose chickens, as they are rarely present on the market. In our case, we aim to assess consumers' stated preferences for different egg and chicken meat attributes and the relevance of the different product characteristics. In choice experiments, respondents make repeated choices between several alternatives with varying attributes. Choice experiments are based on the random utility theory (McFadden, 1974) which assumes that individuals are rational and try to maximise their utility within their budget constraints, and is based on the Lancastrian consumer theory (Lancaster, 1966). This theory says that consumers do not derive the utility from the good itself but from the product attributes and attribute levels. Consequently, choice experiments are a suitable method for estimating the effects of different egg and meat characteristics on consumers' utility, and to determine their willingness to pay. Choice experiments describe the alternatives to choose from using a number of attributes, and can be described as follows:

Individual $n$ chooses alternative $i$, resulting in utility

$U_{n i}=U\left(X_{n i}\right)$,

where $X_{n i}$ is a vector describing the attributes embedded in alternative $i$.

Applying McFadden's random utility model, utility is composed of a deterministic and a

random part: $U_{n i}=V_{n i}+\varepsilon_{n i}$.

Here, $V_{n i}=f\left(X_{n i}\right)$ is deterministic and depends on the product attributes, whereas $\varepsilon_{n i}$ presents the random component. 


\subsection{Experimental Design}

For the experimental design, the products we chose were eggs and chicken breasts, because eggs and meat are the products which are of main interest for determining potential consumer segments. With respect to chicken meat, chicken breast was chosen because the focus group respondents stated that they prefer to buy chicken breast fillets, something which is also reflected in a study by Kennedy et al. (2004). The choice scenarios were constructed with the help of Ngene software using an orthogonal fractional factorial design, which was split into six blocks to avoid fatigue effects among the respondents. Eight choice sets were presented to each respondent, including four choice situations with eggs and four choice situations with chicken breast.

Whether or not the respondents faced the egg or chicken breast choice block first was randomly assigned, as was the order of the choice sets and the alternatives within the choice sets. The choice questions were similar to a typical situation which consumers face when buying products in the supermarket. Examples of choice set questions regarding eggs and chicken breast are presented in Figures 1 and 2. Each choice set included four alternatives. For eggs, the five attributes were the husbandry system (barn-laid, free-range, small-scale free-range and organic), the price for six eggs (€0.99, €1.59, €2.19, €2.79), the size of the eggs (small, medium, large, extra-large), whether they were labelled as dualpurpose chickens (no, yes) and their origin (Germany and local). The four chicken breast attributes were the husbandry system (conventional, organic), the price for $250 \mathrm{~g}(€ 2.49$, $€ 4.16, € 5.82, € 7.49$ ), whether they were labelled as dual-purpose chickens (no, yes) and their origin (Germany and local) (see Table 1). The prices were based on actual prices from a store check in January 2017 and range from the cheapest to that of expensive organic products. The German egg market is dominated by three different husbandry systems: barn-laid, free-range and organic. Additionally, eggs from small-scale free-range farms such as from mobile barns are increasingly found in food retail. Incorporating the egg size into the choice experiment was important, because eggs from dual-purpose chickens tend to be smaller than eggs from conventional laying hens. The origin was included in both products, because previous studies have revealed the importance of origin when buying eggs and chicken meat. Regarding chicken meat, the husbandry system was represented by an organic label (conventional $=$ no label). Essential for this study are consumer preferences and WTP for eggs and meat for dual-purpose chickens. Therefore, a label for dual-purpose chickens with the title "dual-purpose chicken: eggs from the hens, meat from the cockerels" was part of the choice experiment (non dual-purpose chicken = no label). 
Table 1: Attributes and levels of eggs and chicken breast for choice experiment

\begin{tabular}{lll}
\hline Attribute & 6 eggs per carton & 250g chicken breast meat \\
\hline Husbandry system & Barn-laid & Conventional \\
& Free-range & Organic \\
& Small-scale free-range & - \\
Price & Organic & - \\
& $€ 0.99$ & $€ 2.49$ \\
& $€ 1.59$ & $€ 4.16$ \\
& $€ 2.19$ & $€ 5.82$ \\
Size & $€ 2.79$ & $€ 7.49$ \\
& Small & - \\
& Medium & - \\
& Large & - \\
Labelled as dual-purpose chicken & Extra Large & - \\
\multirow{2}{*}{ Origin } & Yes & No \\
& Germany & Yes \\
& Local & Germany \\
\hline
\end{tabular}

Note: Italics denote the reference levels in the model estimation

Before the respondents answered the choice questions, a cheap talk script was presented to them which highlighted the importance of choosing the alternatives as realistically as possible, and trying to behave as if in a real shopping situation (Van Loo et al., 2014). The respondents were also provided with information about the products' attributes, which they could only click away from after a certain time. All the respondents were consumers of chicken meat and eggs, and so were familiar with these products. For this reason, we used a forced choice set without a no-choice option, because according to Parker \& Schrift (2011), respondents use a more evaluative and attribute-based processing pattern when facing choice sets without the opt-out option.

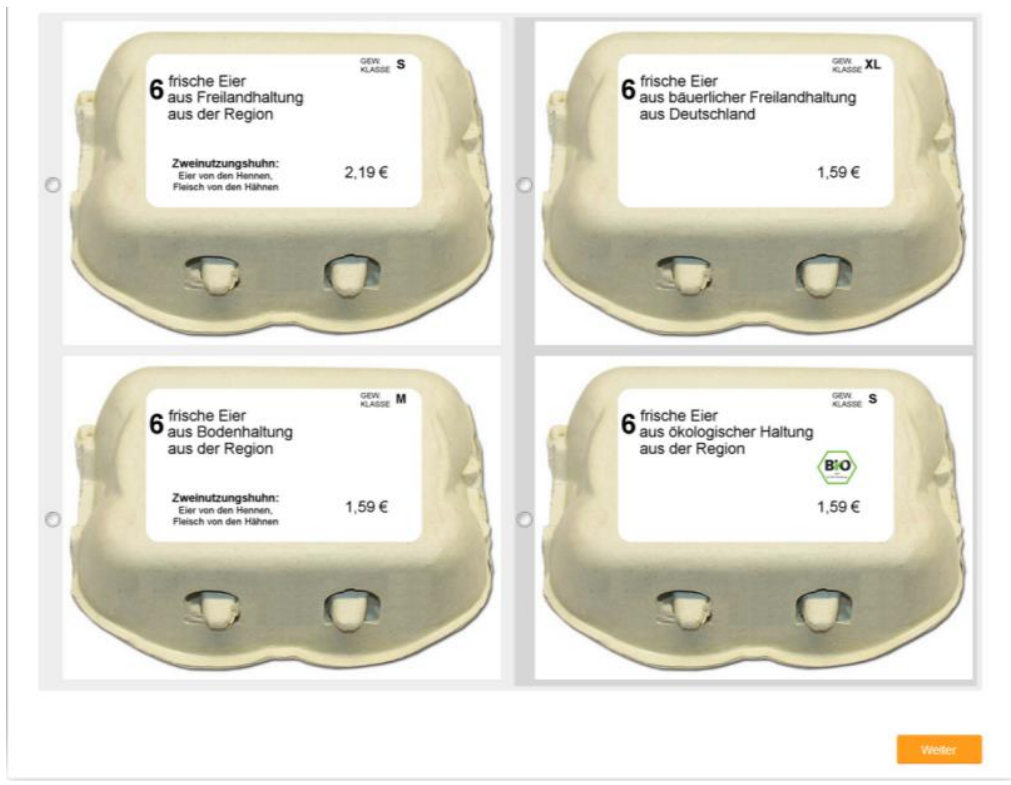

Figure 1: Example of a choice set (eggs) 


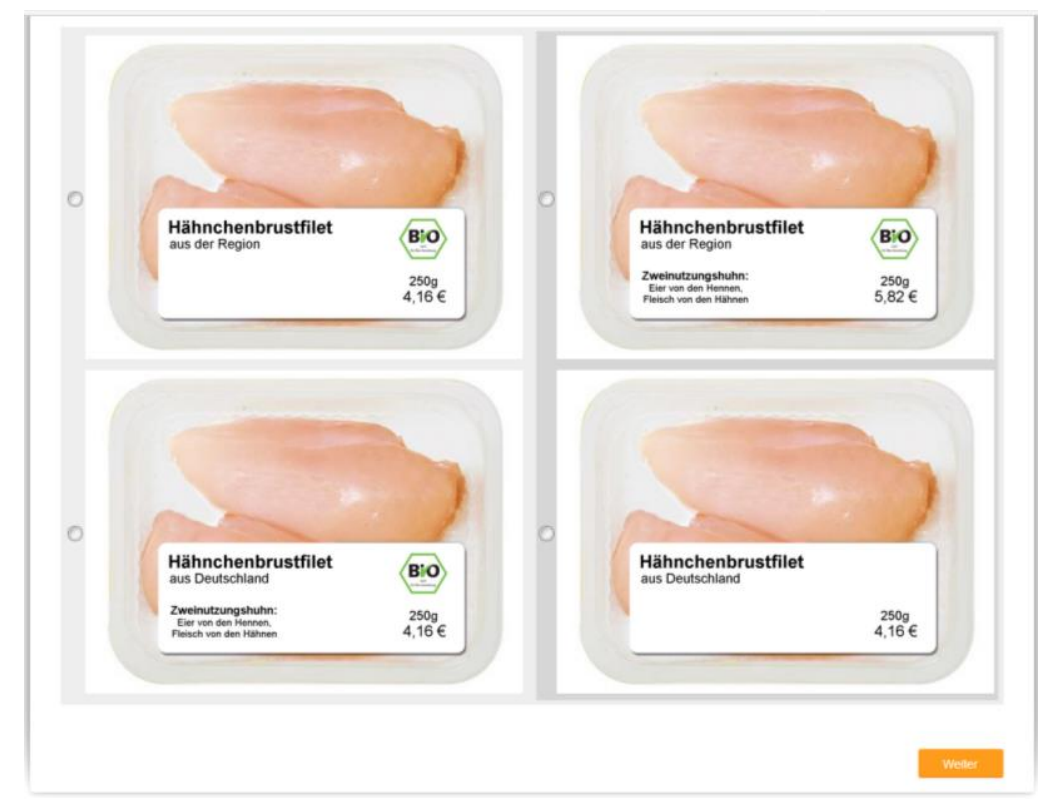

Figure 2: Example of a choice set (chicken breasts)

\subsection{Latent Class Model}

The latent class model (LCM) approach accounts for preference heterogeneity among consumers. LCM's underlying theory is that individual behaviour is composed both of attributes that are observable and those that are on a latent heterogeneity that depends on factors that cannot be observed by analysts (Hensher et al., 2015). Based on the (hypothetical) choices observed, consumers were grouped into classes. In this application, heterogeneity is explained by the results of the factor analysis on consumers' attitudes towards dual-purpose chickens and chicken husbandry in general, as well as variables such as pet ownership and organic purchasing behaviour. The presentation of the latent class model follows Boxall \& Adamowicz (2002) and Hensher et al. (2015).

Individual $n$ chooses alternative $i$, resulting in utility $U_{n i}=U\left(X_{n i}\right)$, where $X_{n i}$ is a vector describing the attributes embedded in alternative $i$. Applying McFadden's random utility model, utility is composed of a deterministic and a random part: $U_{n i}=V_{n i}+\varepsilon_{n i}$.

Here, $V_{n i}=f\left(X_{n i}\right)$ is deterministic and depends on the product attributes, whereas $\varepsilon_{n i}$ represents the random component.

The individual has to choose one alternative among those listed in choice set $\mathrm{C}$. The probability $\left(\pi_{n}(i)\right)$ of choosing alternative $i$ equals the probability that alternative $i$ leads to the maximum utility of all alternatives of choice set $\mathrm{C}$. This is:

$$
\pi_{\mathrm{n}}(\mathrm{i})=\operatorname{Prob}\left\{\mathrm{V}_{\mathrm{ni}}+\varepsilon_{\mathrm{ni}} \geq \mathrm{V}_{\mathrm{nk}}+\varepsilon_{\mathrm{nk}} ; \mathrm{i} \neq \mathrm{k}, \forall \mathrm{k} \in \mathrm{C}\right\} \text {. }
$$

The multinomial logit model can be used to estimate these probabilities under the assumption that the error term follows extreme-value-type-I distribution. 
Substituting a linear functional form of product attributes into the deterministic utility part, the probability results in a multinomial logit model

$$
\pi_{\mathrm{n}}(\mathrm{i})=\frac{\exp \left(\mu \beta \mathrm{X}_{i}\right)}{\sum_{k \in C} \exp \left(\mu \beta \mathrm{X}_{k}\right)}
$$

Here $\mu$ is a scale parameter, normalised to unity and $\beta$ is a vector of parameters to be estimated.

In the traditional multinomial logit model, a common vector $\beta$ is estimated for all individuals. In the latent class model, it is supposed, however, that consumers are heterogeneous. The population consists of $\mathrm{S}$ classes or segments. If consumer $\mathrm{n}$ belongs to segment $\mathrm{s}(\mathrm{s}=1,2, \ldots, \mathrm{S})$, then the utility function can be specified as follows:

$$
U_{n i s}=\beta_{s} X_{n i}+\varepsilon_{n i \mid s} \text {. }
$$

Therefore, parameters are class specific and the likelihood of choosing alternative $i$ given that consumer $n$ belongs to segment s results as

$$
\pi_{n i \mid s}(i)=\frac{\exp \left(\mu_{s} \beta_{s} \mathrm{X}_{i}\right)}{\sum_{k \in C} \exp \left(\mu_{s} \beta_{s} \mathrm{X}_{k}\right)}
$$

where $\beta_{\mathrm{s}} \mu_{\mathrm{s}}$ presents the class specific utility or scale parameter. It is important to note that the classes are latent, that is, they cannot be observed directly. Based on attitudinal factors identified in the factor analysis and possibly based on sociodemographic characteristics, the latent classes can be identified in the estimation procedure. The probability of belonging to a certain class can be derived by a multinomial logit model.

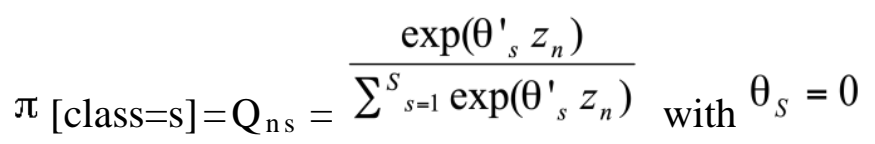

$\mathrm{Z}_{\mathrm{n}}$ is an optional set of person invariant characteristics. It is possible that the class specific probabilities are a set of fixed constants, if there are no other characteristics observed. In our case, the class probabilities are simply functions of $S$ sets of parameters, ${ }{ }_{s}$, where the last is fixed at zero.

The optimal number of classes can be determined by statistical criteria. Boxall \& Adamowicz (2002) and Train (2003) suggest the minimum Akaike Information Criterion (AIC) and the minimum Bayesian Information Criterion (BIC) as indicators for choosing the number of segments. According to them, judgement and simplicity should be also considered when selecting the number of segments.

The marginal willingness to pay (WTP) for an attribute (i) is the negative ratio of the attribute coefficient $\left(\beta_{i}\right)$ and the cost coefficient $\left(\beta_{\text {price }}\right)$ (Hensher et al., 2015).

$$
W T P_{i}=-\frac{\beta_{i}}{\beta_{\text {price }}}
$$

In Tables 4 and 7, the willingness to pay estimates for each class are shown for eggs and chicken meat. The 95\%-confidence intervals were calculated using the parametric bootstrap, also referred to as the Krinsky and Robb simulation, which assumes normal distribution (Hole, 2007). When interpreting the WTP values it is important to note that the WTP is often overstated by the respondents, especially when it concerns products with a normative character (List \& Gallet, 2001; Gerini et al., 2016). 


\subsubsection{Eggs}

Models with two to six classes were estimated in order to find the best model. The BICvalue is the lowest in the 4-segment model, and the AIC-value the lowest in the 6-segment model. As the change of AIC and BIC is the largest between three and four segments, the model with four classes was selected (see Table 2).

Table 2: Class information (egg choice experiment)

\begin{tabular}{cclllll}
\hline $\begin{array}{l}\text { Number } \\
\text { of } \\
\text { classes }\end{array}$ & $\begin{array}{l}\text { Number of } \\
\text { parameters }\end{array}$ & $\begin{array}{l}\text { Log } \\
\text { likelihood at } \\
\text { convergence } \\
\text { (LL) }\end{array}$ & $\begin{array}{l}\text { Log } \\
\text { likelihood } \\
\text { evaluated at } \\
\text { (LL0) }\end{array}$ & $\begin{array}{l}\text { Akaike's } \\
\text { information } \\
\text { criterion } \\
\text { (AIC) }\end{array}$ & $\begin{array}{l}\text { Bayesian } \\
\text { information } \\
\text { criterion } \\
\text { (BIC) }\end{array}$ & $\begin{array}{l}\text { McFadden } \\
\text { Pseudo } \\
\mathrm{R}^{2}\end{array}$ \\
\hline 2 & 30 & -6286.3 & -8328.9 & 12632.7 & 6416.8 & 0.25 \\
3 & 50 & -6015.6 & -8328.9 & 12131.2 & 6233.1 & 0.28 \\
$\mathbf{4}$ & $\mathbf{7 0}$ & $\mathbf{- 5 8 7 8 . 0}$ & $\mathbf{- 8 3 2 8 . 9}$ & $\mathbf{1 1 8 9 6 . 1}$ & $\mathbf{6 1 8 2 . 6}$ & $\mathbf{0 . 2 9}$ \\
5 & 90 & $\mathbf{- 5 8 2 1 . 6}$ & -8328.9 & 11823.3 & 6213.2 & 0.30 \\
6 & 110 & -5792.5 & -8328.9 & 11805.5 & 6271.0 & 0.30 \\
\hline
\end{tabular}

The parameters of the attitudinal and sociodemographic variables of the fourth class were normalised to zero. Therefore the parameters of the other classes have to be interpreted with regard to these variables. From Table 3, we can see that the first segment is characterised by respondents with a high preference for affordable food and is therefore classified in the 'price-conscious consumers' segment. With $40.8 \%$, this class accounts for the largest share of respondents. Within this segment, the price parameter is the most negative, compared to the other segments. Additionally, the parameters of the factors 'acceptance of the current system' and 'critical perception of chicken farming' were positive. The first segment is made up of respondents who have a high preference for extra-large eggs from free-range farms. The organic food buying behaviour is negative, and the preference for locally produced eggs is the lowest in this segment. The preference for eggs from dual-purpose chickens is negative within this segment, and the factors 'support dual-purpose chickens' and 'quality awareness' are also negative in this segment.

Table 3: LCM model estimates (egg experiment)

\begin{tabular}{|c|c|c|c|c|}
\hline & $\begin{array}{l}\text { Segment } 1 \\
(40.8 \%) \\
\text { Price-conscious } \\
\text { consumers } \\
\text { (Standard Error) }\end{array}$ & $\begin{array}{l}\text { Segment } 2 \\
(20.4 \%) \\
\text { Environmentalists }\end{array}$ & $\begin{array}{l}\text { Segment } 3 \\
(13.5 \%) \\
\text { Opponents of } \\
\text { dual-purpose } \\
\text { chickens } \\
\text { (Standard Error) }\end{array}$ & $\begin{array}{l}\text { Segment } 4 \\
(25.3 \%) \\
\text { Supporters of } \\
\text { dual-purpose } \\
\text { chickens } \\
\text { (Standard Error) }\end{array}$ \\
\hline Constant & $\begin{array}{l}0.17242 * * \\
(0.08209)\end{array}$ & $\begin{array}{l}0.29812 * * * \\
(0.10803)\end{array}$ & $\begin{array}{l}-0.16613 \\
(0.11809)\end{array}$ & $\begin{array}{l}0.05441 \\
(0.09299)\end{array}$ \\
\hline $\begin{array}{l}\text { Barn-laid eggs } \\
\text { Free-range eggs }\end{array}$ & $\begin{array}{l}\text { Base level } \\
0.30266 * * * \\
(0.11153)\end{array}$ & $\begin{array}{l}\text { Base level } \\
-0.59893^{* * *} \\
(0.11593)\end{array}$ & $\begin{array}{l}\text { Base level } \\
0.26006 * * \\
(0.11226)\end{array}$ & $\begin{array}{l}\text { Base level } \\
0.74827 * * * \\
(0.09212)\end{array}$ \\
\hline $\begin{array}{l}\text { Small-scale free-range } \\
\text { eggs } \\
\text { Organic }\end{array}$ & $\begin{array}{l}0.25253 * * * \\
(0.08348) \\
-0.16004 \\
(0.10044)\end{array}$ & $\begin{array}{l}0.14022 \\
(0.08843) \\
1.75909 * * * \\
(0.12422)\end{array}$ & $\begin{array}{l}0.47204 * * * \\
(0.13531) \\
-0.75088 * * * \\
(0.15672)\end{array}$ & $\begin{array}{l}1.29238 * * * \\
(0.12876) \\
-0.60204 * * * \\
(0.11470)\end{array}$ \\
\hline
\end{tabular}




\begin{tabular}{|c|c|c|c|c|}
\hline Price & $\begin{array}{l}-4.06249 * * * \\
(0.20830)\end{array}$ & $\begin{array}{l}-0.04118 \\
(0.09377)\end{array}$ & $\begin{array}{l}0.22513 * * \\
(0.10709)\end{array}$ & $\begin{array}{l}-0.79692 * * * \\
(0.08901)\end{array}$ \\
\hline Small size & Base level & Base level & Base level & Base level \\
\hline \multirow[t]{2}{*}{ Medium size } & -0.04580 & $0.14852 *$ & -0.06078 & -0.07840 \\
\hline & $(0.07365)$ & $(0.08448)$ & $(0.13108)$ & $(0.11157)$ \\
\hline \multirow[t]{2}{*}{ Large size } & $0.22758 * *$ & $0.21001 * *$ & $0.21126^{*}$ & $0.32427 * * *$ \\
\hline & $(0.09083)$ & $(0.08381)$ & $(0.11233)$ & $(0.08999)$ \\
\hline \multirow[t]{2}{*}{ Extra-large size } & $0.37366^{* * *}$ & $-0.18034 *$ & $0.26710 * *$ & $0.12784 *$ \\
\hline & $(0.09806)$ & $(0.09894)$ & $(0.10686)$ & $(0.07633)$ \\
\hline No dual-purpose chicken & Base level & Base level & Base level & Base level \\
\hline \multirow[t]{2}{*}{ Dual-purpose chicken } & $-0.09940^{*}$ & $0.11847 * *$ & $-0.48508 * * *$ & $0.60334 * * *$ \\
\hline & $(0.05988)$ & $(0.05730)$ & $(0.10412)$ & $(0.05825)$ \\
\hline German origin & Base level & Base level & Base level & Base level \\
\hline \multirow[t]{2}{*}{ Local origin } & $0.13282 * * *$ & $0.26332 * * *$ & $0.38984 * * *$ & $0.24554 * * *$ \\
\hline & $(0.03801)$ & $(0.05597)$ & $(0.08351)$ & $(0.05007)$ \\
\hline \multirow[t]{2}{*}{ F1: Quality awareness } & $-0.47319 * * *$ & -0.14161 & -0.06976 & - \\
\hline & $(0.13417)$ & $(0.14514)$ & $(0.17629)$ & \\
\hline \multirow{2}{*}{$\begin{array}{l}\text { F2: Rejection of killing } \\
\text { day-old chicks }\end{array}$} & -0.05739 & $-0.49569 * * *$ & -0.08713 & - \\
\hline & $(0.14381)$ & $(0.16719)$ & $(0.19399)$ & \\
\hline \multirow[t]{2}{*}{ F3: Affordability } & $1.55444 * * *$ & -0.07240 & $-0.65914 * * *$ & - \\
\hline & $(0.17793)$ & $(0.16335)$ & $(0.20619)$ & \\
\hline \multirow[t]{2}{*}{ F4: Ecological awareness } & -0.21471 & $1.17965^{* * *}$ & -0.14996 & - \\
\hline & $(0.16511)$ & $(0.19189)$ & $(0.21470)$ & \\
\hline \multirow{2}{*}{$\begin{array}{l}\text { F5: Acceptance of current } \\
\text { system }\end{array}$} & $0.45101 * * *$ & 0.08231 & $1.01219 * * *$ & - \\
\hline & $(0.13784)$ & $(0.13057)$ & $(0.18144)$ & \\
\hline \multirow{2}{*}{$\begin{array}{l}\text { F6: Critical perception of } \\
\text { chicken farming }\end{array}$} & $0.22195^{*}$ & 0.03036 & 0.03607 & - \\
\hline & $(0.12949)$ & $(0.13383)$ & $(0.17031)$ & \\
\hline \multirow{2}{*}{$\begin{array}{l}\text { F7: Support dual-purpose } \\
\text { chicken }\end{array}$} & $-0.27674 * *$ & -0.20946 & $-0.49654 * * *$ & - \\
\hline & $(0.13628)$ & $(0.14118)$ & $(0.17097)$ & \\
\hline \multirow[t]{2}{*}{ Pet ownership } & $-0.42397 * *$ & $-0.70494 * * *$ & $-0.57466 * *$ & - \\
\hline & $(0.20502)$ & $(0.22378)$ & $(0.27913)$ & \\
\hline \multirow[t]{2}{*}{ Buying organic food } & $-0.47278^{*}$ & $0.90807 * * *$ & 0.39293 & - \\
\hline & $(0.26872)$ & $(0.23442)$ & $(0.30632)$ & \\
\hline
\end{tabular}

$20.4 \%$ of the respondents are assigned to the second segment, which can be described as 'environmentalists', because the respondents have a high preference for large organic eggs and the most positive value for the 'ecological awareness' factor. The price parameter within this segment is not significant. Compared to the other segments, the 'rejection of killing day-old chicks' is the lowest in this segment. The probability of class 2 membership is increased by not having pets, and displaying organic food buying behaviour. The third segment can be described as 'opponents of dual-purpose chickens' and makes up $13.5 \%$ of the respondents. This segment has the most negative preference for eggs from dualpurpose chickens, and also the most negative attitude towards dual-purpose chickens. At the same time, respondents within this segment have the highest preference for eggs from a local origin and the highest consent for the 'acceptance of the current system' factor. The parameter of the factor affordability is negative, and the price parameter is positive. The third segment derives the highest utility from extra-large small-scale free-range eggs. The last segment has the strongest preference for eggs from dual-purpose chickens and eggs from small-scale free-range farms. Compared to the other segments, this class supports dual-purpose chickens the most, and also shows more 'quality awareness'. Compared to the other groups, the killing of day old chicks is more frequently rejected. Therefore, it was named 'supporters of dual-purpose chickens', and it includes $25.3 \%$ of the respondents. 
Table 4: Willingness to pay estimates (€) (6 eggs)

\begin{tabular}{|c|c|c|c|c|}
\hline & $\begin{array}{l}\text { Segment 1 } \\
(40.8 \%) \\
\text { Price-conscious } \\
\text { consumers }\end{array}$ & $\begin{array}{l}\text { Segment } 2 \\
(20.4 \%) \\
\text { Environmentalists }\end{array}$ & $\begin{array}{l}\text { Segment } 3 \\
(13.5 \%) \\
\text { Opponents of } \\
\text { dual-purpose } \\
\text { chickens }\end{array}$ & $\begin{array}{l}\text { Segment } 4 \\
(25.3 \%) \\
\text { Supporters of } \\
\text { dual-purpose } \\
\text { chickens }\end{array}$ \\
\hline Barn-laid eggs & Base level & Base level & Base level & Base level \\
\hline Free-range eggs & $\begin{array}{l}0.07 * * * \\
(0.02 ; 0.13)\end{array}$ & $\begin{array}{l}-14.54 \\
(-80.75 ; 51.66)\end{array}$ & $\begin{array}{l}-1.15 \\
(-2.71 ; 0.41)\end{array}$ & $\begin{array}{l}0.94 * * * \\
(0.67 ; 1.21)\end{array}$ \\
\hline $\begin{array}{l}\text { Small-scale free-range } \\
\text { eggs }\end{array}$ & $\begin{array}{l}0.06 * * * \\
(0.24 ; 0.10)\end{array}$ & $\begin{array}{l}3.41 \\
(-12.71 ; 19.52)\end{array}$ & $\begin{array}{l}-2.10^{*} \\
(-4.43 ; 0.24)\end{array}$ & $\begin{array}{l}1.62 * * * \\
(1.21 ; 2.03)\end{array}$ \\
\hline Organic & $\begin{array}{l}-0.03939 \\
(-0.87 ; 0.01)\end{array}$ & $\begin{array}{l}42.72 \\
(-148.42 ; 233.87)\end{array}$ & $\begin{array}{l}3.34 * \\
(-0.29 ; 6.96)\end{array}$ & $\begin{array}{l}-0.76 * * * \\
(-1.07 ;-0.44)\end{array}$ \\
\hline Small size & Base level & Base level & Base level & Base level \\
\hline Medium size & $\begin{array}{l}-0.01 \\
(-0.45 ; 0.02)\end{array}$ & $\begin{array}{l}3.61 \\
(-13.23 ; 20.44)\end{array}$ & $\begin{array}{l}0.27 \\
(-0.83 ; 1.37)\end{array}$ & $\begin{array}{l}-0.10 \\
(-0.37 ; 0.18)\end{array}$ \\
\hline Large size & $\begin{array}{l}0.06 * * \\
(0.13 ; 0.10)\end{array}$ & $\begin{array}{l}5.10 \\
(-18.48 ; 28.68)\end{array}$ & $\begin{array}{l}-0.94 \\
(-2.18 ; 0.31)\end{array}$ & $\begin{array}{l}0.41 * * * \\
(0.17 ; 0.64)\end{array}$ \\
\hline Extra-large size & $\begin{array}{l}0.09 * * * \\
(0.04 ; 0.14)\end{array}$ & $\begin{array}{l}-4.38 \\
(-25.92 ; 17.16)\end{array}$ & $\begin{array}{l}-1.19 * \\
(-2.58 ; 0.21)\end{array}$ & $\begin{array}{l}0.16^{*} \\
(-0.03 ; 0.35)\end{array}$ \\
\hline No dual-purpose chicken & Base level & Base level & Base level & Base level \\
\hline Dual-purpose chicken & $\begin{array}{l}-0.02 * \\
(-0.05 ; 0.00)\end{array}$ & $\begin{array}{l}2.88 \\
(-9.96 ; 15.72)\end{array}$ & $\begin{array}{l}2.15 * * \\
(0.13 ; 4.18)\end{array}$ & $\begin{array}{l}0.76 * * * \\
(0.57 ; 0.95)\end{array}$ \\
\hline German origin & Base level & Base level & Base level & Base level \\
\hline Local origin & $\begin{array}{l}0.03 * * * \\
(0.15 ; 0.05)\end{array}$ & $\begin{array}{l}6.40 \\
(22.54 ; 35.33)\end{array}$ & $\begin{array}{l}-1.73 * * \\
(-3.44 ;-0.02)\end{array}$ & $\begin{array}{l}0.31 * * * \\
(0.18 ; 0.44)\end{array}$ \\
\hline
\end{tabular}

The WTP for egg attributes within the latent classes are presented in Table 4. The 'priceconscious consumers' would pay the highest price premium for extra-large eggs (€0.09) from free-range-farms (€0.06) and an extra $€ 0.03$ for eggs of a local origin. This segment is not willing to pay a premium for eggs from dual-purpose chickens. The price coefficient for the 'environmentalists' is not significant, and therefore the WTP values of the corresponding attributes are also not significant. The price coefficient of the 'opponents of dual-purpose chickens' segment is positive. For this reason, we refrained from interpreting the WTP estimates of this segment. Eggs from dual-purpose chickens yield the highest WTP within the 'supporters of dual-purpose chickens' segment, at $€ 0.76$. This class is also willing to pay an extra $€ 1.62$ for eggs from small-scale free-range farms, and is willing to accept a $€ 0.67$ discount for organic eggs. For large eggs, they would be willing to pay a premium of $€ 0.41$ and for eggs of a local origin, a premium of $€ 0.31$. 


\subsubsection{Chicken Breast}

Models with two to six classes were estimated in order to find the best model. Table 5 shows the results.

Table 5: Class information (chicken breast experiment)

\begin{tabular}{cclllll}
\hline $\begin{array}{l}\text { Number of } \\
\text { classes }\end{array}$ & $\begin{array}{l}\text { Number of } \\
\text { parameters }\end{array}$ & $\begin{array}{l}\text { Log } \\
\text { likelihood at } \\
\text { convergence } \\
\text { (LL) }\end{array}$ & $\begin{array}{l}\text { Log } \\
\text { likelihood } \\
\text { evaluated at } \\
\text { 0 (LL0) }\end{array}$ & $\begin{array}{l}\text { Akaike's } \\
\text { information } \\
\text { criterion } \\
\text { (AIC) }\end{array}$ & $\begin{array}{l}\text { Bayesian } \\
\text { information } \\
\text { criterion } \\
\text { (BIC) }\end{array}$ & $\begin{array}{l}\text { McFadden } \\
\text { Pseudo } \\
\mathrm{R}^{2}\end{array}$ \\
\hline 2 & 20 & -5175.4 & -8328.9 & 10390.8 & 5262.4 & 0.38 \\
3 & 35 & -4837.1 & -8328.9 & 9744.2 & 4989.4 & 0.42 \\
$\mathbf{4}$ & $\mathbf{5 0}$ & $\mathbf{- 4 6 8 8 . 5}$ & $\mathbf{- 8 3 2 8 . 9}$ & $\mathbf{9 4 7 7 . 1}$ & $\mathbf{4 9 0 6 . 0}$ & $\mathbf{0 . 4 4}$ \\
5 & 65 & -4624.0 & -8328.9 & 9378.0 & 4906.8 & 0.44 \\
6 & 80 & -4576.2 & -8328.9 & 9312.5 & 4924.2 & 0.45 \\
\hline
\end{tabular}

A four class-model was seen as suitable as the BIC-value is the lowest in this model. Although the AIC-value is the lowest in the six class model, the four class model was chosen because it considerably improves the fit, as the marginal decrease of the AIC is the highest between classes three and four (Liljenstolpe, 2010).

Table 6: LCM model estimates (chicken breast experiment)

\begin{tabular}{|c|c|c|c|c|}
\hline & $\begin{array}{l}\text { Segment } 1 \\
(48.2 \%) \\
\text { Price- } \\
\text { conscious } \\
\text { consumers } \\
\text { (Standard } \\
\text { Error) } \\
\end{array}$ & $\begin{array}{l}\text { Segment } 2 \\
(14.4 \%) \\
\text { Environmenta } \\
\text { lists } \\
\text { (Standard } \\
\text { Error) }\end{array}$ & $\begin{array}{l}\text { Segment } 3 \\
(16.2 \%) \\
\text { Supporters of } \\
\text { dual-purpose } \\
\text { chickens } \\
\text { (Standard } \\
\text { Error) }\end{array}$ & $\begin{array}{l}\text { Segment } 4 \\
(21.2 \%) \\
\text { Opponents of } \\
\text { dual-purpose } \\
\text { chickens } \\
\text { (Standard } \\
\text { Error) }\end{array}$ \\
\hline Constant & $\begin{array}{l}0.01298 \\
(0.11693)\end{array}$ & $\begin{array}{l}0.11761 \\
(0.16356)\end{array}$ & $\begin{array}{l}0.10391 \\
(0.15217)\end{array}$ & $\begin{array}{l}0.25033 * * * \\
(0.08800)\end{array}$ \\
\hline Conventional & Base level & Base level & Base level & Base level \\
\hline Organic & $\begin{array}{l}0.38493 * * * \\
(0.04669)\end{array}$ & $\begin{array}{l}2.24622 * * * \\
(0.20401)\end{array}$ & $\begin{array}{l}0.33309 * * * \\
(0.06604)\end{array}$ & $\begin{array}{l}-0.21117 * * * \\
(0.03625)\end{array}$ \\
\hline Price & $\begin{array}{l}-2.02239 * * * \\
(0.09074)\end{array}$ & $\begin{array}{l}-0.52494 * * * \\
(0.04906)\end{array}$ & $\begin{array}{l}-0.45936 * * * \\
(0.03066)\end{array}$ & $\begin{array}{l}-0.23399 * * * \\
(0.01983)\end{array}$ \\
\hline $\begin{array}{l}\text { No dual-purpose } \\
\text { chicken }\end{array}$ & Base level & Base level & Base level & Base level \\
\hline Dual-purpose chicken & $\begin{array}{l}0.16655 * * * \\
(0.04643)\end{array}$ & $\begin{array}{l}0.19446 * * * \\
(0.05665)\end{array}$ & $\begin{array}{l}1.25723 * * * \\
(0.08989)\end{array}$ & $\begin{array}{l}-0.50831 * * * \\
(0.04087)\end{array}$ \\
\hline German origin & Base level & Base level & Base level & Base level \\
\hline Local origin & $\begin{array}{l}0.45346 * * * \\
(0.04999)\end{array}$ & $\begin{array}{l}0.52150 * * * \\
(0.08502)\end{array}$ & $\begin{array}{l}0.56033 * * * \\
(0.05670)\end{array}$ & $\begin{array}{l}0.44879 * * * \\
(0.03340)\end{array}$ \\
\hline F1: Quality awareness & $\begin{array}{l}-0.23716 * * \\
(0.11329)\end{array}$ & $\begin{array}{l}-0.31460 * \\
(0.16912)\end{array}$ & $\begin{array}{l}0.23243 \\
(0.16272)\end{array}$ & - \\
\hline $\begin{array}{l}\text { F2: Rejection of killing } \\
\text { day-old chicks }\end{array}$ & $\begin{array}{l}0.03267 \\
(0.11979)\end{array}$ & $\begin{array}{l}-0.32264 * \\
(0.18741)\end{array}$ & $\begin{array}{l}-0.22736 \\
(0.18292)\end{array}$ & - \\
\hline F3: Affordability & $\begin{array}{l}1.58763 * * * \\
(0.15257)\end{array}$ & $\begin{array}{l}-0.33072 * \\
(0.19378)\end{array}$ & $\begin{array}{l}-0.12475 \\
(0.18394)\end{array}$ & - \\
\hline $\begin{array}{l}\text { F4: Ecological } \\
\text { awareness }\end{array}$ & $\begin{array}{l}0.00767 \\
(0.12328)\end{array}$ & $\begin{array}{l}1.31508 * * * \\
(0.24283)\end{array}$ & $\begin{array}{l}0.49487 * * \\
(0.19860)\end{array}$ & - \\
\hline $\begin{array}{l}\text { F5: Acceptance of } \\
\text { current system }\end{array}$ & $\begin{array}{l}-0.51654 * * * \\
(0.11466)\end{array}$ & $\begin{array}{l}-0.67243^{* * *} \\
(0.15158)\end{array}$ & $\begin{array}{l}-0.99549 * * * \\
(0.14737)\end{array}$ & - \\
\hline
\end{tabular}




$\begin{array}{llll}\text { F6: Critical perception } & -0.04427 & -0.10452 & -0.05877 \\ \text { of chicken farming } & (0.11223) & (0.15439) & (0.14488) \\ \text { F7: Support dual- } & 0.40141 * * * & 0.46564 * * * & 0.85608 * * * \\ \text { purpose chicken } & (0.11677) & (0.13946) & (0.15264) \\ \text { Pet Ownership } & 0.00255 & -0.15812 & -0.04097 \\ & (0.18267) & (0.25847) & (0.24419) \\ \text { Buying organic food } & -0.98784 * * * & 0.58456 * * & 0.10402 \\ & (0.24384) & (0.27152) & (0.26791)\end{array}$

$* * *, * *, *=$ Significance at $1 \%, 5 \%, 10 \%$ level

As shown in Table 6, nearly half of the respondents (48.2\%) were assigned to the first segment, characterised by a high preference for affordability, negative organic food buying behaviour and the most negative price parameter. The segment is therefore named 'priceconscious consumers'. Within this segment, a preference was observed for chicken meat from dual-purpose chickens over conventional meat, and support for dual-purpose chickens was also positive. The second segment, 'the environmentalists', accounts for $14.4 \%$ of the respondents and is characterised by the highest consent for ecological awareness, high organic food buying behaviour and the highest acceptance of the current system when compared to other segments. The affordability and quality awareness factors are negative, and the 'environmentalists' derive a utility from chicken breast meat from dual-purpose chickens. $16.2 \%$ of the respondents belong to the third segment, which is labelled 'supporters of dual-purpose chickens'. Compared to the other segments, it has the highest preference for chicken breast from dual-purpose chickens and locally produced meat, and the highest agreement with 'support for dual-purpose chickens'. 'Acceptance of the current system' is lowest in this class. $21.2 \%$ of respondents have been assigned to the fourth segment, characterised by a negative attitude towards dual-purpose chickens and therefore labelled 'opponents of dual-purpose chickens'. Compared to the other segments, this segment has a negative preference for organic chicken breast and the most negative preference for meat from dual-purpose chickens. All the segments have a similar preference for chicken breast from a local origin over chicken breast from Germany.

Table 7: Willingness to pay estimates $(€)(250 \mathrm{~g}$ chicken breast meat)

\begin{tabular}{|c|c|c|c|c|}
\hline & $\begin{array}{l}\text { Segment 1 } \\
(48.2 \%) \\
\text { Price-conscious } \\
\text { consumers }\end{array}$ & $\begin{array}{l}\text { Segment } 2 \\
(14.4 \%) \\
\text { Environmentalists }\end{array}$ & $\begin{array}{l}\text { Segment } 3 \\
(16.2 \%) \\
\text { Supporters of } \\
\text { dual-purpose } \\
\text { chickens }\end{array}$ & $\begin{array}{l}\text { Segment } 4 \\
(21.2 \%) \\
\text { Opponents of } \\
\text { dual-purpose } \\
\text { chickens }\end{array}$ \\
\hline $\begin{array}{l}\text { Conventional } \\
\text { Organic }\end{array}$ & $\begin{array}{l}\text { Base level } \\
0.19 * * * \\
(0.15 ; 0.23)\end{array}$ & $\begin{array}{l}\text { Base level } \\
4.28 * * * \\
(3.64 ; 4.91)\end{array}$ & $\begin{array}{l}\text { Base level } \\
0.73 * * * \\
(0.42 ; 1.04)\end{array}$ & $\begin{array}{l}\text { Base level } \\
-0.90 * * * \\
(-1.22 ;-0.58)\end{array}$ \\
\hline $\begin{array}{l}\text { No dual-purpose chicken } \\
\text { Dual-purpose chicken }\end{array}$ & $\begin{array}{l}\text { Base level } \\
0.08 * * * \\
(0.04 ; 0.13)\end{array}$ & $\begin{array}{l}\text { Base level } \\
0.37 * * * \\
(0.15 ; 0.59)\end{array}$ & $\begin{array}{l}\text { Base level } \\
2.74 * * * \\
(2.25 ; 3.22)\end{array}$ & $\begin{array}{l}\text { Base level } \\
-2.17 * * * \\
(-2.64 ;-1.70)\end{array}$ \\
\hline $\begin{array}{l}\text { German origin } \\
\text { Local origin }\end{array}$ & $\begin{array}{l}\text { Base level } \\
0.22 * * * \\
(0.18 ; 0.27)\end{array}$ & $\begin{array}{l}\text { Base level } \\
0.99 * * * \\
(0.65 ; 1.34)\end{array}$ & $\begin{array}{l}\text { Base level } \\
1.22 * * * \\
(0.96 ; 1.48)\end{array}$ & $\begin{array}{l}\text { Base level } \\
1.92 * * * \\
(1.50 ; 2.33)\end{array}$ \\
\hline
\end{tabular}

$* * *, * *, *=$ Significance at 1\%,5\%,10\% level; $95 \%$ confidence intervals are indicated in parentheses. 
As we can see from Table 7, all the estimates are highly significant. As expected, the 'price-conscious consumers' are willing to pay the lowest price for chicken breast meat of local origin (€0.22). For meat from dual-purpose chickens, they would be willing to pay a premium of $€ 0.08$, and for organic chicken breast $€ 0.19$. The organic claim yields the highest WTP in the 'environmentalists' class (€4.28). This segment is also willing to pay an extra $€ 0.37$ chicken breast meat from dual-purpose chickens, and $€ 0.99$ for the local claim. At $€ 2.74$, 'supporters of dual-purpose chickens' are willing to pay the highest price premium for chicken breast meat from dual-purpose chickens. Additionally, they are willing to pay an extra $€ 0.73$ for organic and $€ 1.22$ for local chicken breast meat. The 'opponents of dual-purpose chickens' are willing to accept a €2.17 discount for chicken breast meat from dual-purpose chickens, and a $€ 0.90$ discount for organic meat over conventional chicken breast meat. For a local origin, this segment is willing to pay the highest price premium, $€ 1.92$.

\section{Discussion}

This study about German consumers' preferences and willingness to pay for eggs and meat from dual-purpose chickens revealed consumer heterogeneity, something also observed in previous studies dealing with chicken meat and eggs (Pouta et al., 2010; Van Loo et al., 2011; Hasselbach \& Roosen, 2015). Regarding eggs and chicken breast meat, four consumer segments were identified each. The findings show that the largest segments for both products are price-conscious consumers. Segments which include environmentalists and supporters as well as opponents of dual-purpose chickens were also identified. For both products, it was observed that local sources were highly preferred. This fits the results of other studies, e.g. Gracia et al. (2013) or Hasselbach \& Roosen (2015). The findings show that preferences for organic products are highest under habitual organic buyers. This was also revealed by Van Loo et al. (2011).

Regarding eggs, Norwood \& Lusk (2011) demonstrated that consumers value animal living conditions and therefore preferred eggs from avian or pasture systems over caged eggs. These finding correspond with our results, that show a preference for free-range and organic eggs over barn-laid eggs. In the case of eggs, our results suggest that the segment with a supportive attitude towards dual-purpose chickens, which accounts for $25.3 \%$ of the respondents, has a WTP of $€ 0.76$ for six eggs from dual-purpose chickens. According to results found by Diekmann et al. (2017), a surcharge of 2.19 cents per egg is needed to cover additional costs. Therefore, the WTP for eggs from dual-purpose chickens within this segment is considerably higher than the surcharge expected. Additionally, this segment has the highest WTP for eggs from small-scale free-range farms (€1.62). Contrary to expectations, this class would not be willing to pay a premium for organic eggs but would be willing to pay a premium of $€ 0.31$ for local eggs. These findings correspond with Andersen (2011), who found out that consumers perceive free-range and organic eggs very similarly. The positive price parameter in the segment 'opponents of dual-purpose chickens' in the case of eggs could be attributed to refusal attitudes of the respondents or lexicographic preferences. The number of attributes and levels was higher for eggs than for 
the chicken breast meat which might have caused complexity. In this case, respondents might have answered inattentively or used lexicographic decision rules which implicates that the respondents always choose the best or worse alternative with respect to one attribute instead of making trade-offs between the alternatives (Campbell et al., 2006; Carlsson, 2011).

Regarding chicken breast meat, the 'supporters of dual-purpose chickens' segment, which includes $16.2 \%$ of respondents, has the highest WTP at $€ 2.47$ for $250 \mathrm{~g}$ of chicken breast meat. In accordance with Damme (2015), the meat from dual-purpose chickens would be $40 \%$ more expensive than conventional broiler meat. A surcharge of $€ 2.47$ for $250 \mathrm{~g}$ chicken breast meat would only marginally cover the additional costs for rearing the male dual-purpose chickens. Additionally, it should be considered that the WTP is often overstated by participants and therefore, the expected WTP in the market would be even lower (Gerini et al., 2016). The 'environmentalists' (14.4\%) would pay a premium of $€ 0.37$ and the 'price-conscious consumers' $(48.2 \%)$ would pay a premium of $€ 0.08$ for meat from dual-purpose chickens. The 'supporters of dual-purpose chickens' would also be willing to spend $€ 1.22$ for the local claim and $€ 0.73$ for the organic claim.

Our results provide indications for the potential marketability of the eggs and chicken breasts of dual-purpose chickens. There are small consumer segments with clear preferences for products from dual-purpose chickens which should be directly addressed. The findings show that, regarding eggs, the supportive segment includes $25.3 \%$ of the respondents and is therefore much bigger than the supportive segment regarding chicken meat, $16.2 \%$ of the respondents. Consequently, eggs from dual-purpose chickens imply bigger marketing opportunities than chicken breast meat from dual-purpose chickens. These results support the findings from Gangnat et al. (2018), in which they indicate that the WTP for eggs from dual-purpose chickens was declared to be generally higher for eggs than for meat. With regard to dual-purpose chicken meat, it can be expected that the marketability of half or even whole chickens could be even more difficult, as consumers prefer to buy cuts such as chicken breast fillet (Kennedy et al., 2004). For both products, our results indicate that respondents with a supportive attitude towards dual-purpose chickens also value better husbandry conditions and local origin. These segments do not necessarily belong to the conventional organic consumers. In further research, the robustness of the data could be tested with experimental auctions as the validation with real market data seems unforeseeable in the near future.

\section{Conclusions}

The usage of dual-purpose chickens is currently being discussed as an alternative to the killing of day-old chicks. Apart from aspects such as animal welfare and economic efficiency, consumer acceptance of dual-purpose chickens plays an essential role in potential marketability. In order to analyse consumer perspectives on dual-purpose chickens, a mixed methods approach was applied. In an explorative first step, six focus groups were used. The results from the focus groups served as basis for a nearly representative online survey in Germany, with 1,502 respondents. A total of seven factors that explained the attitudes of consumers towards dual-purpose chickens were identified. 
Additionally, a discrete choice experiment was performed, including four choice sets with eggs, and four with chicken breasts. Applying the latent class model to analyse the preferences of a near-representative selection of German chicken meat and egg consumers has pointed out heterogenous consumer segments. Regarding eggs and chicken breast meat, four consumer segments were identified. The findings show that the largest segments for both products were price-conscious consumers, but smaller segments were also identified, which showed clear preferences and a WTP for eggs and meat from dualpurpose chickens. In this case, the segment which supports dual-purpose chicken meat is considerably smaller than the segment which supports eggs from dual-purpose chickens. It was also observed that for both products, localness was strongly preferred. These findings should be considered when the suitability of dual-purpose chickens is discussed as alternative to the culling of day-old chicks.

\section{Acknowledgements}

This study is part of the interdisciplinary research project "SocialLab - Nutztierhaltung im Spiegel der Gesellschaft". The project is funded by the Federal Ministry of Food and Agriculture (BMEL) by decision of the German Bundestag. Within the innovation funding the project is managed by the Federal Office for Food and Agriculture (BLE). The authors would like to thank the colleagues from the Integhof project for useful and constructive comments during various phases of the research. 


\section{References}

Andersen, L. M. (2011). Animal Welfare and Eggs - Cheap Talk or Money on the Counter? Journal of Agricultural Economics, 62(3), 565-584. https://doi.org/10.1111/j.14779552.2011.00310.x.

BLE - Bundesanstalt für Landwirtschaft und Ernährung (2017a). Deutsche essen 8 kg weniger Fleisch als vor 20 Jahren.

http://www.ble.de/SharedDocs/Pressemitteilungen/DE/2017/170330_Fleisch.html Accessed 10 April 2017.

BLE - Bundesanstalt für Landwirtschaft und Ernährung (2017b). Jeder Deutsche isst 235 Eier pro Jahr. https://www.ble.de/SharedDocs/Pressemitteilungen/DE/2017/170317_Eier.html Accessed 10 April 2017.

BMEL - Bundesministerium für Ernährung und Landwirtschaft (2018). Alternativen zum Töten männlicher Küken.https://www.bmel.de/DE/Tier/Tierwohl/_texte/Tierwohl-ForschungIn-Ovo.html Accessed 20 December 2018.

Boxall, P. C. \& Adomowicz, W. L. (2002). Understanding Heterogenous Preferences in Random Utility Models: A Latent Class Approach. Environmental and Resource Economics, 23(4), 421-446.

Campbell, D., Hutchinson W. G. \& Scarpa, R. (2006). Lexicographic Preferences in Discrete Choice Experiments: Consequences on Individual-Specific Willingness to Pay Estimates. FEEM working papers "Note di lavoro" series 128.

Carlsson, F. (2011). Non-Market Valuation: Stated Preference Methods. In J. L. Lusk, J. Roosen, \& J. F. Shogren (Eds.), The Oxford Handbook of the Economics of Food Consumption and Policy (pp. 181-214). Oxford: Oxford University Press.

Creswell, J. W. \& Clark, V. L. P. (2011). Designing and conducting mixed methods research. (2nd ed.). Thousand Oaks, CA: Sage Publications.

Damme, K. (2015). Economics of Dual-Purpose Breeds - a comparison of meat and egg production using dual purpose breeds versus conventional broiler and layer strains. LOHMANN Information, 50(2), 4-9.

Diekmann, J., Hermann, D. \& Mußhoff, O. (2017). Wie hoch ist der Preis auf Kükentötungen zu verzichten? Bewertung des Zweinutzungshuhn- und Bruderhahnkonzepts als wirtschaftliche Alternative zu Mast- und Legehybriden. Berichte über Landwirtschaft. Zeitschrift für Agrarpolitik und Landwirtschaft, 95, 1-23.

Faucitano, L., Martelli, G., Nannoni, E. \& Widowski, T. (2017). Fundamentals of Animal Welfare in Meat Animals and Consumer Attitudes to Animal Welfare. In P. P. Purslow (Eds.), New Aspects of Meat Quality: From Genes to Ethics (pp. 537-568). Woodhead Publishing.

Gangnat, I., Mueller, S., Kreuzer, M., Messikommer, R. E., Siegrist, M. \& Visschers, V. (2018). Swiss consumers' willingness to pay and attitudes regarding dual-purpose poultry and eggs. Poultry Science, 97(3), 1089-1098. http://dx.doi.org/10.3382/ps/pex397.

Gerini, F., Alfnes, F. \& Schjøll, A. (2016). Organic- and Animal Welfare-labelled Eggs: Competing for the Same Consumers? Journal of Agricultural Economics, 67(2), 471-490. https://doi.org/10.1111/1477-9552.12154. 
Gracia, A.; Barreiro-Hurlé, J. \& López-Galán, B. (2013). Are Local and Organic Claims Complements or Substitutes? A Consumer Preferences Study for Eggs. Journal of Agricultural Economics, 65(1), 49-67. https://doi.org/10.1111/1477-9552.12036.

Grashorn, M. (2013). Verwendung der männlichen Küken der Legeherkünfte. http://www.wing vechta.de/themen/verwendung_der_maennlichen_legeherkuenfte/verwendung_der_m_nn lichen_k_ken_der_legeherk_nfte.html Accessed 15 May 2016.

Grunert, G. (2005). Food Quality and Safety: Consumer Perception and Demand. European Review of Agricultural Economics, 32(3), 369-391. https://doi.org/10.1093/eurrag/jbi011.

Guyonnet, V. (2012). Eggs and egg products: Consumers' attitudes, perceptions and behaviours. XXIV World's Poultry Congress, Salvador, Brazil.

Hair, J. F., Black, W. C., Babin, B. J. \& Anderson, R. E. (2010). Multivariate Data Analysis. (7th ed.). Upper Saddle River, New Jersey: Pearson.

Hasselbach, J.L. \& Roosen, J. (2015). Consumer Heterogeneity in the Willingness to Pay for Local and Organic Food. Journal of Food Products Marketing, 21(6), 608-625. https://doi.org/10.1080/10454446.2014.885866.

Heng, Y., Peterson, H. \& Li, X. (2013). Consumer Attitudes towards Farm-Animal Welfare: The Case of Laying Hens. Journal of Agricultural and Resource Economics, (38)3, 418-434.

Hensher, D. H.; Rose, J. M. \& Greene, W. H. (2015). Applied choice analysis. (2nd ed.). Cambridge University Press.

Hole, A. R. (2007). A comparison of approaches to estimating confidence intervals for willingness to pay measures. Health Economics, 16(8), 827-840. https://doi.org/10.1002/hec.1197.

Hüttner, M. \& Schwarting, U. (2002). Grundzüge der Marktforschung. (6th ed.). München: Oldenbourg Wissenschaftsverlag.

Kaufmann, F., Nehrenhaus, U. \& Andersson, R. (2016). Das Duale Huhn. Der Verbraucher müsste umdenken. DGS, 35, 22-25.

Kennedy, O. B., Stewart-Knox, B. J., Mitchell, P. C. \& Thurnham, D. I. (2004). Consumer perceptions of poultry meat: a qualitative analysis. Nutrition \& Food Science, 34(3), 122129. https://doi.org/10.1108/00346650410536746.

König, M., Hahn, G., Damme, K. \& Schmutz, M. (2012). Utilization of laying-type cockerels as „coquelets": Influence of genotype and diet characteristics on growth performance and carcass composition. Archiv für Geflügelkunde, 76(3), 197-202.

Lancaster, K. J. (1966). A New Approach to Consumer Theory. Journal of Political Economy, 74(2), 132-157.

Liljenstolpe, C. (2011). Demand for value-added pork in Sweden: a latent class model approach. Agribusiness, (27)2, 129-146. https://doi.org/10.1002/agr.20262.

List, J. A. \& Gallet, C. A. (2001). What Experimental Protocol Influence Disparities Between Actual and Hypothetical Stated Values? Environmental and Resource Economics, 20(3), 241-254. https://doi.org/10.1023/A:1012791822804.

Lu, Y., Cranfied, J. \& Widowski, T. (2013 August). Consumer Preference for Eggs from Enhanced Animal Welfare Production System: A Stated Choice Analysis. Selected Paper prepared 
for presentation at the Agricultural \& Applied Economics Associations. AAEA \& CAES Joint Annual Meeting, Washington, DC.

McFadden, D. L. (1974). Conditional Logit Analysis of Qualitative Choice Behavior. In P. Zarembka (Eds.), Frontiers in Econometrics (pp. 105-142). New York: Academic Press.

Mueller, S., Kreuzer, M., Siegrist, M., Mannale, K., Messikommer, R. E. \& Gangnat, I. D. M. (2018). Carcass and meat quality of dual-purpose chickens (Lohmann Dual, Belgian Malines, Schweizerhuhn) in comparison to broiler and layer chicken types. Poultry Science, 7(9), 3325-3336. https://doi.org/10.3382/ps/pey172.

Napolitano, F., Girolami, A. \& Braghieri, A. (2010). Consumer liking and willingness to pay for high welfare animal-based products. Trends in Food Science \& Technology, 21(11), 537543. https://doi.org/10.1016/j.tifs.2010.07.012.

Norwood, B. \& Lusk, J. (2011). A Calibrated Auction-Conjoint Valuation Method: Valuing Pork and Eggs Produced Under Differing Animal Welfare Conditions. Journal of Environmental Economics and Management, 62(1), 80-94. https://doi.org/10.1016/j.jeem.2011.04.001.

Parker, J. P. \& Schrift, Y. (2011). Rejectable Choice Sets: How Seemingly Irrelevant No-Choice Options Affect Consumer Decision Processes. Journal of Marketing Research, 48(5), 840-854. https://doi.org/10.1509/jmkr.48.5.840.

Pouta, E., Heikkilä, J., Forsman-Hugg, S., Isoniemi, M. \& Mäkelä, J. (2010). Consumer choice of broiler meat: The effects of country of origin and production methods. Food Quality and Preference, 21(5), 539-546. https://doi.org/10.1016/j.foodqual.2010.02.004.

Rautenschlein, S. (2016). Einsatz des Zweinutzungshuhns in Mast und Eierproduktion: Ansätze für ein integriertes Haltungskonzept. Rundschau für Fleischhygiene und Lebensmittelüberwachung (RFL), 68(8), 276-278.

Ritchie, J., Lewis, J., McNaughton Nicholls, C. \& Ormston, R. (2014). Qualitative Research Practice. A Guide for Social Science Students and Researchers. (2nd ed.). London: Sage Publications.

Schjøll, A., Borgen, S. O. \& Alfnes, F. (2013). Consumer preference for animal welfare when buying eggs. Professional report No. 1-2013. http://www.hioa.no/eng/AboutHiOA/Centre-for-Welfare-and-Labour-Research/SIFO/Publications-fromSIFO/Consumer-preference-for-animal-welfare-when-buying-eggs Accessed 1 October 2018.

Siekmann L., Meier-Dinkel, L., Janisch, S., Altmann, B., Kaltwasser, C., Sürie, C. \& Krischek, C. (2018). Carcass Quality, Meat Quality and Sensory Properties of the Dual-Purpose Chicken Lohmann Dual. Foods, 7(10). https://dx.doi.org/10.3390\%2Ffoods7100156.

Sossidou, E. \& Elson, H. (2009). Hens' welfare to egg quality: A European perspective. World's Poultry Science Journal, 65(4), 709-718. https://doi.org/10.1017/S0043933909000488.

Train, K. (2003). Discrete Choice Methods with Simulation. Cambridge: Cambridge University Press.

Van Loo, E. J., Caputo, V., Nayga, R. M., Meullenet, J. F. \& Ricke, S. C. (2011). Consumers' willingness to pay for organic chicken breast: Evidence from choice experiment. Food Quality and Preference, 22(7), 603-613. https://doi.org/10.1016/j.foodqual.2011.02.003. 
Van Loo, E. J.; Caputo, V.; Nayga, R. \& Verbeke, W. (2014). Consumers' valuation of sustainability labels on meat. Food Policy, 49(1), 137-150. https://doi.org/10.1016/j.foodpol.2014.07.002.

Vanhonacker, F. \& Verbeke, W. (2009). Buying higher welfare poultry products? Profiling Flemish consumers who do and do not. Poultry Science, 88(12), 2702-2711. https://doi.org/10.3382/ps.2009-00259.

Verbeke, W. \& Viaene, J. (2000). Ethical challenges for livestock production: Meeting consumer concerns about meat safety and animal welfare. Journal of Agricultural \& Environmental Ethics, 12(2), 141-151. https://doi.org/10.1023/A:1009538613588. 


\subsection{Dual purpose chickens as alternative to the culling of day-old chicks - the ethical perspective}

Nanke Brümmer, Inken Christoph-Schulz and Anja-Karolina Rovers

Eursafe Conference Proceedings: Professionals in food chains. Ed. by S. Springer and H. Grimm (2018). 141-145.

(With kind permission of Wageningen Academic Publishers, Wageningen)

Declaration of originality: The author developed the idea for this paper and wrote the raw manuscript. The results were based, to some extent, on the findings from the focus groups that were conducted by all three authors. The authors discussed the results and Dr. Inken Christoph-Schulz revised the manuscript. 


\title{
20. Dual-purpose chickens as alternative to the culling of day-old chicks - the ethical perspective
}

\author{
N. Brümmer ${ }^{*}$ I. Christoph-Schulz and A. Rovers \\ Thünen Institute of Market Analysis, Bundesallee 63, 38116 Braunschweig, Germany; \\ nanke.bruemmer@thuenen.de
}

\begin{abstract}
This paper considers the ethical evaluation of dual-purpose chickens as an important prerequisite for societal acceptance. According to several studies, chicken farming is seen as one of the most controversial forms of livestock farming due to e.g. the common practice of culling day-old chicks. In 2016, an administrative court in Germany decided that the killing of the male chicks does not violate animal welfare legislation and is permitted for economic reasons. Within the society, this ruling was broadly discussed and largely rejected for ethical reasons. One alternative to the culling of day-old chicks are dual-purpose chicken breeds. These breeds can do both: the hens lay eggs and the cockerels put on meat. But the hens lay fewer and smaller eggs and the cockerels need more time and feed to grow. The ethical evaluation of the topic for this paper has been conducted in six focus groups. In addition, important stakeholders have been identified through a comprehensive literature study. The ethical matrix according to Mepham is a tool of applied ethics for the interpretation of the interests of stakeholders with regard to ethical principles. The matrix is based on the three ethical principles of well-being, autonomy and justice. The aim is to present a well-balanced consideration from different angles and thus to reduce the complexity of the topic. Usually, an innovation is compared with the status quo. In this case: the keeping of dual-purpose chickens with the current practice (culling of day-old chicks). We applied the matrix to five interest groups: dual-purpose chickens, consumers, egg industry, farmers and environment. The results show that the topic dual-purpose chickens as alternative to the killing of day-old chicks is very complex and therefore requires a differentiated consideration of ethical aspects.
\end{abstract}

Keywords: ethics, ethical matrix, laying hens, day-old chicks, dual-purpose chickens

\section{Introduction}

Poultry farming is one of the most controversial discussed farming practices in livestock farming, besides criticized stocking densities and the use of antibiotics, also because of the common practice of day-old male chicks of laying breeds being culled directly after hatch (Verbeke et al., 2000; Leenstra et al., 2011). In 2016, the killing of day-old chicks was subject of a court ruling of the Higher Administrative Court of North Rhine-Westphalia (Federal State in Germany). The ruling states that killing day-old chicks does not violate the animal welfare legislation and is allowed for economic reasons because technical solutions are not ready for use yet (Beckmann, 2016; Oberverwaltungsgericht NRW, 20 A 488/15). The court decision started a public debate about the ethical aspects of this common practice in layer hens breeding. Currently, some alternatives to this practice are discussed. One alternative is the keeping of dual-purpose chickens. This is a chicken breed that is suitable for both, meat and egg production (Rautenschlein, 2016). Because of the negative correlation between meat growth and laying performance which engendered the specialization in chicken breeding, the dual-purpose hens and cockerels cannot compete with the performance of hybrid chickens (Grashorn, 2013). The hens of dual-purpose breeds lay fewer and smaller eggs and the cockerels put on less meat and need more time and feed to grow than conventional laying hens and broiler chickens (Damme, 2003; Koenig et al., 2011). As a consequence, meat and eggs from dual-purpose chickens would be correspondingly more expensive (Leenstra et al., 2010; Diekmann et al., 2017). These aspects have implications not only for consumers but also for other 


\section{Section 3}

stakeholder 'groups' such as the environment. Therefore, this article will focus on the ethical evaluation of dual-purpose chickens as an alternative to the culling of day-old male layer-chicks. According to Marie (2006), the consideration of ethical aspects in livestock farming is an important prerequisite for social acceptance and consequently also for the acceptance of animal products.

\section{Methods}

\section{Focus groups}

The ethical evaluation of the topic is based on six focus groups with the focus on dual-purpose chickens that were conducted with 6-8 participants each in June 2016 in three German places (Berlin, Cloppenburg and Munich). The participants were recruited regarding quotas by a market research agency and were consumers of chicken meat and eggs. The aim of focus groups is to create an atmosphere that fosters an almost natural conversation setting with diverse opinions and statements (Lamnek, 2005). Discussed topics were amongst others the killing of day-old chicks, potential alternatives and the advantages and disadvantages of dual-purpose chickens. The approximately 90-minute discussions were recorded, transcribed and then subjected to a qualitative content analysis. As ethical aspects were also discussed sufficiently in this context, the findings from the focus groups give a valuable input to the ethical evaluation of dual-purpose chickens.

\section{Ethical matrix}

The ethical matrix according to Mepham (2000a) is a tool of applied ethics for explaining the interests of affected groups in relation to ethical principles. The aim is to present a well-founded consideration from different perspectives and thus to reduce the complexity and to provide guidance in the evaluation of a topic (Zichy et al., 2014). The objective of an ethical matrix is not to provide decisions but to facilitate the ethical assessment. Participatory methods can encourage this evaluation in terms of fact finding (Kaiser and Forsberg, 2010; Schroder and Palmer, 2003). The ethical principles of well-being, autonomy and justice were identified by Beauchamp and Childress (1994) and are guided by the three main theories of ethics, namely utilitarianism (well-being), Kantianism (autonomy) and the contractualist theory of Rawls (justice). Usually, the ethical matrix compares an innovation with the status quo (Mepham, 2000a). In Table 1 the ethical matrix contains five stakeholder groups. These were identified by a comprehensive literature review. The stakeholder groups include: the chickens, the consumers as key actors when it comes to the market success of the products from the dual-purpose chickens, the egg and meat industry which has to deal with the changing product properties, the farmers who would have to adapt new husbandry forms and the environment which is affected by the higher resource consumption of dual-purpose cockerels (Bruijnis et al., 2015; Grashorn, 2013; Leenstra et al., 2010, 2011).

\section{Results}

\section{Chickens}

For the chickens, the usage of dual-purpose chicken breeds could imply wellbeing and autonomy if the husbandry is adapted to the needs and natural behaviour of the animals and if animal welfare measurements are taken. It could be argued as well that a longer fattening period of the cockerels has a positive effect on the wellbeing. The point that was mostly stressed in the focus groups was the fairness aspect. If the males could live as well and are not killed as day-old chicks, equality between both sexes is given. 
Table 1. Ethical matrix applied to the usage of dual-purpose chickens (adapted from Mepham, 2000b: 612).

\begin{tabular}{|c|c|c|c|}
\hline & Wellbeing & Autonomy & Justice \\
\hline Chickens & $\begin{array}{l}\text { Wellbeing of the animals } \\
\text { (presumes a good animal } \\
\text { husbandry) }\end{array}$ & $\begin{array}{l}\text { Freedom of behaviour (presumes a } \\
\text { good animal husbandry) }\end{array}$ & $\begin{array}{l}\text { Gender equality (rearing both } \\
\text { sexes) }\end{array}$ \\
\hline Consumers & Affordable and high quality food & $\begin{array}{l}\text { Freedom of choice between products } \\
\text { (informed purchase-decisions) }\end{array}$ & Availability of affordable food \\
\hline Egg and meat industry & Efficiency & $\begin{array}{l}\text { Freedom of choice to market dual- } \\
\text { purpose chickens }\end{array}$ & Fair trade and laws \\
\hline Farmers & $\begin{array}{l}\text { Good working conditions and } \\
\text { satisfying income }\end{array}$ & $\begin{array}{l}\text { Freedom of choice to keep dual- } \\
\text { purpose chickens }\end{array}$ & Fair trade and laws \\
\hline Environment & Nature conservation & Biodiversity & $\begin{array}{l}\text { Sustainability and responsible } \\
\text { use of resources }\end{array}$ \\
\hline
\end{tabular}

\section{Consumers}

The usage of dual-purpose chickens could affect consumers regarding all three ethical principles. If eggs and chicken meat become more expensive, the affordability of food could be affected. These assumptions depend on the question if dual-purpose chickens are implied nationwide or only exist in a niche market. If this is the case the consumers would have the autonomy to choose between different products provided that there is a clear labelling. Dual-purpose chickens could also have an effect on the consumption behaviour of the consumers because the appearance of meat and eggs is different to those from hybrid chickens.

\section{Egg and meat industry}

The transition to eggs and meat from dual-purpose chickens could have far reaching implications for the whole supply chain which has to be adapted to the differing properties of dual-purpose chickens starting from the slaughtering process (conventional slaughterhouses for broiler chickens turned out to be not suitable for dual-purpose cockerels) to the processing and marketing of the eggs and meat. The satisfaction of the principles wellbeing and autonomy strongly depends on the voluntary nature of the implication of dual-purpose chicken breeds.

\section{Farmers}

For the farmers who keep layer hens or broiler chickens the changeover to dual-purpose chickens would imply some changes in the husbandry system and management. If freedom of choice is granted depends on the legal ban of culling day-old chicks and the practicability of alternatives. Premise for the wellbeing of the farmers is that they generate enough income. Therefore, it would be important for the farmers that the dual-purpose chickens are economically profitable and fair trade laws exist.

\section{Environment}

The environment is also affected by the usage of dual-purpose chickens. Due to the fact that the cockerels are fattened almost twice as long as conventional broiler chickens until they reach a sufficient weight, more resources such as water and land for feed are needed. Additionally, more manure occurs which has 


\section{Section 3}

also an environmental impact. Therefore, the principles wellbeing and justice could be violated because nature conservation and sustainability are negatively affected.

\section{Conclusions}

The ethical matrix applied to the usage of dual-purpose chickens as alternative to the killing of day-old male chicks demonstrates that the issue has many different ethical facets and illustrates that there is a moral problem that cannot be easily solved. The implementation of dual-purpose chicken breeds could have on the one hand positive implications for the chickens itself if the husbandry conditions improve but on the other hand might negatively affect the environment and also endanger the availability of affordable food for consumers or a satisfying income for farmers. To finally assess the usage of dualpurpose chickens from an ethical perspective it is necessary to weight the single aspects. Therefore, the ethical matrix could serve as a basis for discussions between the different stakeholders. It is not intended to solve the ethical problem (Mepham, 2000a). A weighting between the different dimensions is necessary in the first place, e.g. the issue whether animal welfare should have priority. For further discussion, the outcome for chickens and the environment could be presented by the according animal rights groups and environmental organizations. This procedure enables a comprehensive fact finding and can be used by policy makers for a detailed consideration of the topic dual-purpose chickens as alternative to the culling of day-old chicks.

\section{References}

Beauchamp, T.L. and J.F. Childress (1994). Principles of Biomedical Ethics. Oxford University Press, New York and Oxford.

Beckmann, M. (2016). Über den vernünftigen Grund im Sinne des $₫ 1$ S. 2 TierSchG bei der Tötung von männlichen Eintagsküken. Natur und Recht 38 (6), 384-390.

Bruijnis, M.R.N., Blok, V., Stassen, E.N. and Gremmen, H.G.J. (2015). Moral 'Lock-In' in Responsible Innovation: The Ethical and Social Aspects of Killing Day-Old Chicks and Its Alternatives. In: Journal of Agricultural and Environmental Ethics 28(5): 939-960.

Damme K. (2003). Fattening performance, meat yield and economic aspects of meat and layer type hybrids. World's Poultry Science Journal 59: 50-53.

Diekmann, J., Hermann, D. and Mußhoff, O. (2017). Wie hoch ist der Preis auf Kükentöten zu verzichten? Bewertung des Zweinutzungshuhn- und Bruderhahnkonzept als wirtschaftliche Alternative zu Mast- und Legehybriden. In: Berichte über Landwirtschaft 95(1): 1-22.

Grashorn, M. (2013). Verwendung der männlichen Küken der Legeherkünfte., in: WING-Themen in der Geflügelhaltung, 15 Mai 2013, S.1-4.

Kaiser, M. and Forsberg, E.M. (2001). Assessing Fisheries - Using an Ethical Matrix in a Participatory Process. In: Journal of Agricultural and Environmental Ethics 14: 191-200.

Koenig, M., Hahn, G., Damme, K. and Schmutz, M. (2011). Utilization of laying-type cockerels as 'coquelets': Influence of genotype and diet characteristics on growth performance and carcass composition. In: Arch.Geflügelk. 76(3): 197- 202.

Lamnek, S. (2005). Gruppendiskussion. Theorie und Praxis. Weinheim: UTB.

Leenstra, F.R.; Munnichs, G.; Beekman, V.; Heuvel-Vromans, E. van den; Aramyan, L.H.; Woelders, H. (2011). Killing day old chicks? Public opinion regarding potential alternatives. In: Animal Welfare 20: 37-45.

Leenstra, F., van Horne, P. and Van Krimpen, M. (2010). Dual purpose chickens, exploration of technical, environmental and economical feasibility. XIIIth European Poultry Conference, Tours, France.

Marie, M. (2006). Ethics: The new challenge for animal agriculture. In: Livestock Science 103: 203-207.

Mepham, T.B. (2000a). A framework for the ethical analysis of novel foods: The ethical matrix. In: Journal of Agricultural and Environmental Ethics 12: 165-176.

Mepham, T.B. (2000b): The role of food ethics in food policy. In: Proceedings of the Nutrition Society 59 (4): 609-618. 
Rautenschlein, S. (2016). Einsatz des Zweinutzungshuhns in Mast und Eierproduktion: Ansätze für ein integriertes Haltungskonzept. In: Rundschau für Fleischhygiene und Lebensmittelüberwachung (RFL) 68(8): 276-278.

Schroeder, D. and Palmer, C. (2003). Technology assessment and the 'ethical matrix'. In: Poiesis \& Praxis 1(4): 295-307. Verbeke, W.A.J. and J. Viaene (2000). Ethical challenges for livestock production: Meeting consumer concerns about meat safety and animal welfare. In: Journal of Agricultural \& Envrionmental Ethics 12(2): 141-151.

Zichy, M., Dürnberger, C., Formowitz, B., Uhl, A. (2014). Energie aus Biomasse - ein ethisches Diskussionsmodell. Springer Vieweg, Wiesbaden. 


\section{Discussion}

In the following, the answers to the research questions that were raised at the beginning of this thesis, in order to depict consumers' perspectives on dual-purpose chickens in a differentiated way, are discussed against the background of the current literature.

$R Q$ 1: Are consumers aware of the killing of day-old male layer chicks and do they have moral concerns? What are consumers' ethical evaluations of dual-purpose chickens as an alternative to the culling of day-old male layer chicks?

Moral issues are often mentioned in relation to the culling of day-old chicks, as it is frequently seen as unacceptable that millions of male chicks are culled directly after hatching, simply for economic reasons. This is the reason why alternatives to this practice are being promoted by representatives from agriculture, economics and politics. Since consumers play a key role in the potential implementation of dual-purpose chicken breeds, it is important to learn how consumers perceive this problem and if they have moral concerns that are reflected in their attitudes and potential purchasing behaviour.

The results of the focus groups in article (1) have shown that most of the participants stated that they knew about the practice of culling day-old male layer chicks. The topic was addressed in every focus group, without being mentioned by the moderator. Compared to the study by Leenstra et al. (2011) in which only $42 \%$ of the respondents knew about the killing of male chicks, our participants stated that they were mostly aware of the culling of day-old chicks. This could be attributed to the fact that the topic was present in the media at that time because of the court ruling dealing with the culling of male chicks. Regardless, many participants expressed their disgust at the culling of dayold chicks. Most of the participants agreed that the culling of chicks is clearly unacceptable from a moral point of view and they demanded this practice to be stopped. Others claimed that the chickens would be killed anyway and that it does not matter if it is sooner or later. Discussing these facts, the participants assumed that the culling of the day-old chicks was for profit. Additionally, the fact was mentioned that consumers could not change the situation because of a lack of market power compared to the food industry. These findings correspond with the results of a study by McEachern and Schröder (2002) and Weible et al. (2016) in which respondents delegated responsibilities to food retailers or to the government. Brujinis et al. (2015) described the dilemma in this context as a "moral lock-in", as there are path dependencies that are difficult and costly to leave and see this as an explanation for morally inferior technologies. 
The results demonstrate that ethical considerations are gaining in importance. According to Frank (2006), they can cause unusual economic behaviour and should be considered as a relevant attribute of goods. In this case, unusual economic behaviour means that consumers would not value chicken products more if less male day-old chicks were culled for that purpose. They would only pay a higher price for eggs and meat from chickens for which no male chicks were culled at all. As animal husbandry is discussed highly controversial between different actors, ethical consensus on animal husbandry but also on environmental aspects are a pre-condition for the acceptance of animal products and animal husbandry as a whole (Marie, 2006; Ohl and van der Staay, 2012; Vanhonacker et al., 2012).

Starting with the explorative approach of focus groups has been approved as an appropriate method, although socially desirable behaviour is likely to occur in the presence of other people (Smithson, 2007). This was also seen in the focus groups in which most of the participants claimed moral concerns; nevertheless, this result was not reflected to this extent in the findings of the online survey in articles (2) and (3). However, discussing a sensitive topic such as the culling of day-old chicks in a group setting enabled the participants to express their discomfort and their feelings, and to discuss and reflect upon this topic (Kitzinger and Farquhar, 1999).

The findings of this thesis underline the fact that respondents found themselves in a dilemma between a morally sound solution which prevents day-old male chicks from being culled and their own financial limitations. Many participants stated that the consumption of less meat that was produced under better husbandry conditions (e.g. organic meat) could be the solution to this financial conflict. Regarding the question of consumers' ethical evaluations of dual-purpose chickens as an alternative to the culling of day-old male layer chicks, the application of ethics in article (4) provided additional insights. The results reveal a wide range of complex ethical issues which cannot easily be solved. The implementation of dual-purpose chicken breeds might have positive implications for the chickens if husbandry conditions improve on the one hand but it might negatively affect the environment as more resources are needed for feed and more manure occurs as a result of a longer fattening period of the male chickens on the other hand. The use of dual-purpose chickens could also endanger the availability of affordable food for consumers or a satisfactory income for farmers. For ethical considerations, it is also important to determine whether the basic assumption is a ban on the culling of day-old chicks which might lead to widespread use of dual-purpose chicken breeds. Or if it is assumed that dual-purpose chickens serve as a niche product, to be set alongside a range of alternatives. Possible alternatives also require a detailed ethical evaluation since, 
for example, in-ovo sex determination on the 9th day of incubation is also questionable from a moral standpoint (Krautwald-Junghanns et al., 2017; Galli et al., 2018). However, results from the focus groups and the online survey suggest that respondents slightly prefer in-ovo sex determination to the use of dual-use chicken breeds. These findings are mirrored in a previous study by Leenstra et al. (2011).

The results of the focus groups in article (1) revealed that respondents focused on arguments related to their own behaviour, such as the affordability, taste and convenience of the products, and to issues related to the chickens, including ethical and animal welfare issues. Environmental aspects hardly played a role. These findings correspond with those published by Heng et al. (2013) and Gremmen et al. (2018). Luy et al. (2019) confirm that the desire to increase animal welfare is dominant in the case of conflicting goals between animal welfare and sustainability issues.

\section{RQ 2: What are consumers' reactions to the concept of dual-purpose chicken breeds and under which conditions would consumers buy products from dual- purpose chickens?}

As shown in article (1), few alternatives to the culling of day-old male chicks were known to the participants. Sex determination in the egg was one alternative that was named several times. Some participants also mentioned the fattening of layer-type males as a potential alternative to the culling of day-old chicks, whereas the use of dual-chicken breeds was not mentioned once. Hardly any participant had an idea of what was meant by "dual-purpose chicken". The participants agreed on the naming being inappropriate and causing misleading associations. The findings from the conducted focus groups, in which the concept of dual-purpose chickens was not known, and participants had difficulties understanding what was meant by this concept, were reflected in a study by Leenstra et al. (2011) who found that the evaluation of alternatives is very complex and respondents experienced difficulties to rank alternatives due to limited information.

Since the focus of this thesis is on consumers' perspectives on dual-purpose chickens, the concept of this chicken breed was explained to the participants at this stage of the discussion. Providing information in qualitative as well as in quantitative consumer studies is debatable as it potentially biases attitudes and beliefs (Ajzen et al, 1996; Gremmen et al., 2018). As illustrated in the focus groups, the concept of 'dual-purpose chickens' was not known to the participants. To discuss this alternative, it was necessary to provide information during the focus group discussions. This was achieved in form of a balanced information text identical in all discussions. However, it should be reflected that the 
provision of information has effects on study outcomes (Ajzen et al, 1996). In the online survey information were provided, too. Before respondents were facing the choice tasks, they received information on the product attributes. This was deliberately kept short to simulate a realistic shopping situation. In the further course of the online survey, the respondents were provided with more detailed information on dual-purpose chickens and other alternatives which they could only click away from after a certain time. In further research, the role of information could be studied in more detail. Especially for potential marketing strategies for products from dual-purpose chickens, it is important to learn what sort of labelling information is demanded by the consumers and which information might result in an increased acceptance and willingness to pay for these kinds of products.

After the presentation of the concept, the reactions were mostly positive, but concerns were also raised. The positive stated aspects were primarily ethical and moral ones related to the fact that the life of the males would be saved. Others presumed that the meat quality would be better, due to a longer fattening period and slower meat growth. The most frequent negative aspect named was the higher price for meat and eggs from the dual-purpose chickens. Some participants described a dilemma between saving the life of male chicks and having to pay more for chicken meat and eggs, which they saw as a conflict between moral aspects and a limited budget for food. Another aspect named was the presumption that the fattening of the cockerels would be economically inefficient. Only one participant remarked that too many resources would be used to produce this type of meat. Another important point that was stressed by some participants was the fear that genetic engineering would be used to breed dual-purpose chickens.

As focus groups are especially useful for research fields that have not yet been comprehensively investigated, the open and interpretative approach of qualitative methods is useful to detect new issues and to allow for deep insights into underlying values that are important to understand consumer behaviour (Finch and Lewis, 2003; Arnould and Thompson, 2005; Holzmüller and Buber, 2009). The focus groups allowed to explain existing alternatives to the culling of day-old chicks and revealed aspects that could not have been identified in a survey but are of great importance for the potential marketing of dual-purpose chickens. During the discussions it became clear that, for many participants, the avoidance of chick culling alone was insufficient to justify buying products from dual-purpose chickens. They would only do so if the husbandry conditions of these animals were improved at the same time. Examples of better husbandry conditions named were "good feed", "no antibiotics", "much more space" and "litter". Luy (2018) describes this phenomenon as a "fair deal" which is a sort of agreement between consumers and 
farm animals by which the fundamental ethical problem of killing and consuming farm animals becomes justifiable when the animals have a "good life" beforehand.

The labelling of origin was also stated as an important purchase criterion for some participants. In this context, indicating the farmer's address on the packaging was proposed. This was also shown by the results of the choice experiment in article (3) in which localness, for eggs and meat, was strongly preferred across all segments, as well as in similar studies (Gracia et al., 2013; Hasselbach and Roosen, 2015). Additionally, these results support the findings from previous studies that dealt with the increasing relevance of credence attributes which include aspects such as animal welfare, health issues and origin, and cannot directly be checked on the product (Grunert, 2005; Napolitano et al., 2010; Pouta et al., 2010).

The results from the focus groups underlined the fact that consumers generally prefer chicken cuts and seldom prepare a whole chicken, in some cases even expressed disgust at chicken carcasses. In this context, participants stated that they would not change their grocery shopping and consumption behavior in order to support the use of dual-purpose chickens which are unsuited for the marketing of meat cuts. This also goes hand in hand with the results found by Kennedy et al. (2004) and Stein (2015) which emphasise an alienation from the animal itself and the fact that chicken meat is often associated with convenience aspects. Some initiatives that fatten dual-purpose chicken cockerels or male layer-type chickens have taken up this aspect by marketing the meat of the cockerels in form of convenience products such as chicken curry (e.g. EZ Fürstenhof, 2019).

As expected, the product price was also mentioned as an important purchase criterion. The majority of respondents indicated that they would pay a premium for meat and eggs from "sympathy with the chicks" or to "eat meat with a clear conscience". However, this willingness to pay a premium was relativised by some discussants: "It depends on how much more I have to pay". In the case of eggs, some participants indicated that they were willing to pay up to $50 \%$ extra. Their willingness to pay a premium for meat did not seem to be as high, as the following statements make clear: "I would pay a premium of $20 \%$ if the meat tasted better" and "I would not pay $€ 10$ more". This can be explained by the fact that the initial price for meat is significantly higher than that for eggs. Only a few participants stated that they were not prepared to pay a surcharge.

Nonetheless, these findings were not reflected in the quantitative survey of this thesis and highlight the application of mixed methods where qualitative and quantitative methods can each compensate for the weakness of the other method (Denscombe, 2008). Particularly when the subject matter is new, sequencing qualitative and quantitative methods can help to get a broader knowledge and to identify the research topic from the 
outset and validate the results in a subsequent step (Kelle, 2004; Kuckartz, 2014; Flick, 2009; Ritchie et al., 2014). The focus groups have helped to identify important purchase criteria and revealed concerns and potential misunderstandings. However, it is precisely with this moral issue of "chick-culling" and in a group setting that social desirability occurs (Smithson, 2007; Acocella, 2011). The anonymous setting of online surveys reduces social desirability (Brace, 2013). In the findings from the choice experiment in article (3) the share of respondents' willingness to pay for eggs and meat from dual-purpose chickens was clearly lower as stated by individual respondents in the focus groups. This is also attributable to the fact that choice experiments are particularly suitable to detect preferences and willingness to pay for specific attributes, as there is less risk of manipulating the selection behaviour of the respondents through strategic behaviour. This is because what should be evaluated in the setting of choice experiments is less clear to the respondents (Breyer et al., 2005). Additionally, it should be noted that within focus groups, statements from individuals were gathered, whereas the results of the latent class analysis reflect average values of a segment.

\section{$R Q$ 3: Are there consumer segments with preferences and a willingness to pay (WTP) for eggs and meat from dual-purpose chickens? If so, is their WTP sufficient?}

With regard to the potential market success of dual-purpose chickens, it is essential that there are consumer segments with preferences and a sufficient willingness to pay for eggs and meat from these chickens. In article (2), an online survey was conducted with 1,502 participants in Germany. Building on this, a factor and a cluster analysis were performed. The factor analysis revealed seven factors describing consumers' attitudes towards dual-purpose chickens and chicken husbandry in general. Based on the factor analysis, a cluster analysis was conducted to identify different cluster groups. Three clusters regarding dual-purpose chickens were identified, which represented typical consumer groups that differ significantly in their attitudes towards chicken husbandry, their level of knowledge and their experience with agriculture, as well as sociodemographic characteristics. The cluster group 'opponents' makes up $37.5 \%$ of the total sample. The cluster group 'supporters' is the smallest group and accounts for $23.4 \%$ of the respondents, it covers exactly the opposite attitudes towards dual-purpose chickens. Attitudes of respondents of this cluster relate to the importance of health, food quality and animal welfare. The respondents' levels of criticism for conventional chicken farming practices as well as the practice of culling day-old chicks were above average and, 
therefore, preferences for low prices and a preference for conventional farming fell below the average of the total sample. Respondents in this cluster group stated to be willing to pay a surcharge for products from dual-purpose chickens if the latter lived under improved housing conditions. The supporters are more likely to be female and to have a high to very high income in comparison to the other two cluster groups. Supporters predominantly have a high level of education and a moderate to high knowledge of chicken husbandry. In addition, they have pets more often and significantly more experience with agriculture. These results correspond to findings from Starr (2009) and Vanhonacker and Verbeke (2009), who concluded that ethical consumption is positively affected by education, income, being female and socio-political participation. This was also mirrored in a study by Gangnat et al. (2018), who found that knowledge about chicken husbandry and a WTP for dual-purpose poultry and eggs have a positive correlation.

With $39.1 \%$ of the total sample, the third cluster group 'indifferents' represents the largest group. This cluster group is characterised by rejective attitudes towards the culling of day-old chicks as well as favourable attitudes towards dual-purpose chickens when compared to the average. However, this cluster group accepts current conventional farming practices and prefers low prices for chicken meat and eggs at a level above the total sample's average. Ultimately, this cluster group shows an indifferent attitude towards dual-purpose chickens. The 'indifferents' are mostly female and have a moderate level of education and moderate knowledge of chicken husbandry. In addition, they have significantly fewer pets and often have less experience with agriculture. It can be concluded that, within this cluster group, there is the highest potential for reducing uncertainty by means of providing more and better information on dual-purpose chickens, which may increase consumer acceptance.

Conducting a discrete choice experiment in article (3) and applying the latent class model to analyse the preferences of a near-representative sample of chicken meat and egg consumers in Germany has pointed out heterogeneous consumer segments. This has also been observed in previous studies dealing with chicken meat and eggs (Pouta et al., 2010; Van Loo et al., 2011; Hasselbach and Roosen, 2015). Regarding eggs and chicken breast meat, four consumer segments were identified. The findings show that the largest segments for both products are 'price-conscious consumers'. Segments which include 'environmentalists', 'supporters' and 'opponents' of dual-purpose chickens were also identified.

In the case of eggs, our results suggest that the segment with a supportive attitude towards dual-purpose chickens, which accounts for $25.3 \%$ of the respondents, has a WTP of $€ 0.76$ for six eggs from dual-purpose chickens. According to the results found by 
Diekmann et al. (2017), a surcharge of 2.19 cents per egg is needed to cover additional costs. In a study by Verbraucherzentrale NRW (2017), 87\% of respondents stated that they would be willing to pay a surcharge of 4 cents or more per egg. The WTP for eggs from dual-purpose chickens within this segment is, therefore, considerably higher than the expected surcharge. Additionally, this segment has the highest WTP for eggs from smallscale free-range farms (€1.62). This high WTP for eggs from small-scale free-range farms illustrates the value the respondents attribute to better husbandry conditions, especially in relation to the use of dual-purpose chicken breeds. Contrary to expectations, this class would not be willing to pay a premium for organic eggs but would be willing to pay a premium of $€ 0.31$ for local eggs. These findings correspond with those of Andersen (2011), who found that consumers perceive free-range and organic eggs very similarly.

Regarding chicken breast meat, the segment 'supporters' of dual-purpose chickens (16.2\% of respondents) has the highest WTP at $€ 2.47$ for $250 \mathrm{~g}$ of chicken breast meat. In accordance with Damme (2015), the meat from dual-purpose chickens would be $40 \%$ more expensive than conventional broiler meat. A surcharge of $€ 2.47$ for $250 \mathrm{~g}$ chicken breast meat would only marginally cover the additional costs of conventionally rearing male dual-purpose chickens. Additionally, it should be noted that the WTP is often overstated by participants, especially in the case of normative products and, therefore, the expected WTP in the market would be even lower (List and Gallet, 2001; Gerini et al., 2016). The 'environmentalists' (14.4\%) would pay a premium of $€ 0.37$ and the 'priceconscious consumers' (48.2\%) would pay a premium of $€ 0.08$ for $250 \mathrm{~g}$ meat from dualpurpose chickens. The 'supporters' of dual-purpose chickens would also be willing to spend $€ 1.22$ for the local claim, and $€ 0.73$ for the organic claim. In this evaluation, it must be considered that the initial prices for the products eggs and meat are very different. The purchase of eggs from dual-purpose chickens is linked to a significantly lower surcharge than the purchase of meat from dual-purpose chickens. In addition, in the case of eggs, the consumption behaviour does not have to be changed. If necessary, there is a possibility that the fattening of the dual-purpose cockerels is cross-subsidised by a higher surcharge on eggs.

The findings show that, regarding eggs, the supportive segment includes $25.3 \%$ of the respondents and is, therefore, much larger than the supportive segment for chicken meat (16.2\% of respondents). Consequently, eggs from dual-purpose chickens imply greater marketing opportunities than chicken breast meat from dual-purpose chickens. These results support findings from Gangnat et al. (2018) which indicate that the WTP for eggs from dual-purpose chickens was declared to be generally higher than for meat. The results of their study also show that the WTP was positively related to consumers of 
organic or free-range products. However, our results indicate that respondents with a WTP for products from dual-purpose chickens value better husbandry conditions and localness but are not inevitable consumers of organic food. This might be attributed to the increased resource consumption that is associated with the husbandry of dual-purpose chickens. With regard to dual-purpose chicken meat, the marketability of half or even whole chickens could be even more difficult, as consumers prefer to buy cuts such as chicken breast fillet (Kennedy et al., 2004).

\section{Conclusions}

The usage of dual-purpose chickens is currently being discussed as an alternative to the culling of day-old chicks. Apart from aspects such as animal welfare and economic efficiency, consumer acceptance of dual-purpose chickens plays an essential role in any potential market success. In order to analyse consumer perspectives on dual-purpose chickens, a variety of methods was used to investigate the subject thoroughly. The methodologies used in this thesis cover qualitative, quantitative and mixed methods research approaches, plus an Ethical Matrix which belongs to the discipline of applied ethics.

The assessment of the ethical perspective has shown that the consideration of alternative dual-purpose chickens is manifold, going far beyond the consumer perspective. Consumers have a strong focus on themselves and animal welfare, while environmental aspects are often not considered. The focus groups revealed that although the culling of day-old chicks was known to most of the participants and ethically questioned, the alternative of the husbandry of dual-purpose chickens was not wellknown. Important findings from the focus groups were that the name 'dual-purpose chicken' was seen as inadequate and misleading, and that the participants linked better husbandry conditions to the potential purchase of eggs and meat from dual-purpose chickens. Also notable was the fact that chicken meat was related to convenience aspects and, therefore, conflicts with the characteristics of dual-purpose chickens, which require more time-consuming preparation.

The results of an online survey, with 1,502 participants in Germany including factor and cluster analysis, identified a total of seven factors that explain the attitudes of consumers towards dual-purpose chickens and based on these three clusters, including 'opponents', 'supporters' and 'indifferents' regarding their attitudes towards dual-purpose chickens. 
Additionally, a discrete choice experiment was performed. Applying the latent class model to analyse the preferences of a near-representative sample of chicken meat and egg consumers in Germany has identified heterogeneous consumer segments. Regarding eggs and chicken breast meat, four consumer segments were identified. The findings show that the largest segments for both products were price-conscious consumers, but smaller segments were also identified which showed clear preferences and a WTP for eggs and meat from dual-purpose chickens. In this case, the segment which has a WTP for dual-purpose chicken meat is considerably smaller than the segment which has a WTP for eggs from dual-purpose chickens. In the case of chicken meat, it is questionable whether the WTP is sufficient to cover additional costs.

In Germany, there is a growing demand for chicken meat and eggs and an increasing interest for animal welfare awareness. Despite this, the findings of this thesis only indicate a low market potential for products from dual-purpose chickens. The potential for eggs is still significantly higher than that of meat, but since the concept of dual-purpose chickens is characterised by the fact that male animals are also fattened, the prospects are not particularly promising. This situation could partly be countered by cross-subsidising the fattening of the dual-purpose cockerels by a higher price for eggs, as the relative willingness to pay for eggs is much higher than necessary to cover additional costs of the dual-purpose laying hens.

The results of the latent class analysis underline the fact that eggs and meat from dualpurpose chickens are suitable for a niche market, as small potential consumer groups with a WTP for eggs and meat from dual-purpose chickens were identified. The meat of the dual-purpose cockerels is appropriate for consumers who consider meat to be something special and invest time in its preparation. The longer fattening period and slower growth of the chickens in particular can also serve as a positive sales argument. In addition, it became clear that improved housing conditions were regarded as being very important, and that clear labelling and local origins were also described as key factors.

If the husbandry of dual-purpose chickens is to be promoted further, targeted consumer information could certainly attract potential consumers who still have ambivalent attitudes towards dual-purpose chickens. The cluster analysis has shown that the 'indifferents' make up $39 \%$ of respondents and are, therefore, a very important segment to address. The studies have also shown that the topic of chick culling and the alternatives to it are very complex and difficult to grasp. For this reason, transparent and trustworthy information measures at the point-of-sale can help consumers to make betterinformed food choices. 
The German organic association 'Demeter' has dedicated itself to the breeding and rearing of dual-purpose chickens, as the alternative to in-ovo sex determination also involves a system question, namely that of the high degree of specialisation in chicken breeding and highly efficient production systems. This demonstrates that discussions about alternatives to chick culling can also open completely new aspects in the current general debate on the future orientation of agriculture and animal husbandry. However, inovo sex determination is the alternative that has been pushed much more strongly by both, the industry and politicians, as it can be carried out much more cost-effectively with a marginal surcharge on the egg price. The culling of day-old chicks can be avoided, and the current system is maintained. Nevertheless, in this case it can be argued whether this alternative raises new ethical issues because it is questionable at which stage embryos can already feel pain. In response to current developments regarding the practicability of alternatives, the alternatives should be discussed in a more comparative way with regard to consumer acceptance in further research.

To conclude, this thesis provides detailed insights into the consumer perspective on dual-purpose chickens and contributes to the debate surrounding alternatives to the culling of day-old chicks in Germany. The findings demonstrate that there is not just "the one" solution to avoiding the culling of day-old chicks. It is becoming apparent that in-ovo sex determination is likely to serve the conventional egg market which primarily serves the demand of price-conscious consumers. On the contrary, dual-purpose chickens display potential in a niche market, which is sought after by highly involved consumers who question efficient production systems and have preferences for higher animal welfare standards. 


\section{References}

Acocella, I. (2012). The focus groups in social research: advantages and disadvantages. Quality and Quantity, 46(4), 1125-1136. https://doi.org/10.1007/s11135-011-9600-4.

Adamowicz, W., Boxall, P., Williams, M, \& Louviere, J. (1998). Stated preference approaches for measuring passive use values: Choice experiments and contingent valuation. American Journal of Agricultural Economics, 80(1), 64-75.

Ajzen, I., Brown, T.C., \& Rosenthal, L.H. (1996). Information Bias in Contingent Valuation: Effects of Personal Relevance, Quality of Information, and Motivational Orientation. Journal of Environmental Economics and Management, 30(1), 43-57, https://doi.org/10.1006/jeem.1996.0004.

Andersen, L.M. (2011). Animal Welfare and Eggs - Cheap Talk or Money on the Counter? Journal of Agricultural Economics, 62(3), 565-584. https://doi.org/10.1111/j.14779552.2011.00310.x.

Anderson, C. (2010). Presenting and Evaluating Qualitative Research. American Journal of Pharmaceutical Education, 74(8). https://doi.org/10.5688/aj7408141.

Arnould, E.J., \& Thompson, C.J. (2005). Consumer Culture Theory (CCT): Twenty Years of Research. Journal of Consumer Research, 31(4), 868-882. https://doi.org/ 10.1086/426626.

Auspurg, K., \& Liebe, U. (2011). Choice-Experimente und die Messung von Handlungsentscheidungen in der Soziologie. Kölner Zeitschrift für Soziologie und Sozialpsychologie, 2, 301-314.

Awater-Esper, S. (2018). Demeter verpflichtet sich dem Zweinutzungshuhn. https://www.topagrar.com/oekolandbau/news/demeter-verpflichtet-sich-demzweinutzungshuhn-10104532.html Accessed 21 December 2018.

Backhaus, K., Erichson, B., Plinke, W. und Weiber, R. (2011). Multivariate Analysemethoden. Eine anwendungsorientierte Einführung. (13th ed.). Heidelberg: Springer VS.

Beckmann, M. (2016). Über den vernünftigen Grund im Sinne des §1 S. 2 TierSchG bei der Tötung von männlichen Eintagsküken. Natur und Recht, 38(6), 384-390.

Berk, J. (2014). Haltung von Masthühnern. Haltung-Fütterung-Tiergesundheit, DLG Merkblatt 405. In Deutsche Landwirtschafts-Gesellschaft (DLG) 1/ 2014 (pp. 1-20).

Bernués, A., Olaizola, A., \& Corcoran, K. (2003). Labelling information demanded by European consumers and relationships with purchasing motives, quality and safety of meat. Meat Science, 65(3), 1096-1106. https://doi.org/10.1016/S0309-1740(02)003273.

BLE - Bundesanstalt für Landwirtschaft und Ernährung (2017a). Deutsche essen 8 kg weniger Fleisch als vor 20 Jahren. http://www.ble.de/SharedDocs/Pressemitteilungen/ DE/2017/170330_Fleisch.html Accessed 10 April 2017.

BLE - Bundesanstalt für Landwirtschaft und Ernährung (2017b). Jeder Deutsche isst 235 Eier pro Jahr. https://www.ble.de/SharedDocs/Pressemitteilungen/ DE/2017/170317_ Eier.html Accessed 10 April 2017.

BLE - Bundesanstalt für Landwirtschaft und Ernährung (2018). Bericht zur Markt- und Versorgungslage Fleisch 2018. https://www.ble.de/SharedDocs/Downloads/ DE/BZL/ DatenBerichte/Fleisch/2018BerichtFleisch.pdf?_blob=publicationFile\&v=4 Accessed 10 November 2018. 
BMEL - Bundesministerium für Ernährung und Landwirtschaft (2015). Wege zu einer gesellschaftlich akzeptierten Nutztierhaltung. http:/www.bmel.de/SharedDocs/ Downloads/Ministerium/Beiraete/Agrarpolitik/GutachtenNutztierhaltung.pdf?Blob=pobli cationFile Accessed 19 October 2017.

BMEL - Bundesministerium für Ernährung und Landwirtschaft (2018b). Alternativen zum Töten männlicher Küken. https://www.bmel.de/DE/Tier/Tierwohl/_texte/Tierwohl Forschung In-Ovo.html Accessed 20 December 2018.

BMEL - Bundesministerium für Ernährung und Landwirtschaft (2018a): Kennzahlen des deutschen Eiermarktes. https://www.bmel.de/SharedDocs/Downloads/Tier/Tierzucht Tierhaltung/KennzahlenEiermarkt.pdf?_blob=publicationFile Accessed 20 December 2018.

BMEL - Bundesministerium für Ernährung und Landwirtschaft (2019). Ernährungsreport 2019. https://www.bmel.de/SharedDocs/Downloads/Broschueren/Ernaehrungsreport2 019.pdf?_blob=publicationFile Accessed 11 January 2019.

Boehm, J., Kayser, M., \& Spiller, A. (2010). Two Sides of the Same Coin? Analysis of the Web-Based Social Media with Regard to the Image of the Agri-Food Sector in Gemany. International Journal on Food System Dynamics, 3, 264-278.

Bonanno, A., Bimbo, F., Costanigro, M., Lansink, A.O., \& Viscecchia, R. (2018). Credence attributes and the quest for a higher price - a hedonic stochastic frontier approach. European Review of Agricultural Economics. https://doi.org/10.1093/erae/jby024.

Borrego, M., Douglas, E.P., \& Amelink, C.T. (2009). Quantitative, Qualitative, and Mixed Research Methods in Engineering Education. Journal of Engineering Education, 98, 53-66. https://doi:10.1002/j.2168-9830.2009.tb01005.x.

Brace, I. (2013). Questionnaire design: How to plan, structure and write survey material for effective market research. (3rd ed.). London: Kogan Page Limited.

Breyer, F., Zweifel, P., \& Kifmann, M. (2005). Gesundheitsökonomik. Berlin: Springer VS.

Brosius, F. (2011). SPSS 19. (1st ed.). Bonn: mitp-Verlag.

Bruijnis, M.R.N., Blok, V., Stassen, E.N., \& Gremmen, H.G.J. (2015). Moral 'Lock-In' in Responsible Innovation: Ethical and Social Aspects of Killing Day-Old Chicks and Its Alternatives. In: Journal of Agricultural and Environmental Ethics 28(5): 939-960.

Brümmer, N., Salthammer, K., Rovers, A., Christoph-Schulz, I., \& Wolfram, J. (2018). Das Abbild der Geflügelhaltung - oder was im Gedächtnis bleibt. DGS-Magazin, 35, 42-45.

Bryman, A. (2012). Social Research Methods. (4th ed.). New York: Oxford University Press.

Buber, R., \& Klein, V. (2009). Zur Bedeutung qualitativer Methodik in der Marktforschungspraxis. In R. Buber, \& H. Holzmüller (Eds.), Qualitative Marktforschung. Konzepte - Methoden - Analysen (pp. 47-61). Wiesbaden: Gabler Verlag.

Burke Johnson, R., \& Onwuegbuzie, A.J. (2004). Mixed Methods Research: A Research Paradigm Whose Time Has Come. Educational Researcher, 33(7), 14-26. https://doi.org/10.3102/0013189X033007014.

Carlsson, F. (2011). Non-Market Valuation: Stated Preference Methods. In J.L. Lusk, J. Roosen, \& J.F. Shogren (Eds.), The Oxford Handbook of the Economics of Food Consumption and Policy (pp. 181-214). Oxford: Oxford University Press.

Christoph, I. (2007). Die Zahlungsbereitschaft für gentechnisch veränderte Produkte unter Berücksichtigung der Integration psychometrischer Daten in Choice-Modelle. Kiel, Univ., Diss., 2007. Frankfurt a.M.: Peter Lang GmbH. 
Christoph-Schulz, I., Hartmann, M., Kenning, P., Luy, J., Mergenthaler, M., Reisch, L., Roosen, J., \& Spiller, A. (2018). SocialLab - Nutztierhaltung im Spiegel der Gesellschaft: erste Ergebnisse und Implikationen. Journal of Consumer Protection on Food Safety, 13(2), 145-150. https://doi.org/10.1007/s00003-017-1144-7.

Cleff, T. (2015). Deskriptive Statistik und Explorative Datenanalyse. Eine computergestützte Einführung mit Excel, SPSS und STATA. (3rd. ed.). Wiesbaden: Gabler Verlag.

Costell, E., Tárrega, A., \& Bayarri, S. (2009). Food Acceptance: The Role of Consumer Perception and Attitudes. Chemosensory Perception, 3, 42-50. https://doi.org/ 10.1007/s12078-009-9057-1.

Creswell, J.W. (2013). Research Design: Qualitative, Quantitative, and Mixed Methods Approaches. (4th ed.). London: Sage Publications.

Creswell, J.W. \& Clark, V.L.P. (2011). Designing and conducting mixed methods research. (2nd ed.). Thousand Oaks, CA: Sage Publications.

Damme, K. (2015). Economics of Dual-Purpose Breeds - a comparison of meat and egg production using dual purpose breeds versus conventional broiler and layer strains. LOHMANN Information, 50(2), 4-9.

Damme, K., \& Ristic, M. (2003). Fattening performance, meat yield and economic aspects of meat and layer type hybrids. World's Poultry Science Journal, 59, 50-53.

Darby, M.R., \& Karni, E. (1973). Free Competition and the Optimal Amount of Fraud. Journal of Law and Economics, 16(1), 67-88.

Denscombe, M. (2008). Communities of practice: a research paradigm for the mixed methods approach. Journal of Mixed Methods Research, 2(3), 270-283.

DGS (2018). Survey - Wie steht der Ökolandbau zum Töten der männlichen Küken und gibt es eine favorisierte Alternative? DGS Magazin, 18, 58.

Diekmann, J., Hermann, D., \& Mußhoff, O. (2017). Wie hoch ist der Preis auf Kükentötungen zu verzichten? Bewertung des Zweinutzungshuhn- und Bruderhahnkonzepts als wirtschaftliche Alternative zu Mast- und Legehybriden. Berichte über Landwirtschaft. Zeitschrift für Agrarpolitik und Landwirtschaft, 95, 1-23.

Drichoutis, A.C., Lazaridis, P., \& Nayga, R.M. (2007). An assessment of product class involvement in food-purchasing behavior. European Journal of Marketing, 41(7/8), 888-914. https://doi.org/10.1108/03090560710752447.

EC - European Commission (2016). Attitudes of Europeans towards Animal Welfare, Special Eurobarometer 442. http:// www.izs.it/IZS/Engine/-RAServeFile.php/f/pdf_vari_grafica_IAttitudes_of_Europeans_towards_Animal_Welfare. pdf. Accessed 19 October 2017.

Evans, A., \& Miele, M. (2008). Consumers' views about farm animal welfare: Part II European comparative report based on focus group research. Cardiff University, Welfare Quality Reports (5).

Evans, J., \& Mathur, A. (2005). The Value of Online Surveys. Internet Research, 15, 195219. https://doi.org/10.1108/10662240510590360.

EZ Fürstenhof (2019). Die neue Ess-Klasse. https://www.bio-haehnlein.de/essklasse/ Accessed 25 January 2019.

Faucitano, L., Martelli, G., Nannoni, E., \& Widowski, T. (2017). Fundamentals of Animal Welfare in Meat Animals and Consumer Attitudes to Animal Welfare. In P.P. Purslow (Ed.), New Aspects of Meat Quality: From Genes to Ethics (pp. 537-568). Woodhead Publishing. 
Finch, H., \& Lewis, J. (2003). Focus Groups. In J. Ritchie, \& J. Lewis (Eds.), Qualitative Research Practice (pp. 170-197). London: Sage Publications.

Flick, U. (2009). An Introduction to Qualitative Research. (4th ed.). London: Sage Publications.

Forsberg, E.M. (2007). A deliberative ethical matrix method - Justification of moral advice on genetic engineering in food production. Oslo, Univ., Diss., 2007.

Frank, J. (2006). Process attributes of goods, ethical considerations and implications for animal products. Ecological Economics, 58(3), 538-547.

Galli, R., Preusse, G., Schnabel, C., Bartels, T., Cramer, K., Krautwald-Junghanns, M.E., Koch, E., \& Steiner, G. (2018). Sexing of chicken eggs by fluorescence and Raman spectroscopy through the shell membrane. PLOS ONE, 13. e0192554. 10.1371/journal.pone.0192554.

Gangnat, I., Mueller, S., Kreuzer, M., Messikommer, R. E., Siegrist, M., \& Visschers, V. (2018). Swiss consumers' willingness to pay and attitudes regarding dual-purpose poultry and eggs. Poultry Science, 97(3), 1089-1098. https://dx.doi.org/10.3382/ps/pex397.

Garcia, C., Fearne, A., \& Wood, L. (2010). The role of involvement in the attention paid by supermarket shoppers to organic products. Journal of Innovation Economics \& Management, 5(1), 127-144. https://doi.org/10.3917/jie.005.0127.

Gerini, F., Alfnes, F., \& Schjøll, A. (2016). Organic- and Animal Welfare-labelled Eggs: Competing for the Same Consumers? Journal of Agricultural Economics, 67(2), 471490. https://doi.org/10.1111/1477-9552.12154.

Giersberg, M.F., \& Kemper, N. (2018). Rearing Male Layer Chickens: A German Perspective. Agriculture, 8(11), 176. https://doi.org/10.3390/agriculture8110176.

Gräfe, G., \& Maaß, C. (2011). Bedeutung der Informationsqualität bei Kaufentscheidungen im Internet. In K. Hildebrand, M. Gebauer, H. Hinrichs, \& M. Mielke (Eds.), Daten- und Informationsqualität (pp.172-197). Wiesbaden: Vieweg+Teubner. https://doi.org/10.1007/978-3-8348-9266-9_10.

Grashorn, M. (2013). Verwendung der männlichen Küken der Legeherkünfte. http://www.wingvechta.de/themen/verwendung_der_maennlichen_legeherkuenfte/ver wendung_der_m_nnlichen_k_ken_der_legeherk_nfte.html Accessed 15 May 2016.

Gremmen, B., Bruijnis, M.R.N., Blok, V., \& Stassen, E.N. (2018). A Public Survey on Handling Male Chicks in the Dutch Egg Sector. Journal of Agricultural and Environmental Ethics, 31(1), 93-107. https://doi.org/10.1007/s10806-018-9712-0.

Großklaus, R.H.G. (2014). Von der Produktidee zum Markterfolg. Innovationen planen, einführen und erfolgreich managen. (2nd ed.). Wiesbaden: Gabler Verlag.

Grunert, G. (2005). Food Quality and Safety: Consumer Perception and Demand. European Review of Agricultural Economics, 32(3), 369-391. https://doi.org/10.1093/eurrag/jbi011.

Guyonnet, V. (2012). Eggs and egg products: Consumers' attitudes, perceptions and behaviours. XXIV World's Poultry Congress, Salvador, Brazil.

Hair, J.F., Black, W.C., Babin, B.J. \& Anderson, R.E. (2010). Multivariate Data Analysis. (7th ed.). Upper Saddle River, New Jersey: Pearson.

Hasselbach, J.L., \& Roosen, J. (2015). Consumer Heterogeneity in the Willingness to Pay for Local and Organic Food. Journal of Food Products Marketing, 21(6), 608-625. https://doi.org/10.1080/10454446.2014.885866. 
Heng, Y., Peterson, H., \& Li, X. (2013). Consumer Attitudes towards Farm-Animal Welfare: The Case of Laying Hens. Journal of Agricultural and Resource Economics, (38)3, 418-434.

Hensher, D.H., Rose, J.M., \& Greene, W.H. (2015). Applied choice analysis. (2nd ed.). Cambridge University Press.

Jacob, R., Heinz, A., \& Décieux, J.P. (2013). Umfrage: Einführung in die Methoden der Umfrageforschung. (3rd ed.). München: Oldenbourg Wissenschaftsverlag.

Jahn, G., Schramm, M., \& Spiller, A. (2003). Zur Glaubwürdigkeit von Zertifizierungssystemen: Eine ökonomische Analyse der Kontrollvalidität. Diskussionsbeitrag des Instituts für Agrarökonomie 0304. Univ. Göttingen.

Jannsen, J., \& Laatz, W. (2009). Statistische Datenanalyse mit SPSS. (7th ed.). Heidelberg: Springer Verlag.

Kaiser, M., \& Forsberg, E.M. (2001). Assessing Fisheries - Using an Ethical Matrix in a Participatory Process. Journal of Agricultural and Environmental Ethics ,14, 191-200.

Kaufmann, F., Nehrenhaus, U., \& Andersson, R. (2016). Das Duale Huhn. Der Verbraucher müsste umdenken. DGS Magazin, 35, 22-25.

Kelle, U. (2014). Mixed Methods. In N. Baur, \& J. Blasius (Eds.), Handbuch Methoden der empirischen Sozialforschung (pp. 153-166). Wiesbaden: Springer VS. https://doi.org/10.1007/978-3-531-18939-0_8.

Kennedy, O.B., Stewart-Knox, B.J., Mitchell, P.C., \& Thurnham, D.I. (2004). Consumer perceptions of poultry meat: a qualitative analysis. Nutrition \& Food Science, 34(3), 122-129. https://doi.org/10.1108/00346650410536746.

Kitzinger, J., \& Farquhar, C. (1999). The analytical potential of 'sensitive moments' in focus group discussions. In R.S. Barbour, \& J. Kitzinger (Eds.), Developing focus group research: Politics, theory and practice (pp. 156-172). London: Sage Publications.

Klint Jensen, K., Forsberg, E., Gamborg, C., Millar, K., \& Sandøe, P. (2011). Facilitating Ethical Reflection Among Scientists Using the Ethical Matrix. Science and engineering ethics, 17, 425-445. https://10.1007/s11948-010-9218-2.

Koenig, M., Hahn, G., Damme, K., \& Schmutz, M. (2012). Utilization of laying-type cockerels as 'coquelets': Influence of genotype and diet characteristics on growth performance and carcass composition. Archiv für Geflügelkunde, 76(3), 197-202.

Korthals, M. (2006). Ethics of Food Production and Consumption. Understanding Consumers of Food Products. https://doi.org/10.1533/9781845692506.5.624.

Krautwald-Junghanns, M.E., Cramer, K., Fischer, B., Förster, A., Galli, R., Kremer, F., Mapesa, E.U., Meissner, S., Preisinger, R., Preusse, G., Schnabel, C., Steiner, G., \& Bartels, T. (2018). Current approaches to avoid the culling of day-old male chicks in the layer industry, with special reference to spectroscopic methods. Poultry Science, 97(3), 749-757.

Kuckartz, U. (2014). Mixed Methods. Methodologie, Forschungsdesigns und Analyseverfahren. Wiesbaden: VS Verlag.

Kühn, T., \& Koschel, K. (2011). Gruppendiskussionen. Ein Praxis-Handbuch. Wiesbaden: VS Verlag.

Kuß, A. (2007). Marktforschung. Grundlagen der Datenerhebung und Datenanlalyse. (2nd ed.). Wiesbaden:Gabler Verlag.

Laaksonen, P. (1994). Consumer involvement: Concepts and research. London: Routledge. 
Lagerkvist, C., Hess, S., \& Johansson, H. (2017). How Much Credence Does It Take? Evidence on the Trade-Off between Country-Of-Origin Information and Credence Attributes for Beef from a Choice Experiment in Sweden. Foods, 6(10), 84. https://10.3390/foods6100084.

Lamnek, S. (2005). Gruppendiskussion. Theorie und Praxis. Weinheim: UTB.

Lancaster, K.J. (1966). A New Approach to Consumer Theory. Journal of Political Economy, 74(2), 132-157.

Lassen, J, Sandøe, P., \& Forkman, B. (2006). Happy pigs are dirty! Conflicting perspectives on animal welfare. Livestock Science, 103, 221-230. https://doi.org/10.1016/j.livsci.2006.05.008.

Leenstra, F.R., Munnichs, G., Beekman, V., Heuvel-Vromans, E. van den, Aramyan, L.H., \& Woelders, H. (2011). Killing day old chicks? Public opinion regarding potential alternatives. Animal Welfare, 20, 37-45.

Leinonen, I., Williams, A.G., Wiseman, J., Guy, J., \& Kyriazakis, I. (2012). Predicting the environmental impacts of chicken systems in the United Kingdom through a life cycle assessment: Broiler production systems. Poultry Science, 91(1), 8-25. https://doi.org/10.3382/ps.2011-01634.

Leng, G., Adan, R., Belot, M., Brunstrom, J., De Graaf, K., Dickson, S., Hare, T., Maier, S., Menzies, J., Preissl, H., Reisch, L.A., Rogers, \& P.J. Smeets, P. (2017). The determinants of food choice. Proceedings of the Nutrition Society, 76(3), 316-327. https://doi.org/10.1017/S002966511600286X.

Lenzner, T., Neuert, C., \& Otto, W. (2016). Cognitive Pretesting. GESIS Survey Guidelines. Mannheim, Germany: GESIS - Leibniz Institute for the Social Sciences. https://doi: 10.15465/gesis-sg_en_010.

List, J.A. \& Gallet, C.A. (2001). What Experimental Protocol Influence Disparities Between Actual and Hypothetical Stated Values? Environmental and Resource Economics, 20(3), 241-254. https://doi.org/10.1023/A:1012791822804.

Louviere, J.J., Hensher, D.A., \& Swait, J. (2000). Stated choice methods: analysis and application. Cambridge: Cambridge University Press.

Lu, Y., Cranfied, J., \& Widowski, T. (2013). Consumer Preference for Eggs from Enhanced Animal Welfare Production System: A Stated Choice Analysis. Selected Paper prepared for presentation at the Agricultural \& Applied Economics Associations. AAEA \& CAES Joint Annual Meeting, Washington, DC.

Luy, J. (2018). Der faire Deal. Baden-Baden: Nomos.

Marie, M. (2006). Ethics: The new challenge for animal agriculture. Livestock Science,103(3), 203-207.

Mayfield, L.E., Bennet, R. M., Tranter, R.B., \& Woolridge, M.J. (2007). Consumption of welfare-friendly food products in Great Britain, Italy and Sweden, and how it may be influenced by consumer attitudes to, and behaviour towards, animal welfare attributes. International Journal of Sociology of Food and Agriculture, 15(3), 59-73.

McCarthy, M., O'Reilly, S., Cotter, L., \& De Boer, M. (2004). Factors influencing consumption of pork and poultry in the Irish market. Appetite, 43(1), 19-28.

McEachern, M.G., \& Schröder, M.J.A. (2002). The Role of Livestock Production Ethics in Consumer Values Towards Meat. Journal of Agricultural and Environmental Ethics, 15(2), 221-237. https://doi.org/10.1023/A:1015052816477.

McFadden, D. L. (1974). Conditional Logit Analysis of Qualitative Choice Behavior. In P. Zarembka (Ed.), Frontiers in Econometrics (pp. 105-142). New York: Academic Press. 
Meffert, H., Burmann, C., Kirchgeorg, M., \& Eisenbeiß, M. (2019). Marketing. Grundlagen marktorientierter Unternehmensführung. (13th ed.). Wiesbaden: Springer Gabler.

Mepham, T.B. (2000). A framework for the ethical analysis of novel foods: The ethical matrix. Journal of Agricultural and Environmental Ethics, 12, 165-176.

Michaelidou, N., \& Dibb, S. (2008). Consumer involvement: a new perspective. Marketing Review, 8(1), 83-99. https://doi.org/10.1362/146934708X290403.

Morgan, D.L. (1997). Focus Groups as Qualitative Research. Thousand Oaks, CA: Sage Publications.

Mueller, S., Kreuzer, M., Siegrist, M., Mannale, K., Messikommer, R.E., \& Gangnat, I.D.M. (2018). Carcass and meat quality of dual-purpose chickens (Lohmann Dual, Belgian Malines, Schweizerhuhn) in comparison to broiler and layer chicken types. Poultry Science, 7(9), 3325-3336. https://doi.org/10.3382/ps/pey172.

Murawska, D., Bochno, R., Michalick, D., \& Janiszewska, M. (2005). Age-related changes in the carcass tissue composition and distribution of meat and fat with skin in carcasses of laying-type cockerels. Archiv für Geflügelkunde, 69(3), 135-139.

Napolitano, F., Girolami, A., \& Braghieri, A. (2010). Consumer liking and willingness to pay for high welfare animal-based products. Trends in Food Science \& Technology, 21(11), 537-543. https://doi.org/10.1016/j.tifs.2010.07.012.

Nelson, P. (1970). Information and Consumer Behaviour. Journal of Political Economy, 78(2), 311-329.

Neuman, W.L. (2006). Social research methods: Qualitative and quantitative approaches. (7th ed.). Harlow: Pearson.

Norwood, B., \& Lusk, J. (2011). A Calibrated Auction-Conjoint Valuation Method: Valuing Pork and Eggs Produced Under Differing Animal Welfare Conditions. Journal of $\begin{array}{lll}\text { Environmental Economics and } & \text { 80-94. }\end{array}$ https://doi.org/10.1016/j.jeem.2011.04.001.

Ohl., F., \& van der Staay, F.J. (2012). Animal welfare: At the interface between science and society. The Veterinary Journal, 192, 13-19.

Olynk, N., Tonsor, G., \& Wolf, C. (2010). Consumer Willingness to Pay for Livestock Credence Attribute Claim Verification. Journal of Agricultural and Resource Economics, 35(2), 261-280.

Porst, R. (2000). Praxis der Umfrageforschung. Stuttgart: Teubner.

Pouta, E., Heikkilä, J., Forsman-Hugg, S., Isoniemi, M., \& Mäkelä, J. (2010). Consumer choice of broiler meat: The effects of country of origin and production methods. Food Quality and Preference, 21(5), 539-546.

Rautenschlein, S. (2016). Einsatz des Zweinutzungshuhns in Mast und Eierproduktion: Ansätze für ein integriertes Haltungskonzept. Rundschau für Fleischhygiene und Lebensmittelüberwachung (RFL), 68(8), 276-278.

Ritchie, J., Lewis, J., McNaughton Nicholls, C. \& Ormston, R. (2014). Qualitative Research Practice. A Guide for Social Science Students and Researchers. (2nd ed.). London: Sage Publications.

Schendera, C.F. (2010). Clusteranalyse mit SPSS. Mit Faktorenanalyse. München: Oldenbourg Wissenschaftsverlag. 
Schjøll, A., Borgen, S.O., \& Alfnes, F. (2013). Consumer preference for animal welfare when buying eggs. Professional report No. 1-2013. http://www.hioa.no/eng/About$\mathrm{HiOA} / \mathrm{Centre-for-Welfare-and-Labour-Research/SIFO/Publications-from-}$

SIFO/Consumer-preference-for-animal-welfare-when-buying-eggs Accessed 1 October 2018.

Schmidt, W.C. (1997). World-Wide Web survey research: Benefits, potential problems, and solutions. Behavior Research Methods, Instruments and Computers, 29(2), 274279.

Schmutz, M., \& Flock, D. (2014). Legehennenhaltung, DLG Merkblatt 405. In Deutsche Landwirtschafts-Gesellschaft (DLG) 1/ 2014 (pp. 1-16).

Schroeder, D., \& Palmer, C. (2003). Technology assessment and the 'ethical matrix'. Poiesis \& Praxis, 1(4), 295-307.

Schulze, B., Spiller, A., \& Lemke, D. (2008). Glücksschwein oder arme Sau? Die Einstellung der Verbraucher zur modernen Nutztierhaltung. Zukunftsperspektiven der Fleischwirtschaft - Verbraucher, Märkte, Geschäftsbeziehungen, 465-488.

Schütz, K., Wittmann, M., \& Mergenthaler, M. (2017). Herausforderungen und Ansatzpunkte für die Geflügelproduktion - Marketing-Mix zur Vermarktung einer Legehybridlinie und Zweinutzungsgenetik. Notizen aus der Forschung 4/2017, Fachhochschule Südwestfalen.

Seleggt (2018). Seleggt process - technologies. http://www.seleggt.com/seleggtprocedure-technologies/ Accessed 3 January 2019.

Siekmann, L., Meier-Dinkel, L., Janisch, S., Altmann, B., Kaltwasser, C., Sürie, C., \& Krischek, C. (2018). Carcass Quality, Meat Quality and Sensory Properties of the Dual-Purpose Chicken Lohmann Dual. Foods, 7(10).

Smithson, J. (2007). Focus Groups. In P. Alasuurtari, L. Bickman, \& J. Brannen (Eds.), The Sage Handbook of Social Research Methods (pp. 356-371). Thousand Oaks, CA: Sage Publications.

Sonntag, W.I, von Meyer-Höfer, M., Ogan, G., \& Spiller, A. (2016). Kommunikationsstrategien zur Vermittlung zwischen Verbraucherlnnen und Gefllügelhalterlnnen. Tagungsband der 26. ÖGA-Jahrestagung, 15. bis 16. September 2016, Wien (Österreich).

Sonntag, W.I., \& Spiller, A. (2018). Measuring Public Concerns? Developing a Moral Concerns Scale Regarding Non-Product Related Process and Production Methods. Sustainability, 10(5), 1375.

Sonntag, W.I., Golze, S., Spiller, A., \& von Meyer-Höfer, M. (2018). NachhaltigkeitsZielkonflikte in der Hähnchenmast aus Verbraucherperspektive. German Journal of Agricultural Economics, 67, 31-47.

Sossidou, E., \& Elson, H. (2009). Hens' welfare to egg quality: A European perspective. $\begin{array}{llll}\text { World's Poultry Science Journal, } & 65(4), & \text { 709-718. }\end{array}$ https://doi.org/10.1017/S0043933909000488.

Spiller, A., Kayser, M., \& Böhm, J. (2012). Unternehmerische Landwirtschaft zwischen Marktanforderungen und gesellschaftlichen Erwartungen in Deutschland aus Sicht der Forschung. Schriften der Gesellschaft für Wirtschafts- und Sozialwissenschaften des Landbaues e.V., 47, 11-22.

Starr, M.A. (2009). The social economics of ethical consumption: Theoretical considerations and empirical evidence. The Journal of Socio-Economics, 38(6), 916925. 
Stein, E.V. (2015). Voll Huhn, voll teilstückig - Strategien und Praktiken am Schnittpunkt Food- und Packaging-Design. In G. Hirschfelder, A. Ploeger, J. Rückert-John, \& G. Schönberger (Eds.), Was der Mensch essen darf (pp. 211-228). Heidelberg: Springer VS.

Swait, J., \& Adamowicz, W. (2001). Environment, Market Complexity, and Consumer Behavior: A Theoretical and Empirical Approach for Incorporating Decision Complexity into Models of Consumer Choice. Organizational Behavior and Human Decision Processes, 86(2), 141-167.

Urselmann, S., \& Damme, K. (2014). Das Zweinutzungshuhn - Hintergründe, Fakten und aktueller Stand der Dinge. Angewandte Forschung und Beratung für den ökologischen Landbau in Bayern, 91-95.

Van Loo, E.J., Caputo, V., Nayga, R.M., Meullenet, J.F., \& Ricke, S.C. (2011). Consumers' willingness to pay for organic chicken breast: Evidence from choice experiment. Food Quality and Preference, 22(7), 603-613. https://doi.org/10.1016/j.foodqual.2011.02.003.

Vanhonacker, F., \& Verbeke, W. (2009). Buying higher welfare poultry products? Profiling Flemish consumers who do and do not. Poultry Science, 88(12), 2702-2711. https://doi.org/10.3382/ps.2009-00259.

Vanhonacker, F., Verbeke, W., Poucke, E., Pieniak, Z., Nijs, G., \& Tuyttens, F. (2012). The Concept of Farm Animal Welfare: Citizen Perceptions and Stakeholder Opinion in Flanders, Belgium. Journal of Agricultural and Environmental Ethics, 25(1), 79-101.

Vanhonacker, F., Verbeke, W., Van Poucke, E., \& Tuyttens, F. (2007). Segmentation based on consumers' perceived importance and attitude toward animal welfare. International Journal of Sociology of Agriculture and Food, 15, 84-100.

Verbeke, W., \& Viaene, J. (2000). Ethical challenges for livestock production: Meeting consumer concerns about meat safety and animal welfare. Journal of Agricultural \& Environmental Ethics, 12(2), 141-151. https://doi.org/10.1023/A:1009538613588.

Verbraucherzentrale (2017). Eierproduktion ohne Tötung männlicher Küken. https://www.verbraucherzentrale.nrw/pressemeldungen/presse-nrw/eierproduktionohne-toetung-maennlicher-kueken-9970 Accessed 30 March 2017.

Weible, D., Christoph-Schulz, I., Salamon, P., \& Zander, K. (2016). Citizens' perception of modern pig production in Germany: a mixed-method research approach. British Food Journal, 118(8), 2014-2032.

Wright, K.B. (2005). Researching Internet-Based Populations: Advantages and Disadvantages of Online Survey Research, Online Questionnaire Authoring Software Packages, and Web Survey Services. Journal of Computer-Mediated Communication, 10(3). https://doi.org/10.1111/j.1083-6101.2005.tb00259.x.

Zichy, M., Dürnberger, C., Formowitz, B., \& Uhl, A. (2014). Energie aus Biomasse - ein ethisches Diskussionsmodell. Wiesbaden: Springer Vieweg. 


\section{Appendix A: Further Publications}

\section{Scientific papers}

Brümmer, N., Luy, J., Rovers, A., \& Christoph-Schulz, I. (2018). Mehr als eine Nische? Das Potential des Zweinutzungshuhns als Alternative zum Kükentöten. Journal of Consumer Protection and Food Safety, 13(2), 226-230. https://doi.org/10.1007/s00003-017-1144-7.

Brümmer, N., Wolfram, J., Mergenthaler, M., \& Christoph-Schulz, I. (2018). Das Bild der Geflügelhaltung in den deutschen Printmedien. 57. GEWISOLA-Tagung in Kiel. http://ageconsearch.umn.edu/record/275868/files/Poster_200.pdf.

Brümmer, N., Christoph-Schulz, I., \& Rovers, A. (2017). Consumers' perspective on dualpurpose chickens. Proceedings in System Dynamics and Innovation in Food Networks 2017, 164-169.

Christoph-Schulz, I., Saggau, D., Rovers, A., \& Brümmer, N. (2018). Die unterschiedlichen Vorstellungen deutscher Bürger zur Haltung von Milchkühen und Fleischrindern. Austrian Journal of Agricultural and Rural Studies, 27(14), 103-109.

Christoph-Schulz, I., Rovers, A., \& Brümmer, N. (2017). Die Einstellung der deutschen Gesellschaft gegenüber der landwirtschaftlichen Nutztierhaltung. Schriften der Gesellschaft für Wirtschafts- und Sozialwissenschaften des Landbaues e.V., 53, 327328.

Christoph-Schulz, I., Brümmer, N., Rovers, A., \& Saggau, D. (2016). SocialLab Nutztierhaltung im Spiegel der Gesellschaft. Schriften der Gesellschaft für Wirtschaftsund Sozialwissenschaften des Landbaues e.V., 52, 363-364.

Rovers, A., Sonntag, W.I., Brümmer, N., \& Christoph-Schulz, I. (2018). Citizens' perception of recent livestock production systems in Germany. German Journal of Agricultural Economics, Special Issue Future Options for Animal Husbandry in Europe, 67(4), 223-233.

Rovers, A., Wildraut, C., Mergenthaler, M., Sonntag, W.I., von Meyer-Höfer, M, Spiller, A., Luy, J., Saggau, D., Brümmer, N., \& Christoph-Schulz, I. (2018). Analyse der Nutztierhaltung durch unterschiedliche gesellschaftliche Gruppen. Journal of Consumer Protection and Food Safety, 13(2), 165-170. https://doi.org/10.1007/s00003017-1144-7.

Rovers, A., Christoph-Schulz, I., Brümmer, N., \& Saggau, D. (2017). Die aktuelle Wahrnehmung der Tiergesundheit in der deutschen Schweinehaltung. Journal of the Austrian Society of Agricultural Economics, 26, 65-74.

Rovers, A., Christoph-Schulz, I., Brümmer, N., \& Saggau, D. (2017). Gesellschaftliche Herausforderungen in der Milchviehhaltung - deutsche Milchbauern im Dialog mit Konsumenten. Tagungsband der SGA-SEE-Tagung "Nachhaltige Landwirtschafts- und Ernährungssysteme" in Chur (Schweiz).

Rovers, A., Christoph-Schulz, I., Saggau, D., \& Brümmer, N. (2017). Nicht vor meiner Haustür - wo soll Nutztierhaltung stattfinden? Schriften der Gesellschaft für Wirtschafts- und Sozialwissenschaften des Landbaues e.V., 53, 329-330.

Rovers, A., Christoph-Schulz, I., Brümmer, N., \& Saggau, D. (2017). Trust no one? Citizens' concerns regarding the pork and dairy supply chain. Proceedings in System Dynamics and Innovation in Food Networks 2017, 87-93. 


\section{Practical contributions}

Brümmer, N., Salthammer, K., Rovers, A., Christoph-Schulz, I., \& Wolfram, J. (2018). Das Abbild der Geflügelhaltung - oder was im Gedächtnis bleibt. DGS-Magazin, 35, 42-45.

Brümmer, N., Christoph-Schulz, I., \& Rovers, A. (2016). Wie schmeckt das Zweinutzungshuhn? DGS-Magazin, 48, 35-38.

Christoph-Schulz, I., Rovers, A., \& Brümmer, N. (2017). Zwischen Almidyll und Industrieanlage - über die gesellschaftliche Wahrnehmung der Milchviehaltung. 18. Jahrestagung der Gesellschaft der Milcherzeugerberater e.V., 09.-11. Oktober 2017, Kleve.

Christoph-Schulz, I., Rovers, A., Brümmer, N., \& Saggau, D. (2017). Gesellschaftliche Perspektiven der landwirtschaftlichen Nutztierhaltung. Tierärztliche Umschau, 3, 6773.

Christoph-Schulz, I., Rovers, A., Brümmer, N., \& Saggau, D. (2017). Landwirtschaft aus Sicht der Gesellschaft - warum es Sinn macht, auch diese Perspektive zu betrachten. In Deutsche Veterinärmedizinische Gesellschaft (Eds.), 92. Fachgespräch über Geflügelkrankheiten (pp.7-8). Hannover: Verlag der DVG Service GmbH.

Christoph-Schulz, I., Brümmer, N., Rovers, A., \& Saggau, D. (2016). SocialLab Nutztierhaltung im Spiegel der Gesellschaft. Milchtrends Januar 2016. http://www.milchtrends.de/fileadmin/milchtrends/5_Aktuelles/1601_Forschungsprojekt_SocialLab.pdf.

Rovers, A., Christoph-Schulz, I., Brümmer, N., \& Saggau, D. (2016). Tierwohl: Näher beieinander als gedacht. Elite, 4, 32-33.

\section{Presentations}

Brümmer, N. (2018). Das Bild der Geflügelhaltung in den deutschen Printmedien. 58. Jahrestagung der Gewisola, 12 - 14 September 2018 in Kiel.

Brümmer, N. (2018). „Dual-purpose chickens as alternative to the culling of day-old chicks - the ethical perspective", EurSafe "Professionals in Food Chains: Ethics, Roles and Responsibilities", 13 - 16 June 2018 in Vienna, Austria.

Brümmer, N. (2017). „Consumers' acceptance of meat and eggs from dual-purpose chickens", XV EAAE Congress, 29 August - 01 September in Parma, Italy.

Brümmer, N. (2017). „Is the dual-purpose chicken an alternative? Consumers' perception in Germany", Xe European Symposium on Poultry Welfare, 19 - 22 June 2017 in Ploufragan, France.

Brümmer, N. (2017). "Consumers' perspective on dual-purpose chickens”, 11th International European Forum on System Dynamics and Innovation in Food Networks, 13 - 17 February 2017 in Igls, Austria. 


\section{Reports}

Simons, J., Luy, J., Birkle, I., Klink-Lehmann, J., Rovers, A., von Meyer-Höfer, M., Vierboom, C., Härlen, I., Brümmer, N., Sonntag, W.I., Saggau, D., Hartmann, M., Spiller, A., \& Christoph-Schulz, I. (2019). Wahrnehmung und Akzeptanz: Zwischen Massentierhaltung und Museumslandwirtschaft. SocialLab - Nutztierhaltung im Spiegel der Gesellschaft, 3-12. Available under https://www.sociallab-nutztiere.de/.

Luy, J., Sonntag, W.I., von Meyer-Höfer, M., Brümmer, N., Purwins, N., Spiller, A., Christoph-Schulz, I., \& Simons, J. (2019). Der Umgang mit Zielkonflikten: Eine Herausforderung. SocialLab - Nutztierhaltung im Spiegel der Gesellschaft, 13-19. Available under https://www.sociallab-nutztiere.de/.

Wolfram, J., Brümmer, N., Mergenthaler, M., \& Christoph-Schulz, I. (2019). Landwirtschaftliche Tierhaltung in den Medien. SocialLab - Nutztierhaltung im Spiegel der Gesellschaft, 35-40. Available under https://www.sociallab-nutztiere.de/.

Groß, S., Brümmer, N., Christoph-Schulz, I., \& Roosen, J. (2019). Verbraucherpräferenzen - Paradoxien, Dilemmata und neue Wege. SocialLab - Nutztierhaltung im Spiegel der Gesellschaft, 55-60. Available under https://www.sociallab-nutztiere.de/. 


\section{Appendix B: Danksagung}

An dieser Stelle möchte ich mich bei all jenen bedanken, die mich im Rahmen dieser Dissertation begleitet haben und ohne deren Unterstützung diese Dissertation nicht zustande gekommen wäre. Dabei gilt ganz besonderer Dank meiner inoffiziellen Doktormutter und Betreuerin Dr. Inken Christoph-Schulz, die mir immer zur Seite stand und mich stets motiviert hat.

Daneben gilt auch ein besonderer Dank meinem Doktorvater PD Dr. Martin Banse für seine bereichernden und konstruktiven Anregungen, die freundliche Betreuung und ständige Erreichbarkeit, insbesondere in der letzten „heißen Phase“. Auch möchte ich mich bei Herrn Prof. Achim Spiller dafür bedanken, dass er sich bereit erklärte, diese Arbeit ebenfalls zu betreuen.

Des Weiteren möchte ich mich bei meiner Projektkollegin Dr. Anja Rovers für die nette und vertrauensvolle Zusammenarbeit bedanken, die uns zu einem guten Team gemacht hat. Auch möchte ich mich bei den Kolleginnen und Kollegen aus der Marktanalyse für die positive, hilfsbereite und motivierende Arbeitsatmosphäre bedanken sowie für viele interessante Diskussionen während des Mittagessens. Besonderer Dank gebührt ebenfalls den weiteren Doktorandinnen aus der MA, die meinen Arbeitsalltag stets bereicherten, und meiner Leidensgenossin Selin, aus einer ganz anderen Forschungsdisziplin stammend, mit der ich sogar in den "Schreiburlaub“ ins tiefste Brandenburg fuhr. 


\section{Doktorandinnen-Erklärung der Georg-August-Universität Göttingen}

Name: Brümmer, Nanke

(Name, Vorname)

Ich beabsichtige, eine Dissertation zum Thema:

Consumers' perspective on chicken husbandry:

The case of dual-purpose chickens

an der Georg-August-Universität Göttingen anzufertigen.

Dabei werde ich von Herrn Prof. Martin Banse betreut.

Ich gebe folgende Erklärung ab:

1. Die Gelegenheit zum vorliegenden Promotionsvorhaben ist mir nicht kommerziell vermittelt worden. Insbesondere habe ich keine Organisation eingeschaltet, die gegen Entgelt Betreuerinnen und Betreuer für die Anfertigung von Dissertationen sucht oder die mir obliegenden Pflichten hinsichtlich der Prüfungsleistungen für mich ganz oder teilweise erledigt.

2. Hilfe Dritter wurde bis jetzt und wird auch künftig nur in wissenschaftlich vertretbarem und prüfungsrechtlich zulässigem Ausmaß in Anspruch genommen. Insbesondere sind alle Teile der Dissertation selbst angefertigt; fremde Hilfe habe ich dazu weder unentgeltlich noch entgeltlich entgegengenommen und werde dies auch zukünftig so halten.

Des Weiteren ist mir bekannt, dass Unwahrhaftigkeiten hinsichtlich der vorstehenden Erklärung die Zulassung zur Promotion ausschließen bzw. später zum Verfahrensabbruch oder zur Rücknahme des erlangten Grades berechtigen.

Göttingen, den 04.03.2019

(Ort)

(Unterschrift) 